


\subsection{Knickerbocker}

Plays for ciass room

C 553042 interpretation

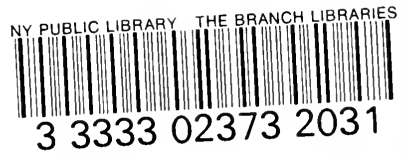




$$
\begin{aligned}
& \text { THE CENTRAL CHILDREN'S ROON } \\
& \text { DONNELL LIERARY CENTER } \\
& 20 \text { WE'ST } 53 \text { STREET } \\
& \text { NEW YORK, N.Y. } 10019
\end{aligned}
$$










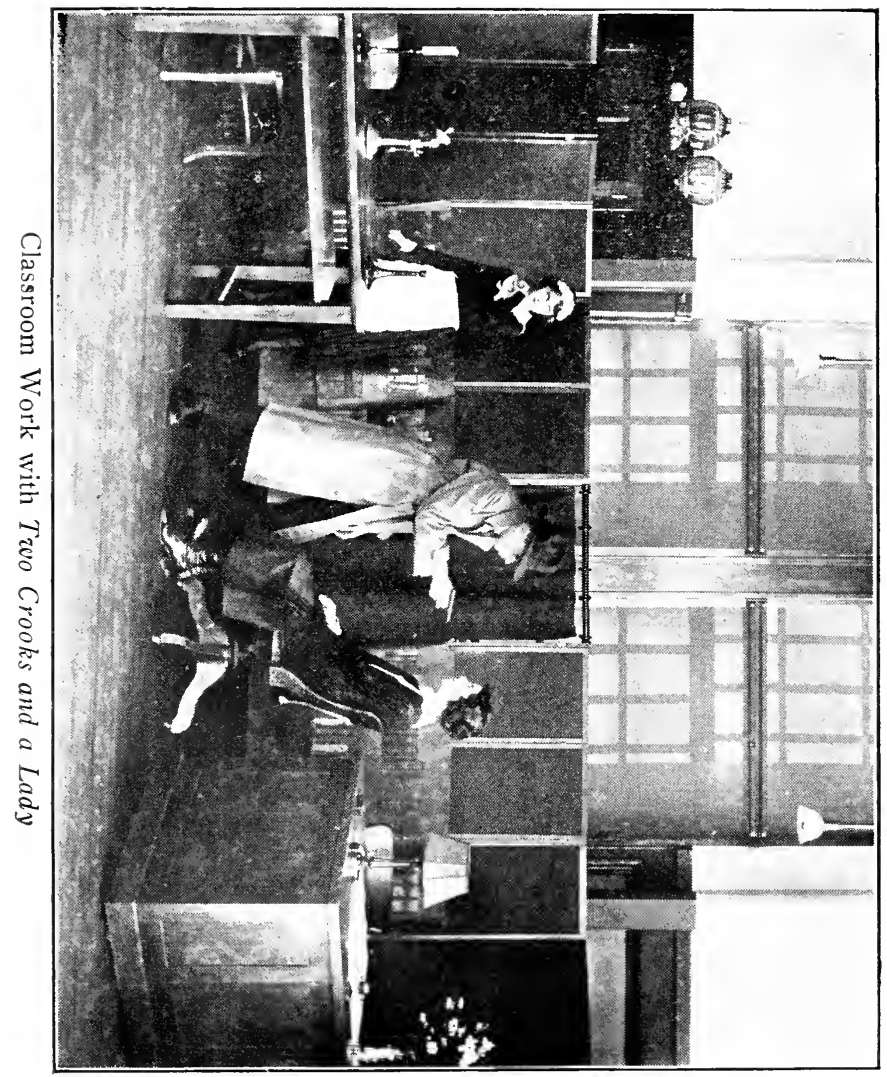




\title{
PLAYS FOR CLASSROOM INTERPRETATION
}

\author{
EDITED BY \\ EDWIN VAN B. KNICKERBOCKER
}

Chairman of the English Department

The George Washington High School

New York

DRAWINGS BY

OLINDO RICCI

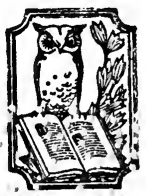

NEW YORK

HENRY HOLT AND COMPANY 
Copyright, 1921

BY

HENRY HOLT AND COMPANY

$\cos 3042$

June, 1930

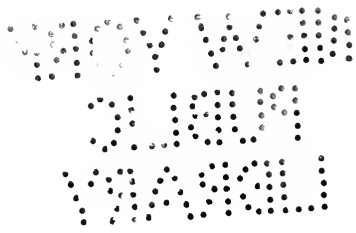

Printed in the U. S. A. 


\section{IMPORTANT NOTICE}

The authors and publishers of the plays included in the present volume have permitted this reprinting of copyrighted material on the understanding that the plays will be used only in classroom work. No other use of any of the plays is authorized, and permission for any such other use must be secured from the holder of the acting rights. For each play in this book the name and address of the holder of such rights is printed below the list of the characters in the play.

The law protecting the rights of the dramatist is quoted herewith:

"Sec. 4966:-Any person publicly performing or representing any dramatic or musical composition for which copyright has been obtained, without the consent of the proprietor of said dramatic or musical composition, or his heirs or assigns, shall be liable for damages therefor, such damages in all cases to be assessed at such sum, not less than one hundred dollars for the first and fifty dollars for every subsequent performance. as to the court shall appear to be just. If the unlawful performance and representation be wilful and for profit, such person or persons shall be guilty of a misdemeanor, and upon conviction be imprisoned for a period not exceeding one year." -U. S. Revised Statutes, Title 60, Chap. 3. 


\section{ACKNOWLEDGMENT}

For permission generously accorded for use of the plays included in this book, the writer acknowledges his obligation as follows:

To Lady Gregory and Messrs. G. P. Putnam's Sons for "Spreading the News."

To Lord Dunsany and Messrs. Little, Brown and Company for "The Golden Doom."

To Mr. Eugene Pillot and Brentano's for "Two Crooks and A Lady."

To Miss Doris F. Halman for "Will o' the Wisp."

To Beulah Marie Dix (Mrs. G. H. Flebbe) and Messrs. Henry Holt and Company for "Allison's Lad."

To Miss Margaret Scott Oliver and Mr. Richard G. Badger for "The Turtle Dove."

To Mrs. Stephen Phillips and The Macmillan Company for the "Ulysses" selection. 


\section{CONTENTS}

Page

Introduction . ............... vii

\section{PART I}

\section{Classroom Work with a Play}

Chapter I. The Preliminary Study....... 3

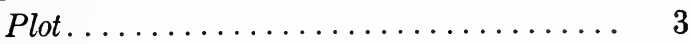

Theme...................... 6

Atmosphere................... 8

Setting.................. 10

Preliminary Characterization.......... 13

Music.................. 14

Chapter II. The Detailed Interpretation. . 16 The Situations................. 17

Realizing the Setting............. 20

Acting as Team-Work.............. 23

Getting Inside the Character. .......... 28

The Auditory Appeal. .............. 33

The Visual Appeal. . . . . . . . . . . 59 


\title{
CONTENTS
}

\author{
PART II \\ The Plays
}

The Golden Doom. . . . . . . . . . . . . 75 Lord Dunsany

Two Crooks and a Lady. . . . . . . . . . 93

Eugene Pillot

Will o' the WisP. . . . . . . . . . . . . 121

Doris F. Halman

Spreading the News.............. 141

Lady Gregory

The Turtle Dove. . . . . . . . . . . . . . . 169

Margaret Scott Oliver

Allison's Lad . . . . . . . . . . . . . . . . . 191

Beulah Marie Dix

Ulysses (Scene 2, Act III). . . . . . . . 213

Stephen Phillips

Notes on the Plays. . . . . . . . . . . . . 237

\section{PART III}

Notes to the Instructor

Notes on Chapter I. . . . . . . . . . . . . . 247

Notes on Chapter II. . . . . . . . . . . . . 251 


\section{INTRODUCTION}

This book has been prepared for use as a high school text-book in the classroom interpretation of short plays.

In such work the plays are acted out in the classroom with expressive oral rendering of the lines, and with complete action, gesticulation, and facial expression. The lines are read from the text, no stage is required, and no stage equipment or costuming is necessary, although some simple provision for these is desirable. The interpretation of a play is highly motivated and socialized project work, providing numerous problems of genuine interest and value. The project as a whole and its component problems all lie properly in the field of English, and the work can be done by any English class. Because the work is group work, it is desirable that something of the spirit of the studio should prevail rather than the atmosphere of the more formal classroom.

Nowadays teachers very generally realize the value of dramatic work, but the practical difficulties peculiar to the problem of working in the classroom with good short plays have been so great that few teachers have attempted it. The writer believes that the use of the present book as a student's text-book will make dramatic interpretation in the 


\section{INTRODUCTION}

classroom an entirely practical phase of high school work in English. Indeed, the book is an outcome of the writer's efforts to overcome the difficulties he has encountered in the course of his work with English classes in the Evander Childs and George Washington High Schools.

Teachers realize that properly directed work in dramatics develops the student's power of selfexpression through its training in the co-ordination of mind and body; that it makes for social efficiency, both in the development of the spirit of team-work and in the inculcation of a knowledge of social usages; that it quickens the powers of vizualization and auditization; that it tends to deepen the student's knowledge of human nature. They realize that such work provides highly motivated and socialized project work; that it affords unusual opportunities for speech improvement and develops in the student an ability to read aloud effectively; that it stimulates interest in related fields of art and history; that it provides occasion for real co-operation between departments in the school. They realize, too, that the work with the modern short play tends to develop in the students a proper taste in an important phase of present day literature.

But teachers know that text-books for the most satisfactory kind of dramatic work have not been available. There are school editions of Shakspere, and there are on the authorized school lists certain other dramatic classics like "She Stoops to Conquer." But these plays are very long for [ viii ] 


\section{LNTRODUCTION}

classroom acting, the diction is frequently difficult, the rolles are often beyond the powers of the students to portray, and the spirit of the plays is generally hard for the students to appreciate and harder for them to create. Our boys and girls will work with enthusiasm and spontaneity only with plays that are not open to these objections. Really good one-act plays are numerous, but not those that are wholly fit for public school use. And when just the right plays are found, they must generally be bought by the students, and such plays are likely to be high in price; very rarely will more than one thoroughly suitable play be found in any one volume, so that the work with a series of short plays necessitates the purchase of several books.

A second difficulty in the classroom interpretation of plays is that the work is new; so far as the writer knows, no method of procedure has before this been presented in text-book form, and many teachers hesitate to make the venture in this field (which they are convinced is a promising one) for fear they may wrongly emphasize values and aims.

A further difficulty, more apparent than real, however, is the fact that courses of study do not mention dramatic interpretation, and teachers must meet course of study requirements.

\section{The Plays}

The seven pieces reprinted in this volume should prove in their type, in their quality, and in their 


\section{INTRODUCTION}

variety, eminently satisfactory for use in the classroom. Their number allows considerable choice, as well.

With the exception of the scene from "Ulysses" they are one-act plays, and the selection from "Ulysses" is dramatically complete and so constitutes practically a one-act play.

The one-act play is for many reasons better suited to classroom use than the longer play. The former has few characters, is simple in construction, and is highly unified in both plot and spirit. There is usually only one setting to be imagined, and the stage action is almost always simpler than in the longer play. The one-act play is modern, and modern plays make a strong appeal to the high school boy or girl; even if they deal with times long past and places far away, plays written to-day are conceived in the modern spirit.

The scene from "Ulysses" may seem somewhat difficult to act in the classsroom, but the writer believes it will not prove so. The story is a familiar one, and the students know something of Greek times and customs. In the classroom work there is no real need for more than a few suitors and serving women. It seemed desirable to include a play in blank verse, and to provide some historic or legendary material; these considerations determined the choice of the "Ulysses" selection. Stephen Phillips's beautiful blank verse is seen here at its best, and the whole treatment of the wellknown home-coming of the hero is at once realistic and imaginative. 


\section{INTRODUCTION}

The seven plays were selected from a very wide field. Many plays that would be effective on the public stage are unsuitable for classroom study in public schools. Not that juvenile plays are wanted; quite the contrary: high school boys and girls demand mature, strong work, and even if they did not, they should be given nothing else. But for classroom purposes it is not enough that the plays be well-written. Any inclusion of characters offensive or indelicate in speech or act, any use of socially unconventional situations, any stressing of denominational religious elements, must periorce result in the exclusion of the play containing it. These considerations narrow the field greatly, and it is further limited by the requirement that the characters be not too difficult for the average high school student to interpret. Then, too, many fine plays must be eliminated because they are in dialect so marked as not to be readily understandable by the students and certainly not easily to be imitated. Again, the spirit of a period must not be too difficult for the students to feel and to create; for example, our students could not be expected to appreciate or show the cynicism and polish that should mark the atmosphere of a fashionable drawing room of the Queen Anne period. (The atmosphere of the period plays in this volume will not be found difficult to comprehend or express.) So much for features that would render compositions otherwise good as plays unsuitable for classroom use. But it is necessary that the plays selected be of really permanent value aside from 


\section{INTRODUCTION}

their conformance to these negative qualifications. They must have a theme worth while, even if it be merely whimsical; there must be an innate dignity, arising from a real truth to life, in the characters, the action, and the dialogue; the emotional tone must be sustained and not exaggerated; and the play must produce a distinctly unified impression. The construction must be simple, the situations inherently interesting, and the language clear and direct as well as appropriate to the characters and the circumstances.

The plays in the present collection meet these requirements and afford excellent examples of what is best in the modern one-act play. The high school students of to-day should be the leaders in public taste to-morrow, and since the drama is an extremely important thing, from both a literary and an artistic standpoint, we must do what we can to form to-morrow's public taste in proper molds. An intimate acquaintance with good plays will cause our students to demand good plays for the rest of their lives. By "good plays" is not meant moral preachments in dramatic form, but strong, wholesome treatments of life, with pathos, humor, and idealism blended. The one-act play is especially effective for this purpose, in its brevity, condensation, and intensity of dramatic quality. It is timely, too, for we are living in an age when the one-act play is assuming the same relation to the longer play that the short story already bears to the novel. In schools where public productions of plays are staged, those plays should be carefully 


\section{INTRODUCTION}

chosen for their real value, not for their power to amuse, merely; but, while considerable, the effect of merely seeing and hearing a performance is slight compared to the effect upon a group of students of work intensively done throughout a term with really first-rate dramatic material. Some literary prophets tell us that we are shortly to see the drama assume the most important place in creative literature-that in the cycle of changing tastes and interests it is passing from its winter of discontent into such a glorious summer as it enjoyed in Elizabethan days. However this may be, dramatic composition is becoming more and more important, and we must equip our pupils for conditions as they will be, not as they have been.

\section{The Method}

The nature of classroom work in dramatic interpretation, briefly summarized on page vii, will be fully evident to one who has read Part I. There the text (which has been written for the student) embodies the matter for study and implies the method; the method itself is explained in detail in the Notes to the Instructor in Part III. In their work, the students first read at home the play to be studied and then do the preliminary work outlined in Chapter I of Part I; after this they are ready to take up the detailed presentation, in which they observe the principles expressed in Chapter II. No one order in the use of the plays is inherently better than another; indeed, the col- 


\section{INTRODUCTION}

lection is so large that the entire seven plays will hardly be studied in any one term.

The instructor is reminded that in all its phases, the study of a play affords ample occasion for practice in written as well as oral composition, and for the development of the principles of good writing. All such work, since it is related to the central project, is thoroughly motivated. The work of interpretation, too, provides wide opportunity for special investigations and committee work. All this is referred to in the Notes to the Instructor in Part III. These notes contain all the suggestions that the average teacher will welcome, for each teacher will wish to follow his own particular bent; the presentation of a detailed step-by-step procedure is unnecessary, and its inclusion in the book would probably be resented by the classroom instructor, who nevertheless may be glad to have a general plan suggested in work so largely novel as full dramatic interpretation in the classroom is at present. The treatment proposed in the Notes has been thoroughly tested in the writer's own English classes, and is sound from the actor's standpoint as well as from the pedagogical point of view.

The Work in Relation to Courses of Study

Work in Dramatic Interpretation may be offered as an elective at any part of the high school course, or the regular work of a term may be so modified as to make it practically a dramatic course while yet satisfying the chief requirements of the syllabus 


\section{INTRODUCTION}

for that term. The latter is the better plan where elective courses do not carry the "credits" or " points" earned in regular courses, inasmuch as the benefits of work in dramatic interpretation should be brought to all, and electives that do not carry "credits" attract small numbers.

Where the dramatic work is taken as an elective, the activity of the class may be concerned solely with the interpretation of the plays, and with such work in composition as the instructor may wish to base upon it. Where the work is not elective, the principal demands of the syllabus must be met in addition to the special work; but the problem thus raised is not difficult of solution, since dramatic interpretation is not essentially so different from the usual English work as it must seem on the surface to be. Study of literary masterpieces or of special types of composition, formal drill, and practice in various types of written and oral composition, are the elements of all required English work. These elements are present in the work of the dramatic classes, though in content and emphasis the work of such groups differs from that of the usual English class. Most syllabuses call for the reading of particular books during the sev. eral years of the high school course; certain literary forms, such as the short story, must be studied; and particular kinds of composition (argument, for example) must be stressed at definite points in the course. In addition, the study may be required of certain commercial or journalistic types.

To meet such requirements, in cases where the 


\section{INTRODUCTION}

course of study cannot well be altered, the dramatic work may best be assigned to terms where the intensive study of definite types of composition is not an important feature of the work, and where the required reading is in the field of creative literature rather than in the field of essay, biography, or argument. The required reading may then be done by the dramatic classes at home, as supplementary reading. To insure adequate care in such reading, and to provide any necessary testing of the pupils' understanding and preparation of it, a certain number of recitations may be devoted to the discussion of the supplementary work. The theory is that a class engaged in the special dramatic study, because its work is highly motivated and vitalized, will rapidly develop a power of literary appreciation and an amount of enthuasism so great as to enable it to grasp the salient features of any novel or narrative poem with far greater readiness than the same pupils would show if they had been doing the less thoroughly motivated work of the usual type of literary study. Then, too, when the "required" books are discussed, the methods of the dramatic work may to a considerable extent be applied; for example, the consideration of any such book may be regarded as something of a project, the discussion being divided into problems of plot, characterization, atmosphere, setting, costumes, scenery, and diction. Parts of the book may also be dramatized.

With classes engaged in the dramatic work, any amount of both written and oral composition can 


\section{INTRODUCTION}

easily be related to some phase or other of the main project (which is the complete interpretation of the play that is being studied), and such composition will be motivated and vitalized to a degree hardly possible with the usual classroom work. And any study deemed necessary in the field of sentence, paragraph, or theme structure, or in matters of spelling, punctuation, pronunciation, or enunciation, will reflect the interest in the larger problem, and so will be vitalized to an extent impossible where formal work is its own excuse for being.

At the George Washington High School the work in dramatic interpretation is not elective, but is done by all the English classes in the sixth term of the eight-term course. The New York City English syllabus now provides for the study of short modern plays in this part of the course, so that the dramatic work is a natural form for the study of such plays to take. Before the new syllabus appeared with its provision for short plays, the sixth term classes were able to do their dramatic work by taking for the purpose some of the time usually devoted to the "required" reading, and certain other time usually assigned to oral drill. These classes established a reputation for initiative and thoroughness in their English work and did extremely well in their English examinations. Since its introduction in the school, dramatic interpretation has been project work, involving of course the pupils' written and oral composition.

It may be well to touch here upon the matter [ $x$ vii ] 


\section{INTRODUCTION}

of the relative values of the interpretation of dramatic composition and the dramatization of pieces of literature non-dramatic in form. A question on this point is frequently raised when work in dramatics is under discussion. Where a good play is acted, the subject-matter has a high value as literature; but where the students dramatize parts of novels or poems, the final form is merely the students' own composition. In the latter type of work, the fine strokes of characterization and the perfect fitness of the diaglogue, which are features of a well-written play, are lacking. An amount of seriousness of effort on the students' part attaches to the study and acting of a play, which cannot be expected where the students change the form from the narrative to the dramatic; in the latter case, the boys and girls cannot but feel that they are working at an exercise, while in the former type of work they realize that they are facing a problem that has the dignity attaching to the work of a profession. Then, too, where a novel or short story is dramatized, the dramatic interpretation is only one feature of the classroom work, for the narrative is first studied as a narrative-something quite different from the dramatization. But where the work is with a play, "the play's the thing " at all stages of the class's activity, and the acting is correspondingly important in the eyes of the students. 


\section{PART I}

Classroom Work With a Play 



\section{CHAPTER I}

\section{THE PRELIMINARY STUDY OF A PLAY}

The interpretation of a play is a two-fold process. We must consider what we are to express in our acting, and then we must express it. This is truly a double process rather than two separate ones, for the detailed study of what to present goes step by step with the detailed study of how to present it. Nevertheless, we must have a preliminary study of the play as a whole before we plan our work in detail. Such a consideration of the play in its entirety gives us at the outset an understanding of the atmosphere or tone of the play, a realization of the setting, a knowledge of the drift of the action and of what the play means as a whole, and a conception of the characters as distinct personalities. This preliminary study of the play follows the first reading, which we shall suppose that we have done at home.

In our treatment of the interpretation of a play in the classroom, we shall consider first this general, preliminary study, and then take up the detailed consideration of just what to express and how to express it.

\section{The Plot}

In working with a one-act play, we must realize that we have to do with a very unified composition. 


\section{THE CLASSROOM STUDY}

A longer play has often several threads of plot; one such thread, for example, may deal with characters and incidents that exist merely to afford contrast with the characters and incidents on another thread; perhaps one set of people does and says comic things to offset the more serious speech and action of a more important group, with the result that there may be an alternating of dignified and intense situations with those that are merely amusing. So it is with a novel. But it is not so with a short story, where all the elements are calculated to make vivid the one unified impression that the author seeks to make. In its unity the one-act play is like the short story, for characters, action, circumstances, setting, and dialogue, make a firmly knit, unified appeal: there is one problem or difficulty presented for solution, and all the forces of character, circumstance, and incident drive straight to that solution. The development of these forces to the proper end of the play is the plot. And let us remember that the end is the end not merely because the play stops there, but because it is the point at which all the forces reach their focus, and consequently the point where the play must end or trail off into an anti-climax. To clarify our understanding of a play after a first reading, it is very helpful to summarize the plot; to do this let us ask ourselves, "What is the problem presented in the play, and how is it solved?" Thus, in "Two Crooks and a Lady," we may state as a synopsis of the plot that it deals with the struggle between Mrs. Simms-Vane and the crooks for the 


\section{OF A PLAY}

possession of the diamonds, and that the lady saves her necklace by setting the two crooks in opposition to each other, playing first upon the greed of one, then upon the jealousy of the other, until the two malefactors are brought into a conflict that ends in their undoing.

Such a brief outlining of the main feature of the plot may be enough to make us sure that we have understood the drift of the action of the play. We may, however, wish to make a somewhat more complete analysis of the plot.

Most plays begin with an explanation of some sort, which is called the exposition. By the action or the conversation that starts the play, the audience is put into possession of certain circumstances, a knowledge of which it must have in order to understand the play. Then-perhaps at the same time that the exposition is being givenbegins the so-called rising action. Every play is a more or less clearly defined struggle of some sort: it may be a conflict of opposing personalities; it may be a struggle of one or more individuals against his or their own weakness or against the forces of law, tradition, custom, prejudice; or it may be merely the attempt of one or more persons to gain certain ends against ordinary and usual obstacles. In a play, if the individual in whom the audience is most interested is to be eventually successful, his difficulties will at first appear to master him, and we wonder how he can win to his goal. Conversely, if the hero is to fail, the audience sees him successful at the start of the play. This 


\section{THE CLASSROOM STUDY}

part of the development is the rising action. Then something happens to change the current of the hero's fortunes, or the audience learns that something did happen previously which they now see will effect that change. This turning point is the dramatic climax. From this point on, we have the so-called falling action, in the course of which the hero's fortunes develop along the channel into which they were turned by the dramatic climax. The falling action is fully developed at the climax of interest, where the operation of the various forces of incident and character come to a head, and the end is then in sight. The actual working out of the end may be left to the imagination of the audience; if it is not, we have the denouement or ending.

If we take the time to analyze our play into $e x-$ position, rising action, turning point, failing action, and ending, we of course have a better understanding of the plot than if we merely summarize the main thread of incident. But we should make some synopsis of the plot as our first step in the general study of our play.

\section{The Theme}

In creating its single impression, the one-act play deals with a single group of characters reacting upon one another in a closely connected set of situations that are pointed to a single climax of interest. But a good one-act play will show upon examination something more fundamental than 


\section{OF A PLAY}

the story that it tells. After reading "Two Crooks and a Lady," for example, we might say that the play is about the struggle of the "Lady" to keep her necklace from the "Crooks." This is true. But perhaps we can see something more underlying than this, of which this struggle is the embodiment and the expression. We should be right in saying that the play has to do with the superiority of trained intelligence backed by character, over mere cleverness clouded by passion and moral weakness. Each of these two statements would be right, but they would deal with different elements. The first statement refers to what happens; that is, to the plot. The second refers to what is called the theme. The theme is the fundamental idea that must, consciously or unconsciously, have been in the author's mind in order to enable him to give form and direction to the elements of his play. Perhaps the dramatist sets out merely to arouse certain feelings within us; perhaps he is concerned with showing us some truth about life in general, or some trait of human nobility or human frailty; perhaps he wishes to present some problem of life. Whatever it is, and whether or not we are sure we can find it, there must be a theme underlying any well-unified play. But the theme is not the plot. In its interest for us and in its hold upon us, the plot may far transcend the theme; but the latter is necessary to give the plot a proper rooting in life itself, without which the play can be only of superficial value.

The average spectator at a performance of " Two 


\section{THE CLASSROOM STUDY}

Crooks and a Lady" may be interested wholly in the plucky struggle of the "Lady" in what seems to him at first a hopeless fight, and he may not look for or care for the existence of any theme at all. But for even that spectator, the play has a richer meaning if he does see its fundamental significance, the theme. And for us who act the play, the value of realizing the theme is, of course, even greater; for with this realization of what the theme is, we can view our work in a truer perspective than otherwise. Let us say, then, that the second matter for us to consider, after reading a play through, is What is the theme?

\section{The Atmosphere}

Next let us consider the emotional tone or atmosphere of our play. If the author's work has been well done, it creates a unified emotional effect upon the reader. In other words, where such a play is properly acted, an audience will find itself feeling in some one predominant mood all the way through, barring some occasional flashes of other emotions that the dramatist may deliberately arouse for the sake of contrast. In Miss Holman's " Will o' the Wisp " we experience at the beginning an eerie feeling of strangeness: we are at the "land's end," where we are away from the wonted things of civilization, and where only the poet and the old countrywoman (who has been born and bred in the place and is as much a part of it as is her moor) are happy or even safe. This feeling is sustained

$$
\text { [8] }
$$




\section{OF A PLAY}

throughouv the play, and is gradually intensified, until at the end we are prepared to find that the Pale-faced Girl is the very "Will o' the Wisp" itself. The exclamations and remonstrances of Nora may seem comic when given in dialect, but they do not shatter the spell; rather they intensify it, as twinkling lights seen at a distance from a lonely and dangerous road intensify the darkness that surrounds the traveler, while they hint of the homely, customary commonplaces of wonted experience. This matter of tone is of the utmost importance, for a play will be entirely effective only when the actors create just the right atmosphere, and many plays are quite ruined unless they are played in exactly the right emotional tone. "The Turtle Dove" would be ineffective if played as a broad farce. There must be a whimsical grace in its humor, a smile, but not a laugh, in its conscious make-believe. The bored manner of the Property Man is obviously an offset to the impossibilities of the piece, and serves as a guarantee to the audience that it is not asked to believe the play, but only to sympathize with the quaint presentation of the romance. The acting of a play should be a piece of team-work, and if it is to be successful, every player must work toward producing one main, unified emotional effect upon the audience, whether that audience be a public gathering or members of his own class. We may have differing ideas of what the proper tone is in which to act a given play; but when we have reached a decision, we should all loyally do our work in the 


\section{THE CLASSROOM STUDY}

key determined upon. Enough has been said in the matter of the illustrations just given to show that it is not meant that each of us is to act and speak so as to produce in his individual work an effect identical with that produced by every other player; but each should bear clearly in mind the general effect to be attained, and should make sure that his own work will suit that. Perhaps ours is a comic part in an essentially pathetic play; then we must see that the comedy in our part is for some purpose of heightening the pathetic tone of the whole, either by contrast or by affording relief lest the pathetic lose its poignancy by continuous iteration; having seen the purpose of our comedy, we must act accordingly and not selfishly develop farcical possibilities in our rôle, which might bring laughter and applause from the audience, but which would make the judicious grieve and spoil the play. After judging the plot and the theme of our play, we should, as a third step in our study of the play as a whole, Determine the emotional tone.

\section{The Setring}

We should now consider the physical background that the dramatist intended for his play, and the dress he meant the characters to wear. This consideration will help us to understand the atmosphere, to see in our mind's eye the men and women that the dramatist created, and to picture the action of the play. In our classroom work, since we can not supply either the proper scenery or the 


\section{OF A PLAY}

proper costumes, we are spared the work of attempting an adequate representation of background or dress. Still, we may wish to provide some slight suggestion of scenery or of costuming, and our problem may become the two-fold one of first calling into being mental pictures of what the setting and costumes would be were the play itself really lived as the dramatist conceived it, and then suggesting in the simplest way possible representations of the most important features of background and dress.

Certainly, we must try to conceive these matters as the dramatist pictured them. As a matter of fact, the author will probably tell us what the scene should be, and we have merely to translate his word pictures into mental ones, in which we can seem to see the particular room, house, garden, bit of woods, or whatever the physical background is. However, if such a background is described as we have never seen, we should do well to try to find pictures of something similar. The same with the costumes. A style of dress may be entirely familiar to us; but if it is not, we should seek detailed descriptions or illustrations. Perhaps such simple books will be available as Constance Mackay's "Costumes and Scenery for Amateurs," or Milicent Stone's "The Bankside Costume Book for Children,"-which, by the way, is not at all a juvenile book. Very likely the Art Department in the school could help, and there may easily be pictures at home or in the school that would prove useful. Illustrated editions of well-known 


\section{THE CLASSROOM STUDY}

works of literature, and histories that contain pictures, may be of great assistance. Perhaps in the nearest public library we could find the help we need. While we are considering the costumes, it is well to imagine the build, features, and predominant facial expression of the persons in the play, so that for each we may have a full-length mental portrait, even though it be but roughly sketched. Perhaps the class will determine the color scheme for a play-especially a play like "The Turtle Dove," where a dainty effect is desirable. Such a color effect, borne in mind by the students, will help them to create the needed atmosphere. The lighting should also be decided upon: does the action take place in full daylight, or by electric light, or by lamplight, or by candlelight, or by moonlight? And does the light change in the course of the play? It is important to know all this, even though we cannot even darken the classroom for our actual work with a play that should be given in dim light.

But it is possible that we may be able actually to represent some features of the physical background and the costuming. This does not mean that we should try to imitate any part of them closely. There are times when a shawl or a hat may help us a great deal in our make-believe, and if we can provide anything of the sort that will be of help to us, we should plan out in the preliminary study of the costuming just what such devices we can use. So with the scenery: perhaps we can suggest walls by screens or by movable 


\section{OF A PLAY}

blackboards; we may be able to use a table where one is called for in the play; probably we can have all the chairs we need. Any practical device that will help us to make our acting definite as to location on the classroom "stage," should be suggested when we are imagining the full setting as the dramatist conceived it.

What has been said about scenery and costumes applies to properties. Properties in a play are articles that are not part of the scenery or the costuming. A weapon, a book, or a hand-bag, for example, are properties. In our preliminary study, we should not only picture the properties along with the physical background and the dress of the persons in the play, but we ought to consider the matter of actually representing the important properties, for this can easily be done. A long ruler or a pointer can represent a sword, for example, and sometimes members of the class would be glad to bring or make the real properties themselves.

Thus for the fourth step in our study of the play as a whole, we must Consider the setting. We must imagine the physical background (including lighting and perhaps the color scheme), the costuming, and the properties, and we should devise any simple representations of these features that are practical.

\section{The Characters}

Our plays deal with people, and our general impression of each person must be right or our calculation of his or her influence in the play will be 


\section{THE CLASSROOM STUDY}

inaccurate. It is well to make up our minds, therefore, as to what sort of man or woman each person in the play is. This is a matter of determining what qualities seem to be the most strongly marked in each person's nature, and what his or her general outlook on life is. In other words, we should decide what general way of thinking and feeling is typical of each character. (For convenience, we shall follow in this book the practice of referring to the people in a play as characters. This is a technical use of the word, of course, for ordinarily the term denotes the sum of a person's qualities.) We cannot reach a complete estimate of the characters after a first reading of the play, but to prepare ourselves to begin the detailed interpretation we do not need complete characterizations so much as judgments that are accurate in the main, although they may be incomplete. As the fifth division of our preliminary study, then, we should Determine about what sort of man or woman each character is.

\section{Music}

The final step in the preliminary study of a play is the consideration of the music that we should have for our presentation. In many cases no music will be called for; but where it is, we should determine what effects are desirable and how we can secure them. Sometimes only singing is required; if the music for this is supplied by the dramatist, our difficulties are slight. Where in- 


\section{OF A PLAY}

strumental music is indicated, we must determine what instruments should be played to give the effect the dramatist had in mind, and how loud and how rapid the playing should be. There will doubtless be at least one member of the class who can bring an instrument to school and play it. Where the music-either vocal or instrumentalis not printed with the play, we must supply it. Possibly one of us can compose something appropriate; if not, we must decide what compositions or parts of compositions would be appropriate. 


\section{CHAPTER II}

\section{DETAILED INTERPRETATION}

When our preliminary study of the play as a whole has been completed, we are in a position to begin the detailed work of presentation. We know what the play is about, with what truth or aspect of life it is concerned, in what spirit or tone it is to be performed, what the setting should be, and about how we can suggest the costuming and the physical background; we know, too, what kind of men and women the characters are in the main.

But these ideas are general, and acting calls for a definite expression of definite ideas and feelings; we must, therefore, study certain phases of our problem more in detail than we have so far done; these phases are the force and relative importance of the various parts of the play, the matter of realizing the setting, the clear conception of the characters as distinct personalities, and the determination of the ideas and feelings that the several characters entertain at each stage of their activity.

Moreover, we must know how to express effectively the results of these detailed studies. This matter of expression constitutes the objective part of the player's work; as players we must express ourselves in two ways: in our speech and in our action-what we may call the auditory appeal and the visual appeal. The auditory appeal is the 


\section{DETAILED INTERPRETATION}

oral delivery of our lines, and the visual appeal comprises facial expression, gesticulation, and bodily movement. If our expression is to be effective, we must observe the principles that underlie effective oral delivery and effective action. In other words, we must study the technique of expression.

Then, too, as players, we must do our work as members of a group with full realization of how we can help the efforts of the others in the cast; for acting is essentially team-work.

In this chapter we shall consider these several matters under the following headings: The Situations, Realizing the Setting, Getting Inside the Character, Acting as Team-work, The Auditory Appeal, and The Visual Appeal.

\section{The Situations}

Our study of the plot showed us that in any play there is one main problem or struggle. In a oneact play the dramatist presents this almost at once, and works out the solution in the rest of the play. This problem is the mainspring of the dramatic action, and the importance of circumstances and characters is determined by their relation to it. If we are to give the right emphasis and interpretation to the several parts of the play, we must see them in their proper perspective, and their perspective is determined by their relation to the central problem.

The well-written one-act play is a unit, because 


\section{DETAILED INTERPRETATION}

every bit of dialogue and action is related to the central problem. And yet every one-act play is made up of a series of what are called situations. These are not to be confused with scenes. A situation arises whenever a definite relation is created between characters, or whenever a character reacts in a definite way to circumstance. In other words, a situation is a state of relation between characters, or between characters and the circumstances that affect them. As soon as that relation is altered, there is a new situation. In a play, as in a bit of life itself, the relation of people to each other or of people to conditions, is continually changing; however, we do not call anything but a pretty clearly defined relation a situation, and a number of faintly distinguished relations may be grouped together to form one situation that will be dominated by a distinct relation between the forces of character and circumstance. Since each situation has its dominant relation, it forms a definite part of the play. It follows, therefore, that we should analyze our play into its component situations in order to be able to emphasize the particular force of each at the same time that we keep the spirit and dramatic action of each part of the play in general harmony with the tone of the play as a whole.*

To illustrate the analysis of a play into its various

* The definition presented here of the "situation" is that which Professor B. Roland Lewis gives in his book, "The Technique of the One-Act Play." His treatment of the "situation" and the "theme" is full, and will be found very helpful. 


\section{DETAILED INTERPRETATION}

situations, take the start of "Two Crooks and a Lady." We may say that Miller's first appearance is the first situation; that the second begins at the entrance of Lucille and covers the dialogue between her and Miller; that the third extends to Miss Jones's exit; that the fourth runs from the reappearance of Miller to Lucille's going out for the milk; that the fifth consists of Mrs. Simms-Vane's talk with Miller up to his taking of the stamp-box; that the talk between Miller and Lucille upon the latter's return marks the sixth situation, and so on.

Some situations contain the so-called "big moments" of the play. They are the situations that contain the major and minor climaxes of interest, and the success of the play largely depends upon the intensity with which these situations grip the audience. But it is bad art for us to actas some professionals as well as amateurs occasionally do-as if these were the only parts of the play that called for our best work. From a standpoint of dramatic appeal they are more important than the other situations, but we must lavish no less care on the correct and artistic enacting of the least interesting bit of preliminary exposition or character drawing than upon the "big moments." The "big" situations, however, contain the high lights of the play, and consequently we must lead up to them. In other words, we must keep in mind the relative importance of the several situations of the play. This is a matter of scaling our emphasis, but not of scaling our care. We must shade our work so that it becomes most intense 


\section{DETAILED INTERPRETATION}

in the intense moments. An example is furnished by the rôle of Winwood in "Allison's Lad." If we play Winwood at the start of the play with as strong feeling as we show when he loses in the fatal dicing and prepares for his death, we detract not only from the artistic performance of our own rôle, but from the force of one of the most dramatic situations of the play. The dramatically unimpressive situations, in other words, we must give in a lower emotional tone than we employ in the climaxes of interest. To do this properly may call for even more art than is needed to show the tenseness of the "big moments." In every play, generally at the start, there is more or less exposition; the dramatic interest is slight, and the need for skilful presentation correspondingly great. We must work hard in such situations, but we must have the more intense moments in mind. This scaling of the emphasis may be a very difficult thing to secure in the classroom work, and too much attention should not be given it. But a monotony of emphasis is inartistic.

\section{Realizing the Setting}

Acting is sometimes defined as "making believe." This is not a good definition if " making believe " implies the fooling of the audience rather than the doing of the player's work so convincingly that the audience must "believe " because of the sincerity of the performance. But if "making believe" applies to the player rather than to the 


\section{DETAILED INTERPRETATION}

audience, the definition covers an important phase of acting. Indeed, the player, to be effective, must make himself " believe," to a considerable extent, that he is the character he impersonates and that he is the character in the conditions and surroundings of the play. If he does not do this, his work will lack sincerity and conviction.

One part of the player's effort to make his work real to him concerns an endeavor to realize the setting. As players, we should try to see in the actual setting of the stage the physical background as we imagine the dramatist to have conceived it. If we are supposed to be in an old-fashioned room such as that imagined by the author of "Allison's Lad," we must feel ourselves there and not elsewhere. We shall be greatly helped in this by imagining in detail the walls, the ceiling, the furniture, and all the rest of the furnishings. Are there beams in the ceiling? Is there a wainscoting? Are the windows made of many small panes? Are there casements to the windows? Are there candles in the room? And where are they? And of what kind are they? Is there a low shelf around the room? If so, are there pewter dishes upon it? Just where is the table? And of what shape is it? Are there chairs or stools, or both? And what shape are they? Is there a fire-place? Where is it? How large is it? And are there logs burning there? What is the tone of the room-cozy? somber? dreary? Here the few suggestions we have made in the course of our preliminary study will help us, but as players we must see the room and the objects in it; and if 


\section{DETAILED INTERPRETATION}

we cannot visualize the scene, and feel the objects we are to touch, our work must suffer.

We must also see the other players as the characters they are representing. Are they large men or small? What is their bearing-erect? easy? constrained? Are they mean-looking, or noble, or commonplace? What color is the hair of each? And how is it cut or dressed? What is each man wearing? What is the material? How is it cut? And what color is it?

Again, we must visualize the properties. Is this school pen a quill pen? Is the ordinary glass inkwell an ink horn? Is the pocket-book a heavy leather wallet with a strap? Is the pistol a heavy weapon with a wooden handle ornamented with a strip of silver? If that long ruler is a sword, is it a slender rapier, or a strong curved weapon with a heavy brass handle? Is the flagon one of pewter, or earthenware, or leather?

It may be objected that we cannot make ourselves believe that the setting and properties and players are other than they are. Not fully, of course; but to some extent we can do just this. And if the preliminary discussion of setting, properties, and costumes has been careful and enthusiastic, the combined contributions of the class should have afforded a considerable wealth of definite material to employ in conceiving whatever was not definitely shaped in the course of that discussion. Any actor, professional or amateur, knows that his work is easier and more effective at the dress rehearsals and actual performances than it 


\section{DETAILED INTERPRETATION}

was before the dress rehearsal. In large part this is due to the fact that before the dress rehearsal it was more difficult for him to see the background and the properties as they were supposed to be, and the players as the people they represented, than it is when he has the full equipment of costume, scenery, and properties to help him realize the setting. One reason why professionals do better work than amateurs is that they make a real effort to visualize the setting, where amateurs either fail to realize the need of doing so, or find it irksome and consequently do not make the effort. This is the old difference between the capable and the less capable worker: the capable worker has mastered and knows the importance of technique, where the less capable worker trusts to inspiration and enthusiasm. Proper technique in acting calls for a whole-souled, painstaking effort to "make-believe," and the make believe must in part take the form of realizing the setting.

\section{Acting as Team-work}

The acting of a play is essentially a matter of team-work. For one thing, we must all, as players, be constantly mindful of the tone or atmosphere that the class has judged to be the proper one for the play; we must not sacrifice the spirit of the play as a whole either to exercise our own special abilities or to get greater individual results through broadening our rôles or making them more subtle than will best suit the tone of the entire performance. 


\section{DETAILED INTERPRETATION}

None of us should detract from the main interest of any situation by indulging in "business" that will take the attention of the audience from its proper main concern. Each rôle should be made life-like and interesting, but not to the extent of sacrificing the proper dramatic value of any situation as a whole. At the Evander Childs High School the students once gave a public performance of Seumas O'Brien's "Matchmakers" as part of a bill of three one-act plays. In the course of the play two men talk together about the marriage of the son of one and the daughter of the other. The daughter, who is present, shows her disapproval of the turn the conversation is taking. But she ought not to express her disapproval in such a way as materially to attract the attention of the audience from the talk of the two fathers. On the night of the performance the "daughter" was so carried away by the spirit of her part that she did more than she had done during the rehearsals. She had been wont to take up and set down in evident disapproval the high silk hat of her father's friend; but now she pretended to pour water into the hat, which so amused the audience that it gave her almost its whole attention and lost much of what the two men were saying. This was bad team-work on her part, for (though she did not mean to do so) she sacrificed the more important conversation for the less important matter of her by-play.

It is very important, further, that each of us be constantly helping the rest to get the most out of 


\section{DETAILED INTERPRETATION}

their parts. Suppose some one is telling us a bit of surprising news. It will help him if we show surprise or whatever other feeling may be called for; but if we give no evidence that we are concerned -worse yet, if we turn away (unless we do so to hide our concern), -we weaken the effect he should get, thus causing the scene to miss some of its force and making both the other player and us ourselves lose some of the spirit of the passage.

To illustrate another consideration in the matter of team-work, suppose another player is to use an article that we shall have handled before his time comes to use it; we must be very careful to leave it just where he should find it. Or suppose some property (a revolver, or a candle, for example) plays an important part in the action. The dramatist has probably arranged for some reference to be made to that article before the audience sees it to be important; or he may have planned to have had it used before that time comes. This preliminary reference or use must be clearly made by the player assigned to make it, so that the later importance of the article will not surprise the audience. In "Two Crooks and a Lady" Miller not only uses his revolver to threaten Mrs. SimmsVane, but after he has placed it on the table (and placed it rather noisily, be it noticed), he takes it up later in a half-formed intent to threaten her again. Then, when Mrs. Simms-Vane calls Lucille's attention to the weapon, the audience considers it entirely reasonable that the lady has had it in mind-although the audience has forgotten 


\section{DETAILED INTERPRETATION}

it. Another phase of this matter is illustrated in the Countrywoman's account of how the Will $o$ ' the Wisp leads people over the cliff to their death: her telling this enables the audience to know just what, at the end of the play, the Palefaced Girl means to do with the poet's wife. Here the use of an article is not concerned, but the same principle is involved as in the case where an article is used, since the audience is prepared for an important development of the action by the preliminary reference that is made to the practice of the Will o' the Wisp. Take the little boy's wish for a hoop, in "The Golden Doom ": this prepares for the disappearance of the king's crown later on, and for that reason the boy's wish should be very clearly expressed.

Another thing to consider here is the matter of the relative positions of any two or more players who may be on the "stage" at any given time. It is important that each shall know where the other or others are going to be, and the only way to insure such an understanding is to plan out, before the particular bit of acting in question is begun, just about where everyone is going to be. At the start of any recitation where a part of the play is to be acted, the class should determine where the various players are to be in the course of the day's work, and what they should do in so far as their action affects one another. To do this, students should be asked to "walk through" the action at the direction of the class. "Walking through" the action means making the movements that are [26] 


\section{DETAILED INTERPRETATION}

called for, and making them in order, but without reading any lines. Something that would take half an hour to act may be "walked through" in a moment or two, because the dialogue will not be read, and only such movements need be made as affect the relative positions of the players. There will be differences of opinion as to what positions, groupings, and changes of position are proper, but these can be threshed out and the best procedure determined in a few minutes. The advantage of determining in advance the positions of the players lies in the fact that the students who act during the recitation will know where they should be and what they should do in relation to one another, with the result that they will be free to concentrate their efforts on the problems of expression that are involved in the interpretation of their own rôles.

But, though we plan out in advance the grouping and positions of the players, we do this only in a general way, and in the course of the day's acting we may need to make little adjustments where we find we are not working out the details of position quite as we planned. If we believe that the grouping is becoming ineffective, we should change our position slightly to heighten the effectiveness of the stage picture, but we must be careful not to violate the general scheme that we worked out at the beginning of the recitation. For example, we may be getting too nearly in front of one another, or getting too close together, or working too far to one side of the "stage"; in such cases it may be possible for one or more of us to make a slight 


\section{DETAILED INTERPRETATION}

change in position. This, however, must be done carefully, for it is a cardinal principle of acting that nothing should be done on the stage unless it will seem to the audience to be a natural thing for the player concerned to do under the circumstances and in the rôle that he is playing. ${ }^{1}$

\section{Getting Inside the Character}

As players we have to express the thoughts and feelings of the persons we represent, and we have to do this so as to make their personalities plain. In a later section of this chapter, we shall take up in detail the way to present the characterization at which we have arrived in the study of a rôle; but here we must consider how to go about the matter of making the personality of a stage character seem real to us. We cannot know how the

1 No mention has been made of the reed of giving one's cues exactly, since in the classroom acting the various parts are read from the text and not delivered from memory. However, if the class elects to commit to memory any part of a play, the matter of the cues is important, for each speaker counts on being given, with absolute exactness, the last few words of the dialogue immediately preceding his own lines. He waits for these and is at a loss if he does not get them. Likewise, where any part of a play is memorized, the players must "pick up" their cues promptly, or the dialogue drags and loses in interest. Except as a matter of experiment, memorizing the text for classroom work is inadvisable. The labor attendant upon learning parts is very considerable, and what may be gained in freedom of action when the players know their lines is more than balanced by the effort necessary to recall the lines perfectly. This effort takes the player's attention from his representation, and when a slip in the delivery occurs there must be a break in the work, and this causes a letting down in the spirit of the scene. 


\section{DETAILED INTERPRETATION}

character feels and thinks at any given moment in the play unless we know the sort of person he is; and certainly we cannot speak and act in a manner to show his personality unless we know what this personality is.

Suppose we have been asked to prepare to act the rôle of Miller in " Two Crooks and a Lady." The preliminary study that the class made of Miller's nature will not have afforded us a sufficiently clear-cut and complete understanding of the man to enable us to be Miller in imagination. To get a proper conception of Miller we must determine just what sort of man his speech and action show him to be, and then we must seek to identify ourselves with him; that is, to make ourselves look at matters as he does, and feel about them the way he does.

Miller has the criminal's lack of the sense of right. He is not brave, for the dramatist tells us he is " frightened " by Lucille's sudden recognition; Mr. Pillot uses the word "frightened" rather than the term "startled." Miller is suspicious of Lucille at the beginning: "Going to hog the necklace yourself, 'stead of divvying up with me, huh?" he says. Miller cannot keep his word: not only does he break faith with Mrs. Simms-Vane in taking the stamp-box, but he plays false with Lucille when he agrees to Mrs. Simms-Vane's plan of taking the necklace and keeping Lucille from her share. Miller exhibits his cruelty in his treatment of the helpless invalid. He bullies both of the women. The revengefulness of his nature, 


\section{DETAILED INTERPRETATION}

and his lack of sportmanship are evident when he "peaches" on Lucille instead of taking her shooting of him as something he has brought upon himself. He is not really clever, but in his plans and the way he proceeds to carry them out he shows merely a familarity with the thief's ordinary methods of procedure. He is vain: Mrs. Simms-Vane sees this and plays upon his good opinion of his own appearance; he shows his vanity, too, in his obvious wish to impress Lucille with his plans for the robbery, in his effort to appear efficient in the search, and in the airy way in which he refers to the "little way we have" of picking the stones from their settings. Miller's "Hello, Inspector" is pure bravado. He shows irritation rather than the strength of self-control when Mrs. SimmsVane says "Almost your first words disclosed the fact that you did not know where the necklace is laid away"; his reply is "You're not very clever yourself. You've just as well as admitted the Thirty-three's in this room."

These are many qualities, but they are all related, for they are all rooted in selfishness. The character of Miller is entirely unified and consistent, and we may sum it up by saying that he is thoroughly selfish and lacking in moral fiber, and that he is tricky rather than really intelligent.

Now let us seek to identify ourselves with this " crook,"-to get inside the rôle. We know what sort of man he is, and we must try to put ourselves in his place and think and feel with him. Of course, his ideas and feelings vary throughout the play; but 


\section{DETAILED INTERPRETATION}

there is a fundamental mental attitude toward life that Miller has, and a tendency to entertain certain kinds of emotions rather than others. Our first problem is to get ourselves into Miller's general attitude of thought and feeling. How can we do this? We are not criminals, to be sure: we are not greedy, nor vain, nor cruel, nor conceited, nor any of the other things that Miller is. Well, no; but these traits are all weaknesses that the flesh is heir to, and we all have a touch of selfishness in us, doubtless, and probably a trace of the other qualities. Keats said:

"Where's the Poet? Show him! Show him, Muses nine! that I may know him!

'Tis the man who with a man

Is an equal, be he King,

Or poorest of the beggar-clan,

Or any other wondrous thing

A man may be "twixt ape and Plato."

And it is our task for the time being to be an equal with this weak, ignorant, wrong-thinking man, who, although he is most unlovely, is one of "the wondrous things 'twixt ape and Plato "-a man. We can do this so far as the feelings are concerned by recalling times when we were selfish, or vain, or greedy, and reviving those feelings; or we can imagine circumstances under which we might show these qualities, and so experience these feelings in imagination. In the matter of getting the general attitude of thought that Miller entertains, it is doubtless enough if we can realize that he thinks of his 


\section{DETAILED INTERPRETATION}

own wishes so exclusively that ideas of obligations to society and to individuals do not seem to enter at all, or very slightly, into his mental processes. We can imagine the criminal's super-selfish outlook on life, but we can hardly entertain it, for it is really an abnormal one.

So much for the attempt to experience the general attitude of thought and feeling which Miller shows. The definite ideas and feelings that a character entertains at the various points in a play must, of course, be realized by the player who seeks to get inside his part. Suppose, as Miller, we are trying to force Mrs. Simms-Vane to tell where the necklace is. To help us to appreciate his feelings and thoughts, can we recall any incident in our experience, or imagine one, where we were placed, or might be placed, in a situation similar to Miller's? Miller is seeking to force a physically weaker person to reveal the location of something that that person does not wish to have him take, and Miller has no right to take the object, or even to ask where it is. Miller has the assistance of another person who admires him, but also mistrusts him. This is something like trying to force little brother or sister to tell where the jam is, when we have the backing of a chum who is prepared to help us, and to whom we have promised a share. If little brother or sister heroically refuses to tell, greed, wounded vanity, irritation over impending defeat, the fear of being caught if we are not soon successful, will all tend to rouse the disagreeable qualities that Miller shows. We have not, pre- 


\section{DETAILED INTERPRETATION}

sumably, ever tried to rob the family store of jam under just these circumstances; but we might have done so, and we can realize how we should have felt and what we should have thought at such a time. Now if we intensify all the unpleasant qualities and ideas that the imagined jam robbery would have aroused in us, we can come fairly close to identifying ourselves with Miller's attitude at the particular point in the play where he threatens Mrs. Simms-Vane.

\section{The Auditory Appeal}

In our presentation of a rôle we appeal ordinarily both to the eye and to the ear of the spectators. Such unusual rôles as those of the Pale-faced Girl in "Will o' the Wisp," who does not speak, and Mrs. Simms-Vane in "Two Crooks and a Lady," who does not move, are exceptions; but even in the playing of Mrs. Simms-Vane there is an appeal to the eye, for the lady is seen, and she moves her eyes. This double appeal of the player is implied in the two words "audience" and "spectators" as applied to those who are present at a dramatic performance. Strictly speaking, the term "spectators" refers to those watching, and the word "audience" to those hearing a performance; but for convenience, either word is commonly used to denote those receiving the double appeal to eye and ear. To be effective in our work, we must make this double appeal according to correct principles. We shall consider the two parts of the work 


\section{DETAILED INTERPRETATION}

separately under the headings "The Auditory Appeal " and "The Visual Appeal," in this section treating of the former, which is, of course, the oral delivery of the player's lines.

The problem of reading our lines is partly a matter of observing the mechanics of vocal delivery, and partly a matter of calculating how to express the thought and feeling effectively in our speech. The so-called "old style" actor gave a great deal of attention to his elocution, and very likely even went so far as to regard a good mechanical rendering of his lines as of more importance than the expression of the exact shade of emotion or the exact ideas that the lines implied. The actor of to-day has doubtless gone to the other extreme, and slights the matter of elocution. The right attitude to take is to hold a proper mechanical foundation as a most important means to an end, though not an end in itself. In considering here the various elements of good delivery, we shall treat both their mechanical foundation and their significance in the expression of thought and feeling. Of these elements, breathing, enunciation, and articulation are almost purely mechanical matters, while pitch, quality, rate, and intensity of voice, together with phrasing and emphasis, are important elements in the expression of thought and feeling.

a. Breathing. Diaphragm breathing is the best for good speaking because it best develops power of control over the breath supply. We use the diaphragm in breathing when we seem to breathe with the bottom of the chest and not with the 


\section{DETAILED INTERPRETATION}

upper part. The upper abdomen and lower chest move when we breathe in this way, and the upper chest and the shoulders do not move.

b. Enunciation. Whenever the breath causes the vocal cords to vibrate, sound is produced. This sound is the foundation of various speech sounds, but it does not become speech sound until it has been molded by the several organs of speechthe hard and soft palate, the tongue, the lips, the teeth, and the cheeks. These operate to modify the shape of the great resonance chamber,-the mouth,-and to control its adjunct,- - the nasal cavity. When the organs of speech are in certain positions, the sound resulting from the vibration of the vocal cords will result in certain definite speech sounds. The production of speech sound, which is called enunciation, is thus a matter of the position of the organs of speech. Of course, certain sounds are made upon a breath foundation rather than upon a sound foundation. " $\mathrm{H}$," "f," "s," "wh," "sh," and "th" as in thought, are breath sounds. Breath sounds differ from one another in the same way that voice sounds differ from one another, in each case the difference being due to the difference of position in the organs of speech at the time the sounds are made.

Bad enunciation may be due only to carelessness or indifference: "doo" for "dew," "thoid " for " third," "wen" for "when" are examples of what may be simply careless errors. To correct faults in enunciation that are due to carelessness or indifference, one has merely to 


\section{DETAILED INTERPRETATION}

speak with care; but even so, one will be helped by a realization of what constitutes the proper position of the speech organs for the production of any given sound. But when one has some fault that one cannot overcome simply by the exercise of care in speaking, a study of the position of the speech organs is called for, and this should be followed by drill exercises. Such drills can be found in any good book on sound formation. Professor Calvin L. Lewis's "A Handbook of American Speech" will prove a useful and simple practice book.

c. Articulation. Practice, following a realization of their errors, is all that most people need to correct faults in joining sounds together. Most of us have faults of this sort, some of us very serious ones. "Yes'day" or "yes'dey" for "yesterday," "wanna" for "want to," "an' you" for " and you" are faults of articulation. Of course, one must not go to the extreme of saying " anduh you " or "want-t to," either.

d. Phrasing. Phrasing in speaking or reading is the grouping of words together by the use of pauses. We may say that there are two kinds of phrasing, since we may pause for either of two reasons. We may pause before or after an expression in order to make it emphatic, or we may pause in the course of a remark in order to make the thought clearer than it would otherwise be. When we use the first type of pause we are phrasing for emphasis; this will be discussed later on in the chapter. When we phrase for clearness, we group 


\section{DETAILED INTERPRETATION}

together sets of words that constitute grammatical elements in the sentence. Phrasing is thus not a matter of mere mechanics; it is true that in the course of an expression of any length we must pause for breath, but we should take breath at points where we pause for the purpose of making the thought emphatic or clear.

In the following passage the vertical lines indicate points at which we phrase for clearness. It will be seen that each group of words is grammatically a unit of some sort. The double lines indicate the more important grammatical divisions, and the longer phrase pauses fall at these places.

"Indeed, || the cheerlessness | of the midnight hour, | in the dim chamber, | with the rain tapping on the mullioned windows, II may well bring home to them | the dubiousness of their captive state $\|$ and set them to anxious question | of what the dawn | may have in store for them."

We cannot, in reading our lines, make a rapid mental survey of the grammatical structure of a sentence in order to know just how to phrase for clearness. But we can pause where we think our pausing will make the thought clear. By doing so we shall unconsciously be making plain the grammatical relation of the sentence elements through our use of the pause, and that is just what phrasing for clearness is.

The punctuation of any passage should be an aid to correct phrasing, but it is only an aid. Too often students regard punctuation marks as sig- 


\section{DETAILED INTERPRETATION}

nals for changing or sustaining the pitch of their voices. Many young people believe that the period calls invariably for a "dropping of the voice," and that the comma and the interrogation mark call just as invariably for a "keeping up of the voice "; therefore they obey these signs irrespective of the thought of the passage they are reading. As a matter of fact, punctuation marks are not to be taken as direct guides in the use of voice pitch, but rather as indications of grammatical relation. Often we very properly "drop our voices" after interrogation marks, and likewise after commas. A writer punctuates a passage to aid the reader in grasping the grammatical relation of its various parts, and thus the punctuation is a help in phrasing. But it is only a help. In the passage quoted there are phrase pauses at other points than those marked by punctuation, and in general it may be said that people phrase badly who phrase only according to punctuation.

Phrasing, always important, becomes particularly so when for any reason there is likelihood that an audience may fail to grasp the thought of a passage. If we have occasion to speak in a tone lower than our usual pitch, we may not be understood unless we make more phrase pauses than we should normally make, and at the same time make them more marked. In this matter it should be noted that extreme care in enunciation is another means of making clear the thought of a passage that an audience might be expected to have difficulty in grasping. Mrs. Simms-Vane speaks in 
a voice that her illness has rendered weak and low and slightly monotonous. But her cultured speech would naturally be marked by an enunciation so clear as to serve as an offset to the faintness of tone. We must remember, too, that a third help in the matter of insuring clearness of thought lies in the proper use of emphasis.

Phrasing for clearness is, then, a very important element in the adequate presentation of thought, and it is obvious that no one can phrase properly who does not completely understand the thought of what he is saying or reading. The rest of the matters to be treated in connection with the Auditory Appeal are, like phrasing, not matters of voice mechanics; neither are they wholly concerned, as phrasing is, with making clear the structural relation of the various parts of the sentence. The importance of these further matters lies in their value as aids in the presentation of ideas so as to show the personalities of the various characters and their emotional states, as well as to make plain their thoughts.

When we act a rôle, we should constantly ask ourselves five questions: First, "Just what is the thought that our character expresses here?" Second, "How can we make this plain in the way we read the lines and in what we do?" Third, "Just what feeling does our character entertain here?" Fourth, "How can we make this plain in the way we read the lines and in what we do?" Fifth, "Bearing in mind what qualities of mind 


\section{DETAILED INTERPRETATION}

and heart mark the personality of the character whose rôle we are playing, how can we make his individuality plain in what we say and in what we do?" Of course, in the Auditory Appeal we are concerned with how we speak and not with what we do; but with this limitation, it is these five questions that we must bear in mind in considering the matters of the Rate of Delivery, Pitch of Voice, Quality of Voice, Force and Volume of Voice, and Emphasis. Inflection and Pronunciation, both of which will be briefly treated, have little importance as elements in the presentation of particular thoughts and feelings, though Dialecta division of Pronunciation-has a real value in the matter of characterization.

e. The Rate of Delivery. 1. Taking for granted that we realize the need of reading our lines slowly enough for the audience to hear just what we are saying, our first consideration in this phase of oral delivery is the possible demands of the general characterization of our rôle. For example, if our sharacter is a slow-thinking, phlegmatic person, we must make this plain by speaking slowly,perhaps with a drawl. In "The Golden Doom" the Chief Prophet may well be represented as speaking slowly in the effort to impress his hearers. The oily smoothness of Eurymachus in "Ulysses" may to a considerable extent be indicated by a deliberateness in the delivery of the lines; certainly a rapid delivery would be wrong, for it would tend to indicate a nature different from that which the 


\section{DETAILED INTERPRETATION}

dramatist plainly assigns to Eurymachus. The Magistrate in "Spreading the News" would well be made to speak with a nervous rapidity. Miller in "Two Crooks and a Lady" might also be represented as speaking in a rapid, jerky way, partly as a result of the pressure he is under, partly because we may conceive him as wishing to appear business-like and efficient, but largely because we may well consider him a tense, nervous man.

Aside from general matters of characterization, we must make the rapidity with which we speak at any given time accord with the particular thought and feeling to be expressed. In what is said below, possible demands of any general characterization are disregarded in order to show certain principles; but it must be borne in mind that the demands of the general characterization are of prime importance, and the expression of particular ideas or emotional states must never weaken the consistency that must mark our delineation of the character we represent.

2. Our rate of delivery varies with the strength of our feelings. Offhand, we should say that the stronger the feeling is that we entertain, the more rapid will be our speech. This is the case with feeling that is not restrained. When we are not controlling ourselves emotionally, we are "letting ourselves go" to a certain extent, and this general attitude will perforce affect our rate of speech. It is practically impossible to lose control of our emotions and retain a control of their expression as far as the rate of delivery is concerned. But when we force 


\section{DETAILED INTERPRETATION}

a control of ourselves emotionally we are making a successful effort to keep down our feelings; and this effort will carry over to our rate of speech. The result is that we speak more slowly than we should ordinarily do. In the "Will o' the Wisp," where the Poet's Wife realizes what the Pale-faced Girl is, she speaks very fast in uncontrolled anger and indignation. Penelope's reply to Antinous, beginning "Splendid Antinous, I tell thee this," may be rendered either slowly or somewhat rapidly, depending upon whether Penelope's feelings are to be understood as repressed or as being beyond her control.

Rate varies not only with the strength but with the kind of feeling. Certain feelings commonly mark an excited emotional state, and when we entertain them our speech is faster than our usual rate; gaiety and irritation are examples. On the other hand, certain feelings mark a subdued emotional condition and make for a slow rate of delivery; examples are tenderness and awe.

3. When our speech is not noticeably colored by feeling, the rate will be neither rapid nor slow except to the extent that the thought of what we are saying may cause us to speak rapidly or slowly. For rate of delivery varies with the thought. If our thought is rapid, our speech will be faster than is usual with us. Conversely, slowness of thought is reflected in slowness of speech. Miller's explanation to Lucille of his plans to secure an uninterrupted search for the necklace calls for a quickened rate of delivery partly because he is expressing ideas pre- 


\section{DETAILED INTERPRETATION}

conceived and familiar. The Mandarin in "The Turtle Dove" speaks slowly when he is considering how to have Kwen-lin carried to the house.

When we are delivering an important exposition we must speak slowly, so that the audience will not fail to grasp the thought. Passages of this kind are the announcements of the Chorus in "The Turtle Dove" and the remarks of the Countrywoman to the Pale-faced Girl at the beginning of the "Will o' the Wisp."

f. Pitch of Voice. The speaking voice varies in pitch in the same way that the singing voice does.

1. Of course, we never speak a single sentence of any length where every sound is on the same pitch or key. In the line, " But' tis mere murder. "Tis against all law," the pitch steadily rises from " but " to the first syllable of " murder," drops at the second syllable to a lower note than was used for "but," strikes the same note for the second " " tis" that was used for " but," steadily rises again through the word "all," and remains the same for "law" as for " all." This variation in pitch is what we call Inflection. But an entire passage with its inflections may be pitched predominantly in any of many keys, and this choice of key for any passage is largely determined by the feeling that the passage should reflect.

2. As in the case of Rate, the demands of character portrayal may enter into the determination of the pitch of voice. As a rule, the demands of characterization in the matter of pitch, as in the other elements of oral delivery, are determined by 


\section{DETAILED INTERPRETATION}

the predominant emotional state and mental attitude of the character. Thus Mrs. Simms-Vane in "Two Grooks and a Lady" speaks in a low pitch because she is tranquil, having been schooled to self-control by years of suffering, and because she is innately dignified and unselfish. The pitch of Mrs. Tarpey's voice should be high, partly because she is somewhat deaf, but also because a high pitch is characteristic of the voice of a gossip,--one given to talking a good deal without saying much.

3 . The pitch of our voices varies with our feelings exactly as the rate of delivery does, and for the same reasons. What was said in division 2 under Rate applies here. Rapid rate and high pitch go together, and slow rate and low pitch are similarly associated,- - so far, that is, as they are affected by feeling. It is to be noted, however, that pitch does not depend on thought as rate does, except as ideas may affect feeling and so affect pitch indirectly.

4. It is important that we do not strain our voices by pitching them habitually too high or too low. In his "A Handbook of American Speech" Professor Lewis states that for each of us there is a normal pitch, and he tells how one can ascertain what one's normal pitch is. He says: "Run up the musical scale to the highest note that can be comfortably sounded. Then run down the scale to the lowest note that can be comfortably sounded. Midway between the two, perhaps a tone or two below the middle, is the tone that should predominate in speech, the tone of departure, the keynote, so to speak.' 


\section{DETAILED INTERPRETATION}

g. Quality. Unless we speak in absolutely colorless tones, the voice is shaded with some feeling. This shading, which is not the rate of utterance or the pitch of the voice, is called Quality. Whatever emotion we feel at a given time has its effect upon the operation of the organs of speech, and it is this effect that shows in what we call voice quality. It is very difficult to analyze quality to the extent of finding out just how emotion affects it, although we can realize in rather an inexact way the nature of the effect. If we are in a fault-finding mood, our speech is likely to have a querulous quality. This, we can see, is due in part to our manipulating the palate so as to send much more than the normal amount of breath into the nasal cavity, and in part to our closing the mouth more than we do normally. Certainly no one ever showed querulousness in his voice who spoke with the back of his mouth relaxed. Now, if we feel in a fretful mood, we can keep our mood from showing in our voice by making a conscious effort to avoid a querulous quality. We may not know that we do this by sending only a normal supply of breath into the nasal cavity; we simply put our attention upon the need for avoiding the unpleasant quality in question, and we find we do avoid it. Conversely, we can express the querulousness we may wish our voice to show if we simply bear in mind that we are to show that quality; the physical adjustment of the speech organs is made instinctively. This is true of all the other qualities that the voice can show. For our work in acting our plays, about all we can do 


\section{DETAILED INTERPRETATION}

in the matter of showing quality is to bear constantly in mind the need of showing whatever quality is the proper one to show; the matter is so subtle a thing that practically it is only to a very slight extent a matter of the mechanics of speech.

There are almost numberless shadings of quality possible in the human voice, for every shade of emotion is reflected by a particular quality. But just as we may for practical purposes group the many tints of the color spectrum into a few welldefined colors, so we may speak of tone qualities as divisible into a few distinct classes. These are the head-tone or upper range quality, the orotund, the metallic, and the aspirated or whispered. The term "metallic" is taken from Mr. Louis Calvert's remarks on "tones" in his book, "Problems of the Actor." 1

1. The head-tone or upper-range quality marks our speech when we talk in the course of ordinary business, social, and domestic relations, where we have little occasion to express any marked feeling. This quality reflects the very moderate interest that is manifest in our voices when we speak of mere everyday affairs; but although we entertain no pronounced feeling of any kind when

${ }^{1}$ Though written primarily for those who may wish to become actors or actresses, Mr. Calvert's book is in no way technical and will prove very interesting to students in dramatic classes. It presents fully many of the matters set forth in the present volume, and contains a wealth of entertaining anecdote given for illustrative purposes. $\mathrm{Mr}$. Calvert is a distinguished actor and writes with the authority of his position and experience. 


\section{DETAILED INTERPRETATION}

we talk on such matters, we do have a polite regard for making our conversation reasonably animated. It is not right, therefore, to say that the head-tone quality reflects an entire absence of feeling. In any play most of the simple explanations, dispassionate questions, and unemotional remarks generally, are given in the headtone quality.

2. The orotund quality is the strong, rich, clear quality which marks the voice when the deeper feelings are stirred to expression in serious, noble thought. Expressions of patriotism, self-sacrifice, honor, justice, unselfish love, and the like, are naturally delivered with clear, full-toned, musical quality. We can say that the throat is relaxed, and that the organs of speech move unconstrainedly; but we cannot trace the thrilling timbre of the voice to its complete and exact mechanical source. The adjustment of palate, lips, tongue, throat muscles, and vocal cords is so subtle and delicate as practically to defy analysis. But when we feel a certain exaltation, this beautiful quality is present, and it never marks an emotion that is essentially and intensely concerned with self, or that is either subdued through repression or marked by an abandonment of feeling. By conscious effort we can bring the orotund quality into our voices; let us but realize the tint of emotion that we wish to have shade our speech, and the subtle adjustment is, to a certain extent, made. Practice makes for perfection in this as in everything else, and of course the more completely we make-believe emo- 


\section{DETAILED INTERPRETATION}

tionally, the more completely will we show in our voices the feeling we wish to appear to possess. Some voices are more sensitive than others to changes of feeling, but no one that is not emotionally wooden can read Penelope's lines spoken in reply to Ctesippus's offer of marriage, or her reply to Antinous's proposal, without really experiencing some echo or reflection of her deep love, which is so great as to be unselfish in the sense that it lifts her out of herself.

3 . The metallic quality of voice marks the delivery of passages that are emotionally the opposite of those naturally spoken with the orotund quality. Anger, ill-will and petulance are feelings that show in the metallic quality. Unlike the production of the orotund, the metallic tone results from a contracted, constrained position of the upper throat and the organs of speech. When Miller talks as he presses the pliers down upon Mrs. SimmsVane's hand, his voice has the metallic quality. Here again, the realization of the desired emotional shade in the voice is enough to induce a sufficient metallic coloring, though an ability to feel in part what he felt, will result in a greater amount of the desired quality.

4. The aspirated or whispered quality is a softness marking the expression of the softer emotions generally, as well as those of mystery, mild fear, awe, or horror. It follows largely from the use of a greater amount of breath than is normally used. This condition results from not bringing the vocal cords as close together as in normal emo- 


\section{DETAILED INTERPRETATION}

tional states. As with the other qualities, the player will attain something of the desired emotional shading in his voice, if he merely realizes that the whispered quality is wanted in the passages he is to deliver; but he will approximate the full amount of the quality to the degree that he is able to make his own the feeling that his character entertains. In the "Turtle Dove," at the start of the second scene, Kwen-Lin speaks with the whispered quality when she says, "His fiery breath will wither our blood. Feel how it scorches the grey veil of night. $\mathrm{He}$ is coming to consume us, he is coming to consume us! I fear his terrible rage." And her next lines are also marked with the whispered tone: "The wine cup is drained, the love songs all are silenced."

In connection with the whispered quality it may be pointed out that the failure to bring the vocal cords together, with its resultant breathiness of voice, may be due to physical weakness because the muscles of the larynx, not being under proper control, will not bring the vocal cords normally close together. Extreme emotion will also sometimes result in the partial paralysis of the muscles of the larynx, again with the result of making the voice breathy. Consequently, when a player wishes to show either great physical weakness or such an amount of feeling as would produce marked breathiness of voice, he should try to secure a whispered quality. But under these circumstances, the quality would be a harsh rather than a soft breathiness, more like the voice of a person "out of breath" 


\section{DETAILED INTERPRETATION}

than that of one whose tone is soft through tenderness or pity. ${ }^{1}$

h. Force. Force is intensity of voice. As a rule, the stronger the feeling we entertain, the greater the force with which we speak. Important ideas will for the most part be given forcibly, but only because they are associated with strong feeling.

i. Volume. Volume in speaking is amount of sound produced. As with Force, it is largely true that the stronger the feeling, the greater the amount of volume in expression. But this is the case only with strong feeling that is unrepressed; repressed

${ }^{1}$ Beauty of Voice. From what has been said, it will be plain that correct voice quality is an important matter in the technique of a player's delivery. More than that, the quality of one's voice is at all times an indication of one's nature. Really, the voice shares with the eye-" the great soul's apparent seat"- the importance of being the most valuable index of character. If for no other reason than that we wish to appear as well as possible among our fellows, we should at all times be careful of the quality of our voices. But we can make our voices a softening and inspiring influence on ourselves: we all know how hard it is to be irritable when we smile,-no matter how forced and mechanical that smile may be-for the reflex effect cannot be disregarded. A beautiful tonal quality in the voice has its effect upon the speaker as well as upon the hearer. "Her voice was soft and low, an excellent thing in woman." Excellent for its direct and for its reflex effect. And note that while it was soft, - the quality -it was low-the pitch. For quality, as we have technically used the word, is not the only element that makes voice an indication of character and a developer of character. The other elements all have their value, though quality is the most important element. The human voice is an instrument of limitless emotional and even spiritual effectiveness, and yet we for the most part are oblivious of that effectiveness, except as we note a voice of striking beauty, like Forbes-Robertson's. But a voice like his should not be the exception, and need not be. 
emotion, however strong, is expressed by a moderate volume, although there may be great intensity (force) in the expression of restrained emotion. The distinction as to volume is the same as that which obtains in the matters of Rate and Pitch: strong feeling that is unrepressed is marked by rapid Rate, high Pitch, and great Volume, whereas strong, repressed feeling is represented by a slow Rate, low Pitch, and moderate Volume. Penelope's reply to Antinous's declaration of love is marked by very strong feeling, and Penelope speaks with much force; but because the feeling is repressed, the expression is intense without being loud.

j. Emphasis. So far we have spoken of the last five elements of oral delivery as matters concerned with the direct expression of emotional states, or, in the case of Rate, as reflecting the importance of ideas. But all of these elements have a contrast value. That is, differences in feeling or in thought may be indicated by changes in Rate, Pitch, Quality, Force, or Volume. This contrast value is Emphasis. Changes in any of these elements may emphasize changes in feeling, but emphasis is more frequently employed to indicate relative impor. tance of ideas. Thus, in the matter of rate, the idea contained in anything we say is brought strongly to the attention of our hearers if we give the expression either more rapidly or more slowly than the rest of what we say. As an example of emphasis secured by the shading of volume and pitch, we may take the following passage from "Will o' the 


\section{DETAILED INTERPRETATION}

Wisp." The Lady is speaking to the Countrywoman.

"Ah, now I understand you. You have a point of view; well, so have the wives of poets. Just as he gave you comfort in return for his inspiration, we give them ease in which to love us."

The italics (not in the text) indicate the expressions for which the Poet's Wife would probably use an increased volume of voice and a higher pitch because the importance of the thoughts they convey call for their being emphasized. Importance of thought may be due either to inherent value, or to value by contrast. In the passage quoted, the expressions now, so, and point of view are important because of the idea they express by themselves; the other italicized expressions are important because of the contrast they imply or express; $w e$, for example, contrasting with he, and ease with comfort.

In connection with the securing of emphasis, the matter of Pause should particularly be borne in mind. A pause before an expression, or a pause following it, or pauses both before and after it, will cause the attention to be strongly centered on the word or words thus set off. Thus, to emphasize the word now in the passage just quoted, we might pause both before and after it. In the same way, we might pause before, or before and after, any of the other italicized expressions and emphasize it in doing so. This use of pause constitutes the phrasing for emphasis to which reference was 


\section{DETAILED INTERPRETATION}

made on page 36. It will be noticed that the emphasis pauses sometimes coincide with the pauses in phrasing for clearness. The more experience a playe: or any other public speaker has had, the more he realizes the emphasis value of pause.

k. Inflection. Closely connected with Emphasis is the matter of Conventional Inflection. This has to do with Pitch and Volume. In the section on Pitch, that element was shown to be a factor in Inflection; the relation of Volume to Inflection will be evident if we take the words that the Poet's Wife speaks immediately following the remarks we quoted a moment ago. She goes on to say, "Why shouldn't we?" Here the most important word so far as the thought is concerned is why. But an American would undoubtedly, as a matter of conventional inflection, give the expression shouldn't with greater volume of voice than the other words, at the same time-also as a matter of conventional inflection-speaking it with a somewhat higher pitch than either the why or the we. Conventional inflection is necessary to avoid a monotony of speech, which would result if pitch or volume were heightened only to express shading of thought or feeling. American inflection is compounded, as we have just seen, of variations in pitch and volume. Inflection among the people of Great Britain has less to do with volume than is the case with us, and depends more largely upon pitch. Thus, most British people would say, "Why shouldn't we?" using practically the same 


\section{DETAILED INTERPRETATION}

volume for all the words, but giving a higher pitch to the first and last than to the shouldn't. This illustrates the undulating rise and fall of emphasis that marks British inflection and that is absent in our flatter American speech. As a matter of fact, inflection, since it is wholly a conventional matter, is so largely a thing of habit with us all that we need pay little attention to it beyond realizing that it must not be disregarded.

1. Pronunciation. So far, nothing has been said of the matter of pronunciation. This is not because correct pronunciation is not extremely important in acting, but because in all English classrooms the matter is appreciated at its real value, and the writer of this book knows that in the classroom work with these plays it will receive proper attention without definite suggestion from him. Where a mistake in pronunciation is made, the attention of the audience is immediately centered upon it, and what the player is saying is for the moment largely disregarded. More than this, a wrong pronunciation (unless the part calls for this as a matter of characterization) will spoil the atmosphere of the scene in which it occurs, for whatever emotional spell is being woven will immediately be snapped by anything so remote from the proper spirit of the situation. So important has the matter of pronunciation always been considered by actors, that in France, where there is a national theater, the pronunciation of the actors in that theater has for years been accepted throughout the country as the standard. 


\section{DETAILED INTERPRETATION}

Where a stage character is not conceived by the dramatist to be a person of education, incorrect pronunciation of certain words will doubtles's be indicated in the text; if this is not done, incorrect pronunciations may be purposely given by the players. In such cases, what would be an error in the speech of cultured and educated people becomes under the circumstances the proper pronunciation for the occasion.

In the plays contained in this book, there is little or no call for dialect in the reading of the lines. Nora, in "Will o' the Wisp," may speak with more or less brogue, and the characters in " Spreading the News," except the magistrate, may use brogue also, though this is not necessary. No direction can well be given here for the mechanical production of dialect, which must always be largely a matter of imitation. The writer believes that in the speaking of each language there are certain typical, distinctive tendencies in the use of the organs of speech, which largely give each language its individual quality. Thus the Scotch and Irish seem not to open their mouths as much as the English and the Americans do; certainly the speech sounds are formed further toward the front of the mouth in the case of the Scotch and Irish, and the consonants are more sharply and distinctly spoken. But it is idle to give rules for what is essentially a matter of imitation. In general, it is well not to make the peculiarities of dialect very strong. A slight tinge is all that is necessary to give the distinctive shading required. 


\section{DETAILED INTERPRETATION}

\section{Aids to Effective Oral Interpretation}

1. Pause. The pause for phrasing and the pause for emphasis have been mentioned. The pause is also useful for the purpose of making effective a change in thought or feeling. In "The Turtle Dove," at the end of the first scene, Kwen-lin says, "Let us fly on our illustrious legs, and be married with the six ceremonies, before my father returns. I like that lip magic. It makes singing here." In this case there is a change in both thought and feeling after the expression "before my father returns." A real Kwen-lin would pause here, for neither she nor anyone else would run the expression of one idea right on to the expression of another. And even if the thought of the two parts of what she says were connected, so long as they were marked by distinct emotional states there would be the need for pausing to make the transition seem natural. When Kwen-lin makes her proposal to $\mathrm{fly}$, she speaks rapidly because the thought is rapid and also because the feeling of eagerness is unrepressed and is not one of the more quiet, subdued emotions. Feeling as she does, she speaks with a somewhat high pitch of voice. All this is changed when she declares her liking for Chang-sut-yen's kisses: here her feeling is one of quiet pleasure, and it is certainly repressed to a considerable extent, for she speaks shyly, with much maidenly reserve; consequently she will speak slowly and with a distinctly low pitch of voice. The pause prepares for this change, and it may be 


\section{DETAILED INTERPRETATION}

stated as a rule that we should pause before a change in thought or feeling.

For yet other reasons than those that have been mentioned, a proper use of Pause makes for effectiveness in the Auditory Appeal. For one thing, people naturally pause before making a reply when they have just heard something that demands a moment's consideration before it can be answered. Hesitation, likewise, always calls for slow delivery, often with one or more noticeable pauses in the course of a single statement or question. Again, Pause may be an aid in making the general manner of speaking fit the character. As an example of this, take the lines of the Chief Prophet in "The Golden Doom," which will be particularly effective if they are preceded by pauses. A real chief prophet, in order to arouse suspense in his hearers, would purposely pause before making his pronouncements and explanations, and a player in this rôle who makes such pauses increases the realistic rendering of his part.

2. Mannerisms. What has just been said brings us to the matter of making the way in which a character speaks emphasize his individuality. The repeated use of any definite peculiarity of speech will help to this end, provided the peculiarity is one that accentuates any quality that is strongly marked. Such a peculiarity may be a rapidity or a slowness in speech, a trick of pausing, a certain emphatic manner of enunciation, a nasality or gruffness of voice,-in short, any stressing of any. element of oral delivery. A peculiarity of this sort 


\section{DETAILED INTERPRETATION}

that is consistently employed is a mannerism of speech. There is a real danger in the use of such mannerisms, however: it is very easy to develop them, and if we are not careful, we may find ourselves trusting too much to them, so that our characterization will be very superficial. Again, if mannerisms are at all overdone, the characterization becomes a caricature.

3. Fully Loading the Lines. It is true that few of us can so identify ourselves with our stage characters that we find ourselves feeling just what they feel. Until we can do that, we must trust for effectiveness in our auditory appeal to an analysis of our lines. Such an analysis will show us what ideas our character entertains, and how he feels. Next, we must seek to make his thoughts and emotions plain in the way we speak, bearing in mind what we have said about the value of the several elements of oral expression. A common fault with young players is that they do not make the thought sufficiently emphatic or the feeling sufficiently plain. A very good rule for us to follow is: Express all the feeling that the lines will properly carry, and present the thought just as emphatically as the language warrants. Where more expression is given than the lines warrant, the reading becomes theatric and artificial; but high school students are very seldom guilty of this fault. They are wont to underexpress their lines, and underexpression makes for colorlessness in characterization, and for failure to bring out the full value of any given situation. We should con- 


\section{DETAILED INTERPRETATION}

stantly ask ourselves, "Are we making the thought and the feeling just as evident as we possibly can,in other words, are we properly loading the lines? "

A fully expressive reading of our lines will tend to make us feel our rôle. Just as we cannot smile without feeling more pleasant than otherwise, so in giving our lines with all the feeling they should carry, we come actually to feel more as our character feels than we should otherwise be able to. Such a reaction is very valuable, for the more we can feel our part, the more natural our work becomes, and the less we have to depend upon conscious analysis of thought and feeling.

\section{The Visual Appeal}

We have seen that the player's delivery of his lines constitutes the Auditory Appeal. The Visual Appeal is what the player does; it comprises facial expression, gesture, and action. By the way we read our lines, if we read them well, we can do much to show the kind of person our character is and to make plain what he thinks and how he feels. By what we do, if our facial expression, gestures, and action are good, we strengthen our character portrayal and make plainer the thoughts and feelings of the man whose part we play. We shall the better realize the effectiveness of a proper visual appeal when we recall that the moving picture actor gets his results entirely through his appeal to the eye. Indeed, since students are given to relying too much on their appeal to the ear, it would be 


\section{DETAILED INTERPRETATION}

interesting as well as instructive to try the experiment of acting some situation in one of our plays as though we were performing for the camera.

a. Facial Expression. The young player need hardly be afraid of overdoing his facial expression any more than he need be afraid of putting too much expression in the way he reads his lines. A professional director may caution his actors and actresses against so much use of the eyes, mouth, and face muscles as would result in grimacing; but high school students are given to too great woodenness of face rather than to over-expression. The rule for the young player is to use as much facial expression as the lines will properly carry. For the stronger unrepressed feelings, the whole face can easily be made to reflect the emotion that the circumstances demand. To express rage, the face may be contorted by a heavy scowl and a drawing back of the corners of the mouth so as to show the teeth. But the use of the eyes and mouth is generally sufficient to suggest the dominant feeling. A stare, coupled with a partly dropped lower jaw, will suggest horror or amazement. A pursed mouth and slight frown will express a moderate amount of anger or will indicate much repressed anger. A smile and a slight raising of the eyebrows will show pleasure. A sidelong glance may denote suspicion or, together with contracted eyebrows, dislike. This is said only by way of illustration, and it should be remarked that merely conventional facial expressions are to be avoided. Our work will be grimacing where we simply "register" cut and 


\section{DETAILED INTERPRETATION}

dried conventional facial attitudes that we have on tap, as it were. We must make a real effort, after realizing how our character feels at a given point in the play, to express that feeling as our character would express it. A facial expression that would be proper for one character would be unnatural or inappropriate for another. Of course, we should try to feel just as our character does; but if this is difficult, we can at least show his feelings as we think he would show them. When we employ a fitting facial expression, the physical attitude will react upon us to make us entertain some degree of the proper emotion; and when we feel an emotion ourselves, the expression of it becomes largely instinctive.

So far we have spoken of facial expression as a means of making clear the emotional state of the character to be represented. But certain facial expressions may very properly be used as mannerisms. In our study of our rôle we have analyzed our stage personality and determined the predominant quality of thought and feeling that our character shows. Most people develop little tricks or mannerisms of facial expression, and to make our characterization fully effective we should determine what such mannerisms it would be proper to use. A frown, a pursing of the lips, a halfclosing of the eyes, a smile,-all are facial expressions that may be used so often as to constitute mannerisms that will lend individuality to our characterization. It should be unnecessary to add that any mannerism must be in keeping with our character's predominant qualities. 


\section{DETAILED INTERPRETATION}

b. Gestures. Gestures are chiefly motions with the hands and arms, but the term also includes the bodily bearing, and motions of the head as well. Gestures must never be partial and incomplete unless an instinctive, half-expressed feeling is to be shown. Oftentimes a student while reading his part makes half-formed gestures that are wholly impulsive. These instinctive movements show that the player is inside his part so far as the emotion is concerned; but since his gestures are not developed beyond impulsive jerks or half-motions, they are ineffective. It is well to remember that if a gesture is worth making at all it is worth making properly, and a good rule to follow is "No gesture that is not a complete one." Sometimes a rôle calls for an intentional crudeness in the visual appeal; in such a case, half-formed gestures may be very effective, but these cases are rare. Gestures are to be used when there is an emotion to be definitely expressed, or a thought that calls for gesticulation to make it plain or forceful; but gestures are needed to express thought far less frequently than to express emotion. Any over-gesticulation is bad, but over-gesticulation in expressing thought is especially bad; when we are in doubt whether to use a gesture in order to express an idea, we should decide against doing so. But the danger of too much gesture to show feeling is not so great; and if we are uncertain whether to gesticulate to express emotion, we need not hesitate to try the effect.

Gestures should always be natural, not conventional. We must not merely "saw the air" or 


\section{DETAILED INTERPRETATION}

wave the hand to show that we feel strongly. No one stock gesture is to be used whenever a certain emotion is to be indicated. The player who uses set gestures to "register" the various emotions will conventionalize his work, and his gesticulation will be ineffective and theatric. Our gestures must be the sort that our character would use, not the kind we might ourselves employ. Eumaeus, in "Ulysses," is a rougher, cruder man than the prince Antinous, and his gestures are less graceful than those of the younger man. The Countrywoman, in "Will o' the Wisp," will use cruder gestures than the Poet's Wife, who shows the graces of refined living.

Another point to remember is that it is well to let the gesture precede the remark it is to illustrate. This both prepares for the spoken word, and provides two separate expressions of the thought or emotion rather than one double one, with the result that the effect is greater.

A very important matter is the question of how well any desired mood is implied in our general bearing. Sitting or standing, we must at any time be erect or leaning forward or inclining backward, and our choice of these physical attitudes should reflect our dominant mental attitude. If the mood that we should show is aggressive to any degree, we should lean somewhat forward. On the contrary, if our mental attitude is to be at all either defensive or reposeful, we should certainly not lean forward; in such a case the axis of the body should be inclined somewhat backward. In acting, 


\section{DETAILED INTERPRETATION}

it is well to decide for each situation whether an aggressive or a non-aggressive inclination of the body is the proper one to assume. A player who feels a bit self-conscious during a scene may be disposed to take a restful attitude in an unconscious attempt to seem at ease; but if an aggressive posture is clearly called for, he must throw the weight of the body forward. In connection with this matter, let us remember that the nature of a player's gestures must suit his general physical attitude. Miller, when he threatens Mrs. SimmsVane, will bend menacingly toward her. In keeping with this aggressive posture, he may very likely point his finger at her; certainly he should not put his hand in his pocket, for that is a gesture indicating repose.

Gestures, like facial expressions, may be used for the special purpose of providing mannerisms for stage personalities. The hands, for example, may repeatedly be clapsed behind the back, or the arms folded across the chest, as though such were a habit. Miller, in "Two Crooks and a Lady," may be given a trick of opening and closing his fingers, or quickly glancing about him. The Country-woman, in "Will o' the Wisp," may be made to shake her head frequently. The employment of such mannerisms not only helps to make the acting effective, but aids the player to get the spirit of the rôle, provided, of course, that the gestures selected be plainly in keeping with the fundamental traits of the character he is playing.

c. Action. Action that is more than gesticula[64] 


\section{DETAILED INTERPRETATION}

tion is called for in the playing of any part except such a one as that of Mrs. Simms-Vane in "Two Crooks and a Lady." In present-day plays, the more important movements will be mentioned in the dramatist's stage directions; but there is always opportunity for much effective minor action or by-play. To conceive this calls for some imagination on our part as players; but if we constantly ask ourselves "What would the character we are representing do now?" we shall doubtless conceive sufficient action, or " business," to make our work realistic.

We must, however, remember that no business is proper that is effective merely for itself and does not illuminate the thought or feeling to be expressed, aid the characterization, or further the effect of the scene as a whole. This principle is discussed in the section on "Team-Work"; but it may be repeated here that no action is proper (1) that is out of keeping with the spirit of the situation and of the play as a whole, (2) that takes the interest from the main incidents of a situation, (3) that centers it upon a player who is not so dramatically important as another, (4) that fails to be as helpful as possible to another player in his attempts to secure effects, (5) that does not provide as far as possible for effects later on in the play, (6) that tends to make a dramatically unimportant part of the play so impressive as to detract from the effectiveness of the dramatically " big moments," (7) that does not make for the most effective grouping of the players who are on the stage. 


\section{DETAILED INTERPRETATION}

For the most part, a player will make his rôle the more life-like the more he can find to do, provided the business is not open to one of the seven objections just mentioned. But whatever he does must either help the play as a whole, or illuminate his own characterization. It is really a very interesting problem to determine what the character one is representing would do, were the characters and the situation real.

Frequently repeated acts or practices of the nature of mannerisms may be conceived, and such are always effective. Care must, however, be taken to keep them in harmony with the predominant features of the personality to be represented. The Magistrate in "Spreading the News," may make greater use of a notebook than the dramatist's direction calls for, since that would tend to make plain his petty, foolish devotion to the unessentials of his duties. In this particular play it is very important that the players conceive the characters as distinct from one another and play their rôles accordingly, for the author has not provided descriptions of the people, and although the careful reader will see that the characters are as highly individualized as they are brilliantly conceived, the inexperienced reader may fail to grasp from the text all the points of differentiation. As a rule, the several people in any play should be strongly distinguished in the visual appeal. Sometimes, however, the dramatist does not care to individualize the minor characters whose personalities are unimportant: indeed, to do so may detract from 


\section{DETAILED INTERPRETATION}

the effectiveness of plays where certain minor characters are to be regarded as picturesque types. The Spies, in "The Golden Doom," are not individualized by the dramatist, probably for this reason; but different ways of moving across the stage may be devised by the three players who represent them, or the three spies may all be given what we might call a type or class mannerism,say, moving with a crouching gait. Except in minor parts where the dramatist has not cared to individualize the personalities, type mannerisms should be sparingly used. The so-called "stage" Englishman, Irishman, German, Frenchman, Chinaman, are examples of type mannerisms being made to take the place of individual character representation, and these "stage" types for the most part should be avoided, for they cannot be vital representations if they lack individuality.

"Properties" often help much in making one's character distinctive or colorful. The Countrywoman in "Will o' the Wisp " may well use a cane, Ulysses in Phillips' play will have his beggar's wallet, and the King in the "Golden Doom" will wear his crown. The dice-boxes and the dice in "Allison's Lad" will help the three players to get the spirit of the situation, and each can hold and use the dice-box in a distinctive and characteristic way. Costumes, where they can be used, will also prove a very great help in the characterization, being important as much for their effect upon the wearers themselves as for their appeal to the audience. 


\section{DETAILED INTERPRETATION}

The art of " doing nothing" is a difficult one to master. There are times in every play where a player must " do nothing," either because the character he is representing would naturally stand or sit still, or because his moving would detract from the effect that another character, more important dramatically, should obtain. However, a player never does absolutely nothing. Perhaps he does not move, but he will probably in some way show a reaction to what is being done or said. Suppose he has merely to listen: then he can at least seem to be interested; or, if he ought to appear to be indifferent to what is going on, he can let the audience know that this indifference is assumed. He may show this either by an expression of face, or by a gesture not to be seen by the other players but visible to the audience. A good rule is, "Act all the time even when you are "doing nothing." "

The Pale-faced Girl, in "Will o'the Wisp," has a part that is played wholly by facial expression, gesture, and action, for she does not speak a word. Part of the time she has " nothing to do," and yet her bearing during the time that she is motionless is eloquent, and her face expresses just enough feeling to give a hint of her identity. When the Poet's Wife speaks belittlingly of the Poet, the Pale-faced Girl makes her own feelings plain in her facial expression and action, and by these means she also makes very plain the full force of what the Poet's Wife says. Later on, of course, she dominates the scene; but her earlier work affords a good example of "business" that, while effective in the 


\section{DETAILED INTERPRETATION}

expression of character, aids in developing a situation and strengthening the atmosphere of a play.

In our " action," we should bear in mind certain mechanical matters. When we take a single step forward while we are facing either the right or the left side of the "stage," we should use the foot that is further from the audience. And the same principle applies to movements of the arms and hands. The reason for this is that if we face the left of the stage, our left side is further from the audience, and a step forward with the left foot, or backward with the right one, tends to swing the body so that we shall more nearly face the front. It is to be remembered, in the matter of stage directions, that "Right" and "Left" refer to the actor's right and left when he is facing the audience, and that "Front" and "Down" mean nearer the audience, while "Up" and "Back" mean away from it. It is of great importance, too, that we should seek to face the audience as nearly as possible. Perhaps we cannot, at times, stand at an angle of much more than 90 degrees from the back wall; still, by observing the principles just laid down for the use of our arms and feet, we can be sure that the angle is as great as we can possibly make it.

These are mechanical matters, but the mechanics must be cloaked with an appearance of naturalness. Naturalness, which is without price in acting, is much more than gracefulness; we cannot be natural unless what we do seems appropriate and reasonable. The expression of ideas or states 


\section{DETAILED INTERPRETATION}

of feeling may be cause enough for acts that serve no other purpose, but sometimes the exigencies of a situation call for a movement that must be adroitly prepared for. For example, suppose a player, who has been busy at one side of the stage, has to do something later at the other side. Very likely the dramatist will have provided a reason for his crossing over; but if not, the player must not simply walk across the stage for no reason that the audience can see except that of getting to the other side. In such a case, he must conceive some "business" that will provide a reason for his change of position.

\section{Summary: The Interpretation in Brief}

In the sections on the Situations, Realizing the Setting, Acting as Team-work, Getting Inside the Character, the Auditory Appeal, and the Visual Appeal, certain principles of dramatic interpretation have been presented. These principles underlie the technique of the actor's work, and the student who carefully observes them will find his interpretation sound. It is not to be understood that in our expression we are to deliberate upon just what rate of speech, what quality, force, and volume of voice, we should employ in rendering each phrase; or that we are to determine our every facial expression, gesture, and movement only after deciding what principles of the visual appeal seem to be concerned. Where we have a knowledge of the principles of expression, we shall be [70] 


\section{DETAILED INTERPRETATION}

likely to avoid error in our work, even though we do not consciously make the effort to recall just the particular principle that applies in each detail of our expression. However, there will be many occasions where we shall find ourselves in doubt as to just how we should express ourselves, and in such cases a consideration of the principle involved will enable us to adopt the correct expression.

When we have made the general study of the play, as outlined in Chapter I, we should proceed to study the situations in the play, and to realize the setting. Next, each of us should seek to "get inside" the character assigned to us. After this comes the acting itself, where our problem is to express adequately the thought and feeling of each passage in our part, and to do this so as to make evident the individuality of the character we represent. In our work we must now constantly ask ourselves the five questions printed on page 39 . It is not a laborious task to make sure that we realize the different ideas that we must make plain and the various feelings that we must show, or to make sure that we are doing all we can to express these in the way we speak and in what we do. The thing to remember here is that we must make the delivery of every sentence count, and that we must be expressing ourselves constantly in facial expression, gesture, and movement, or in the deliberate omission of any or all of these phases of the visual appeal.

This, in brief, is our procedure. One point should be stressed: it is that we must seek to "make 


\section{DETAILED INTERPRETATION}

believe" in the sense of making ourselves believe in our rôle. The suggestions in this book have been devised for those who find it difficult to feel the part they are playing. If a student realizes the setting, if he makes a careful analysis of the situations, if he studies his stage character and the thought and feeling in each passage of his part, and if he follows this by making a genuine effort in the auditory and the visual appeal, he will speak and act so like the character that before long he will find himself unconsciously thinking and feeling much as the character does. The point has been made more than once that when we smile we cannot feel so ungracious as we might otherwise feel, and that when we frown or assume any other unpleasant facial expression, it becomes the harder for us to entertain a pleasant attitude. The same relation between physical states on the one hand, and mental and emotional states on the other, obtains for every shade of facial expression, gesture, and action, and for every element of speech. For this reason, when we play our rôle as well as we can, we find that we unconsciously assume more or less of the mental and emotional attitudes of the character we represent; we re-act to the physical states (of voice and body) by which we seek to express those same attitudes of our character. In other words, the more we act and speak as our character would, the more we think and feel as he does, and consequently the easier it becomes to act and speak like him as we proceed in the characterization. 


\section{PART II}

\section{Plays and Notes}



, 


\title{
THE GOLDEN DOOM
}

\author{
BY \\ LoRd Dunsany
}

Reprinted from Five Plays by Lord Dunsany through the courtesy of

Lord Dunsany

and

Messrs. Little, Brown and Company, Boston 


\section{PERSONS}

THE KING

CHAMBERLAIN

CHIEF PROPHET

GIRL

BOY

SPIES

FIRST PROPHET

SECOND PROPHET

FIRST SENTRY

SECOND SENTRY

STRANGER

ATTENDANTS

Scene: Outside the King's great door in Zericon.

Time: Some while before the fall of Babylon.

Copyright, 1914, by Little, Brown and Company. Permission for amateur or professional performance of anv kind must be secured from Stuart Walker, Carnegie Hall, New York. 


\section{THE GOLDEN DOOM}

Two Sentries pace to and fro, then halt, one on each side of the great door.

First Sentry. The day is deadly sultry.

Second Sentry. I would that I were swimming down the Gyshon, on the cool side, under the fruit trees.

First Sentry. It is like to thunder or the fall of a dynasty.

Second Sentry. It will grow cool by night-fall. Where is the King?

First Sentry. He rows in his golden barge with ambassadors or whispers with captains concerning future wars. The stars spare him!

Second Sentry. Why do you say "the stars spare him "?

First Sentry. Because if a doom from the stars fall suddenly on a king it swallows up his people and all things round about him, and his palace falls and the walls of his city and citadel, and the apes come in from the woods and the large beasts from the desert, so that you would not say that a king had been there at all.

Second Sentry. But why should a doom from the stars fall on the King?

First Sentry. Because he seldom placates them. Second Sentry. Ah! I have heard that said of him.

First Sentry. Who are the stars that a man 


\section{THE GOLDEN DOOM}

should scorn them? Should they that rule the thunder, the plague and the earthquake withhold these things save for much prayer? Always ambassadors are with the King, and his commanders, come in from distant lands, prefects of cities and makers of the laws, but never the priests of the stars.

Second Sentry. Hark! Was that thunder?

First Sentry. Believe me, the stars are angry.

[Enter a Stranger. He wanders toward the King's door, gazing about him.]

Sentries [lifting their spears at him]. Go back! Go back!

Stranger. Why?

First Sentry. It is death to touch the King's door.

Stranger. I am a stranger from Thessaly.

First Sentry. It is death even for a stranger.

Stranger. Your door is strangely sacred.

First Sentry. It is death to touch it.

[The Stranger wanders off.]

[Enter two children hand in hand.]

Boy [to the Sentry]. I want to see the King to pray for a hoop. [The Sentry smiles.]

Boy [pushes the door; to girl]. I cannot open it. [To the Sentry] Will it do as well if I pray to the King's door?

Sentry. Yes, quite as well. [Turns to talk to the other Sentry.] Is there anyone in sight?

Second Sentry [shading his eyes]. Nothing but a dog, and he far out on the plain.

First Sentry. Then we can talk awhile and eat bash.

Boy. King's door, I want a little hoop. [The 


\section{THE GOLDEN DOOM}

Sentries take a little bash between finger and thumb from pouches and put that wholly forgotten drug to their lips.]

Girl [pointing]. My father is a taller soldier than that.

Boy. My father can write. He taught me.

Girl. Ho! Writing frightens nobody. My father is a soldier.

Boy. I have a lump of gold. I found it in the stream that runs down to Gyshon.

Girl. I have a poem. I found it in my own head.

Boy. Is it a long poem?

Girl. No. But it would have been only there were no more rhymes for sky.

Boy. What is your poem?

Girl. I saw a purple bird

Go up against the sky

And it went up and up

And round about did fly.

Boy. I saw it die.

Girl. That doesn't scan.

Boy. Oh, that doesn't matter.

Girl. Do you like my poem?

Boy. Birds aren't purple.

Girl. My bird was.

Boy. Oh!

Girl. Oh, you don't like my poem!

Boy. Yes, I do.

Girl. No, you don't; you think it horrid.

Boy. No. I don't.

Girl. Yes, you do. Why didn't you say you liked it? It is the only poem I ever made. 


\section{THE GOLDEN DOOM}

Boy. I do like it. I do like it.

Girl. You don't, you don't!

Boy. Don't be angry. I'll write it on the door for you.

Girl. You'll write it?

Boy. Yes, I can write it. My father taught me. I'll write it with my lump of gold. It makes a yellow mark on the iron door.

Girl. Oh, do write it! I would like to see it written like real poetry. [The Boy begins to write. The Girl watches.]

First Sentry. You see, we'll be fighting again soon.

Second Sentry. Only a little war. We never have more than a little war with the hill-folk.

First Sentry. When a man goes to fight, the curtains of the gods wax thicker than ever before between his eyes and the future; he may go to a great or to a little war.

Second Sentry. There can only be a little war with the hill-folk.

First Sentry. Yet sometimes the gods laugh.

Second Sentry. At whom?

First Sentry. At kings.

Second Sentry. Why have you grown uneasy about this war in the hills?

First Sentry. Because the King is powerful beyond any of his fathers, and has more fighting men, more horses, and wealth that could have ransomed his father and his grandfather and dowered their queens and daughters; and every year his miners bring him more from the opal-mines [80] 


\section{THE GOLDEN DOOM}

and from the turquoise-quarries. He has grown very mighty.

Second Sentry. Then he will the more easily crush the hill-folk in a little war.

First Sentry. When kings grow very mighty the stars grow very jealous.

Boy. I've written your poem.

Girl. Oh, have you really?

Boy. Yes, I'll read it to you. [He reads.]

I saw a purple bird

Go up against the sky

And it went up and up

And round about did fly.

I saw it die.

Girl. It doesn't scan.

Boy. That doesn't matter.

[Enter furtively a Spy, who crosses stage and goes out. The Sentries cease to talk.]

Girl. That man frightens me.

Boy. He is only one of the King's spies.

Girl. But I don't like the King's spies. They frighten me.

Boy. Come on, then, we'll run away.

Sentry [noticing the children again]. Go away, go away! The King is coming, he will eat you.

[The Boy throws a stone at the Sentry and runs out. Enter another Spy, who crosses the stage. Enter third Spy, who notices the door. He examines it and utters an owl-like whistle. No. 2 comes back. They do not speak. Both whistle. No. 1 comes. All examine the door. Enter the King and his Chamberlain. The King wears a purple robe. [81] 


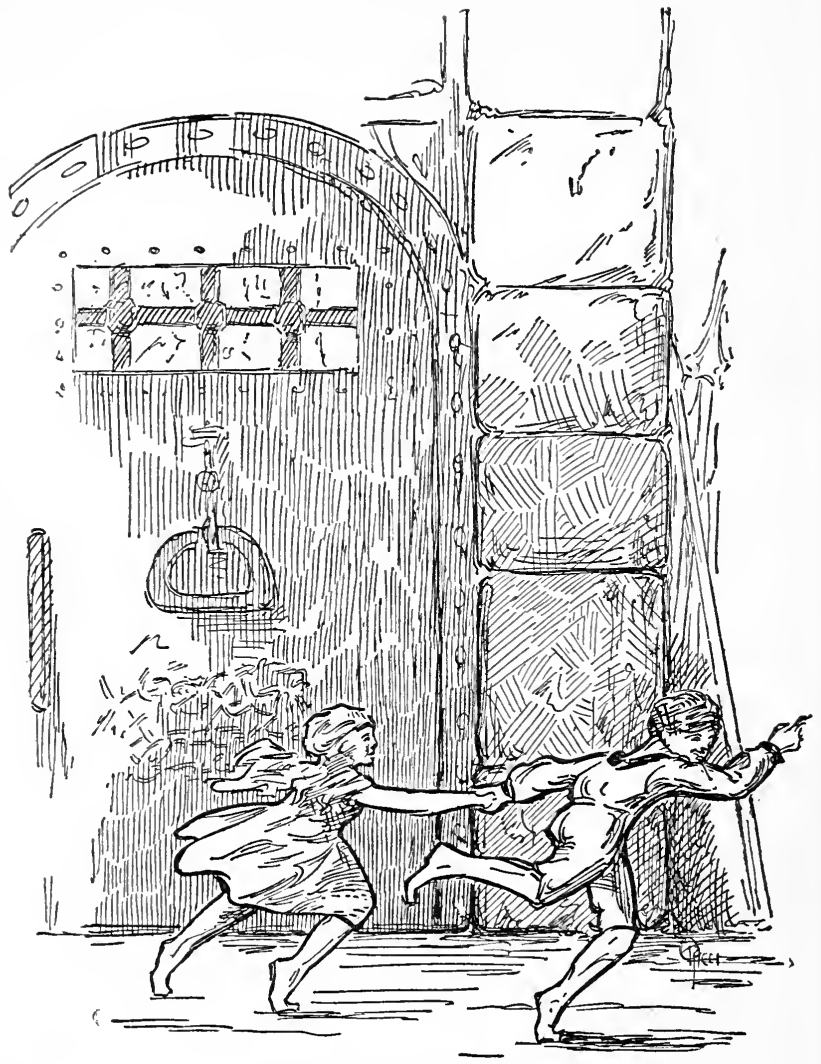

THE CHILDREN RUN OUT 


\section{THE GOLDEN DOOM}

The Sentries smartly transfer their spears to their left hands and return their right arms to their right sides. They then lower their spears until their points are within an inch of the ground, at the same time raising their right hands above their heads. They stand for some moments thus. Then they lower their right arms to their right sides, at the same time raising their spears. In the next motion they take their spears into their right hands and lower the butts to the floor, where they were before, the spears slanting forward a little. Both Sentries must move together precisely.]

First Spy [runs forward to the King and kneels, abasing his forehead to the floor]. Something has written on the iron door.

Chamberlain. On the iron door!

King. Some fool has done it. Who has been here since yesterday?

First Sentry [shifts his hand a little higher on his spear, brings the spear to his side and closes his heels all in one motion; he then takes one pace backward with his right foot; then he kneels on his right knee; when he has done this he speaks, but not before]. Nobody, Majesty, but a stranger from Thessaly.

King. Did he touch the iron door?

First Sentry. No, Majesty; he tried to, but we drove him away.

King. How near did he come?

First Sentry. Nearly to our spears, Majesty.

King. What was his motive in seeking to touch the iron door?

First Sentry. I do not know, Majesty. 


\section{THE GOLDEN DOOM}

King. Which way did he go?

First Sentry [pointing left]. That way, Majesty, an hour ago. [The King whispers with one of his Spies, who stoops and examines the ground and steals away. The Sentry rises.]

King [to his two remaining Spies]. What does this writing say?

A Spy. We cannot read, Majesty.

King. A good spy should know everything.

Second Spy. We watch, Majesty, and we search out, Majesty. We read shadows, and we read footprints, and whispers in secret places. But we do not read writing.

King [to the Chamberlain]. See what it is.

Chamberlain [goes up and reads]. It is treason, Majesty.

King. Read it.

Chamberlain.

I saw a purple bird

Go up against the sky,

And it went up and up

And round about did fly.

I saw it die.

First Sentry [aside]. The stars have spoken.

King [to the Sentry]. Has anyone been here but the stranger from Thessaly?

Sentry [kneeling as before]. Nobody, Majesty. King. You saw nothing?

First Sentry. Nothing but a dog far out upon the plain and the children of the guard at play.

King [to the Second Sentry]. And you?

Second Sentry [kneeling]. Nothing, Majesty.

[84] 


\section{THE GOLDEN DOOM}

Chamberlain. That is strange.

King. It is some secret warning.

Chamberlain. It is treason.

King. It is from the stars.

Chamberlain. No, no, Majesty. Not from the stars, not from the stars. Some man has done it. Yet the thing should be interpreted. Shall I send for the prophets of the stars?

[The King beckons to his Spies. They run up to him.]

King. Find me some prophet of the stars. [Exeunt Spies.] I fear that we may go no more my chamberlain, along the winding ways of unequalled Zericon, nor play dahoori with the golden balls. I have thought more of my people than of the stars and more of Zericon than of windy Heaven.

Chamberlain. Believe me, Majesty, some idle man has written it and passed by. Your spies shall find him, and then his name will be soon forgotten.

King. Yes, yes. Perhaps you are right, though the sentries saw no one. No doubt some beggar did it.

Chamberlain. Yes, Majesty, some beggar has surely done it. But look, here come two prophets of the stars. They shall tell us that this is idle.

[Enter two Prophets and a Boy attending them. All bow deeply to the King. The two Spies steal in again and stand at back.]

King. Some beggar has written a rhyme on the iron gate, and as the ways of rhyme are known to 


\section{THE GOLDEN DOOM}

you I desired you, rather as poets than as prophets, to say whether there was any meaning in it.

Chamberlain. 'Tis but an idle rhyme.

First Prophet [bows again and goes up to door. He glances at the writing]. Come hither, servant of those that serve the stars. [Attendant approaches.]

First Prophet. Bring hither our golden cloaks, for this may be a matter for rejoicing; and bring our green cloaks also, for this may tell of young new beautiful things with which the stars will one day gladden the King; and bring our black cloaks also, for it may be a doom. [Exit the Boy; the Prophet goes up to the door and reads solemnly.] The stars have spoken. [Reënter Attendant with cloaks.]

King. I tell you that some beggar has written this.

First Prophet. It is written in pure gold. [ $\mathrm{He}$ dons the black cloak over body and head.]

King. What do the stars mean? What warning is it?

First Prophet. I cannot say.

King [to Second Prophet]. Come you then and tell us what the warning is.

Second Prophet [goes up to the door and reads]. The stars have spoken. [He cloaks himself in black.]

King. What is it? What does it mean?

Second Prophet. We do not know, but it is from the stars.

Chamberlain. It is a harmless thing; there is no harm in it, Majesty. Why should not birds die? [86] 


\section{THE GOLDEN DOOM}

King. Why have the prophets covered themselves in black?

Chamberlain. They are a secret people and look for inner meanings. There is no harm in it.

King. They have covered themselves in black.

Chamberlain. They have not spoken of any evil thing. They have not spoken of it.

King. If the people see the prophets covered in black they will say that the stars are against me and believe that my luck has turned.

Chamberlain. The people must not know.

King. Some prophet must interpret to us the doom. Let the chief prophet of the stars be sent for.

Chamberlain [going toward left exit]. Summon the chief prophet of the stars that look on Zericon.

Voices off. The chief prophet of the stars. The chief prophet of the stars.

Chamberlain. I have summoned the chief prophet, Majesty.

King. If he interpret this aright I will put a necklace of turquoises round his neck with opals from the mines.

Chamberlain. He will not fail. $\mathrm{He}$ is a very cunning interpreter.

King. What if he covers himself with a huge black cloak and does not speak and goes muttering away, slowly with bended head, till our fear spreads to the sentries and they cry aloud?

Chamberlain. This is no doom from the stars, but some idle scribe hath written it in his insolence upon the iron door, wasting his hoard of gold.

King. Not for myself I have a fear of doom, 


\section{THE GOLDEN DOOM}

not for myself; but I inherited a rocky land, windy and ill-nurtured, and nursed it to prosperity by years of peace and spread its boundaries by years of war. I have brought up harvests out of barren acres and given good laws unto naughty towns, and my people are happy, and lo, the stars are angry!

Chamberlain. It is not the stars, it is not the stars, Majesty, for the prophets of the stars have not interpreted it. Indeed, it was only some reveller wasting his gold. [Meanwhile enter Chief Prophet of the stars that look on Zericon.]

King. Chief Prophet of the Stars that look on Zericon, I would have you interpret the rhyme upon yonder door.

Chief Prophet [goes up to the door and reads]. It is from the stars.

King. Interpret it and you shall have great turquoises round your neck, with opals from the mines in the frozen mountains.

Chief Prophet [cloaks himself like the others in a great black cloak]. Who should wear purple in the land but a King, or who go up against the sky but he who has troubled the stars by neglecting their ancient worship? Such a one has gone up and up increasing power and wealth, such a one has soared above the crowns of those that went before him, such a one the stars have doomed, the undying ones, the illustrious. [A pause.]

King. Who wrote it?

Chief Prophet. It is pure gold. Some god has written it.

Chamberlain. Some god?

[88] 


\section{THE GOLDEN DOOM}

Chief Prophet. Some god whose home is among the undying stars.

First Sentry [aside to the Second Sentry]. Last night I saw a star go flaming earthward.

King. Is this a warning or is it a doom?

Chief Prophet. The stars have spoken.

King. It is, then, a doom?

Chief Prophet. They speak not in jest.

King. I have been a great King-Let it be said of me "The stars overthrew him, and they sent a god for his doom." For I have not met my equal among kings that man should overthrow me; and I have not oppressed my people that man should rise up against me.

Chief Prophet. It is better to give worship to the stars than to do good to man. It is better to be humble before the gods than proud in the face of your enemy though he do evil.

King. Let the stars hearken yet and I will sacrifice a child to them-I will sacrifice a girl child to the twinkling stars and a male child to the stars that blink not, the stars of the steadfast eyes. [To his Spies] Let a boy and girl be brought for sacrifice. [Exit a Spy to the right looking at footprints.] Will you accept this sacrifice to the god that the stars have sent? They say that the gods love children.

Chief Prophet. I may refuse no sacrifice to the stars nor to the gods whom they send. [To the other Prophets] Make ready the sacrificial knives. [The Prophets draw knives and sharpen them.]

King. Is it fitting that the sacrifice take place [89] 


\section{THE GOLDEN DOOM}

by the iron door where the god from the stars has trod, or must it be in the temple?

Chief Prophet. Let it be offered by the iron door. [To the other Prophets] Fetch hither the altar stone.

[The owl-like whistle is heard off right. The Third Spy runs crouching toward it. Exit.]

King. Will this sacrifice avail to avert the doom?

Chief Prophet. Who knows?

King. I fear that even yet the doom will fall.

Chief Prophet. It were wise to sacrifice some greater thing.

King. What more can a man offer?

Chief Prophet. His pride.

King. What pride?

Chief Prophet. Your pride that went up against the sky and troubled the stars.

King. How shall I sacrifice my pride to the stars?

Chief Prophet. It is upon your pride that the doom will fall, and will take away your crown and will take away your kingdom.

King. I will sacrifice my crown and reign uncrowned amongst you, so only I save my kingdom.

Chief Prophet. If you sacrifice your crown which is your pride, and if the stars accept it, perhaps the god that they sent may avert the doom and you may still reign in your kingdom though humbled and uncrowned.

King. Shall I burn my crown with spices and with incense or cast it into the sea?

Chief Prophet. Let it be laid here by the iron door where the god came who wrote the golden 


\section{THE GOLDEN DOOM}

doom. When he comes again by night to shrivel up the city or to pour an enemy in through the iron door, he will see your cast-off pride and perhaps accept it and take it away to the neglected stars.

King [to the Chamberlain]. Go after my spies and say that I make no sacrifice. [Exit the Chamberlain to the right; the King takes off his crown.] Good-bye, my brittle glory; kings have sought you; the stars have envied you. [The stage grows darker.]

Chief Prophet. Even now the sun has set who denies the stars, and the day is departed wherein no gods walk abroad. It is near the hour when spirits roam the earth and all things that go unseen, and the faces of the abiding stars will be soon revealed to the fields. Lay your crown there and let us come away.

King [lays his crown before the iron door; then to the Sentries]. Go! And let no man come near the door all night.

The Sentries [kneeling]. Yes, Majesty.

[They remain kneeling until after the King has gone. King and the Chief Prophet walk away.]

Chief Prophet. It was your pride. Let it be forgotten. May the stars accept it. [Exeunt left.] [The Sentries rise.]

First Sentry. The stars have envied him!

Second Sentry. It is an ancient crown. $\mathrm{He}$ wore it well.

First Sentry. May the stars accept it.

Second Sentry. If they do not accept it what doom will overtake him?

First Sentry. It will suddenly be as though there

[91] 


\section{THE GOLDEN DOOM}

were never any city of Zericon nor two sentries like you and me standing before the door.

Second Sentry. Why! How do you know?

First Sentry. That is ever the way of the gods.

Second Sentry. But it is unjust.

First Sentry. How should the gods know that?

Second Sentry. Will it happen to-night?

First Sentry. Come! we must march away. [Exeunt right.]

[The stage grows increasingly darker. Reënter the Chamberlain from the right. He walks across the Stage and goes out to the left. Reënter Spies from the right. They cross the stage, which is now nearly dark.]

Boy [enters from the right, dressed in white, his hands out a little, crying] King's door, King's door, I want my little hoop. [He goes up to the King's door. When he sees the King's crown there, he utters a satisfied] O-oh! [He takes it up, puts it on the ground, and, beating it before him with the scepter, goes out by the way that he entered.]

[The great door opens; there is light within; a furtive Spy slips out and sees that the crown is gone. Another Spy slips out. Their crouching heads come close together.]

First Spy [hoarse whisper]. The gods have come!

[They run back through the door and the door is closed. It opens again and the King and the Chamberlain come through.]

King. The stars are satisfied.

\section{CURTAIN}

[ 92 ] 


\title{
TWO CROOKS AND A LADY ${ }^{1}$
}

BY

\author{
Eugene Pillot
}

1 The author acknowledges his indebtedness to a short story, Fibre, by Richard Washburn Child, which suggested the play.

Reprinted by the courtesy of the Author and of Brentano's from Volume I of Plays of The 47 Workshop, published by Brentano's, New York. 


\section{CHARACTERS}

Miller....................... The Hawk Lucille. .................. His accomplice Mrs. Simms-VAne

Miss Jones.................. Her companion PoLICE InSPECTOR

GARRITY. ................... A policeman

First produced by The 47 Workshop, Harvard University, November 16, 17, 1917.

Copyright, 1917, by Eugene Pillot.

Permission for amateur or professional performances of any kind must be obtained from The 47 Workshop, Lower Massachusetts Hall, Harvard University, Cambridge, Massachusetts. 


\section{TWO CROOKS AND A LADY}

SCENE: Library in the old Fifth Avenue mansion of Mrs. Simms-Vane. It is an old-fashioned, thoroughly substantial room and an ideal setting for its owner. French windows, overlooking Fifth Avenue and extending to the floor, are in the middle of the rear wall. Bookcases on each side of them extend to a door at rear right and to a writing desk at left front. There is a chair near the window, one by the table, and one by the desk. Prominent among the usual desk fittings must be a small gold stamp box. A waste-paper basket stands beside the desk, in full view of the audience. Several porcelain vases are placed about the room. A long library table, holding two brass candlesticks, is at right front. Just above it, on the right wall, a large, long mirror hangs so that it reflects the opposite side of the room.

PlaCE: New York City. TIME: The present. About three o'clock on a rainy afternoon.

The curtain rises on an empty stage, rather dark because of the rainy day and the drawn curtains. The French window in the rear opens cautiously and Miller stealthily slips into the room. He is a tall, handsome man-the usual type of gentleman crook who has emerged from the bottom of his nefarious profession. He wears a dark raincoat and a soft black hat, pulled down a little over his eyes. As he starts to advance into the room, approaching footsteps are 


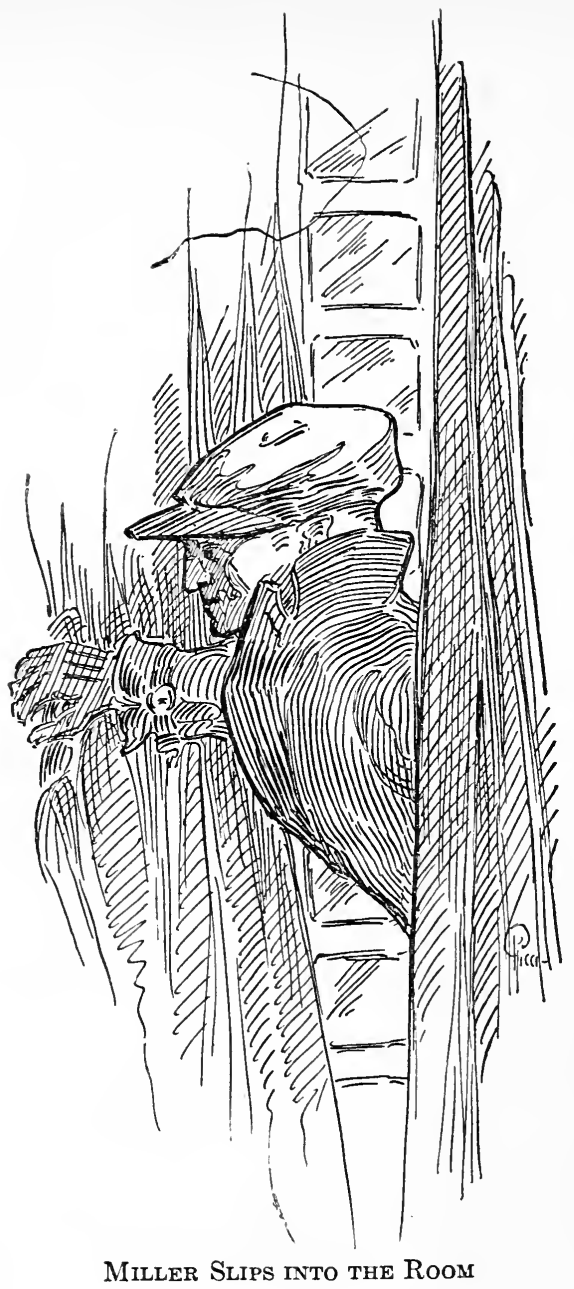




\section{AND A LADY}

heard off right. Frightened, he slips behind the heavy curtains at the windows.

Lucille enters from the door at right. She is in the conventional white apron and cap of a wellgroomed parlor maid. She stops for a moment to tidy the table, glances up at the mirror, and starts to make a slight readjustment of her cap. Suddenly she realizes that it is too dark for her to see, goes to the window, and quickly pulls back the curtains, flooding the room with light and revealing Miller. The moment she sees Miller, she jumps back frightened.

Lucille [in a loud voice]. Miller!

Miller [frightened, he comes forward cautiously]. Don't shout!

Lucille. You nearly scared the life out of me!

Miller. Don't tell it to the whole house. [Glances toward door.] Lucille, anybody about?

[Throughout the following scene, Lucille and Miller give their lines quickly, feverishly, for they fear that they may be interrupted at any moment.]

Lucille. Not yet; but they wheel Mrs. SimmsVane in here every afternoon. You're not safe here! [Tries to hurry him to the window.]

Miller [catching her by the arm]. Quick! Where does she keep the Thirty-three?

Lucille [carelessly, as she jerks her arm away]. Why should I tell you?

Miller. Going to hog the necklace yourself 'stead of divvying up with me, huh?

Lucille. No.

Miller. Then what's the matter with you? 


\section{TWO CROOKS}

Lucille. You've been taking that Minnie out again!

Miller. Naw, I'm on the level with you.

Lucille [scornfully]. Huh!

Miller. Didn't I say we'd get married soon's we cop the necklace?

Lucille [arrogantly]. I know you said that.

Miller. Then, what's in your craw? Jealous again?

Lucille. Why not? I've got everything staked on you!

Miller. And you can play it for all it's worth. It'll take both of us to steal the Thirtythree.

Lucille. Miller, it's a wonderful necklace.

Miller. Worth forty thousand dollars.

Lucille. Thirty-three blue-white diamonds. Wouldn't think an old dame would be so stuck on it!

Miller. No more than we are. [Nudges her affectionately.] Now, where does she keep it?

Lucille. In this room!

Miller. This room?

Lucille. Yes, they say she comes in here to look at it; but no one's ever seen her do it!

Miller. Good enough; we'll cop it this very afternoon!

Lucille. How?

Miller. Listen, this is the dope.

Lucille [eagerly]. Uh-huh.

Miller. Servants are off to-day, ' cept you, the cook, and the old dame's companion. Cook's way [ 98 ] 


\section{AND A LADY}

down in the kitchen-and I've fixed it to get the companion away.

Lucille. How?

Miller. Dennis is across the street-watching this window.

\section{Lucille. Why?}

Miller. When the time's ready, I'll signal him with this handkerchief and right off the phone here will ring. You answer it.

Lucille [puzzled]. What's the game?

Miller. Dennis is going to send a fake message -something about a phony check-that'll get Miss Jones out of the house. Want you to answer the phone so's to be sure it's Dennis. Then call her, understand?

Lucille. Yes!

Miller. After that it'll be plain sailing.

Lucille. But Dennis'll want some of the boot for doing that?

Miller. Naw, I promised him a tenner if he'd send the phone message and then beat it to the station and get a couple of tickets for us. [Murmur of voices from off right.]

Lucille. Oh, they're coming now. Better get away in a hurry! [Miller runs to the window.]

Miller. Don't forget to answer that phone!

Lucille. I won't! They're almost here! Hurry up and get out!

Miller. No, I'm going to stay right here.

Lucille. But they'll see you!

Miller. No, they won't. I'll slide behind this curtain. [He slips behind one of the window curC\$53042

[99] 


\section{TWO CROOKS}

tains, which remain partly open. He is completely concealed. Lucille pretends to arrange articles on the desk, furtively glancing at right door.]

From right enter Miss Jones, pushing an invalid's chair in which is seated Mrs. Simms-Vane.

[Miss Jones, the paid companion of Mrs. SimmsVane, is a rather dull, systematic English woman, not in the least understanding her mistress, but as a result of long service, obeying her to the letter. Mrs. Simms-Vane, a hopeless paralytic for twenty years, cannot move her chin a quarter of an inch to left or right. Her body is rigid; her cheeks are webbed with the fine wrinkles of the years; her eyes are beautiful with patience; and her mouth is lovely with the firmness of suffering. Once very beautiful, she is now, at the age of sixty, as inert as a faded flower. She wears a rich but simple dress of black silk with white lace at the throat. Miss Jones wheels the chair to left center, somewhat to rear, and facing the table and the mirror on the right wall. She lifts one of the invalid's hands and places it so that it rests easily on the arm of her chair. As she goes to the other side of the chair and arranges the other hand in a similar manner, Miller, with his eye on Miss Jones and watched by Lucille, silently steps from behind the curtain, glances out the window, gives a quick wave of his handkerchief-the signal to the unseen Dennis-and slips behind the curtain again without being seen by either Miss Jones or Mrs. Simms-Vane.] 


\section{AND A LADY}

Mrs. Simms-Vane [as Miss Jones starts to make a slight adjustment of the old lady's head against the back of her chair]. No, to the right. [Miss Jones moves the head slightly.] Too much. More to the left. [Miss Jones moves the head again.]

Miss Jones. May I ask why you always want your head faced that way?

Mrs. Simms-Vane [coolly amused]. You may ask.

[Mrs. Simms-Vane's tone causes Miss Jones to step back abashed, and she does not venture the question. The telephone on the desk rings. Miss Jones starts toward it; but Lucille has already picked it up.]

Lucille. I'll answer it, Miss Jones. [Speaks into the telephone.] Hello-Yes-Yes! [Glances in direction of Miller.]-All right, I'll call her. [Turns to Miss Jones.] It's for you, Miss Jones.

Miss Jones. Thank you. [Goes to telephone.] Hello-Yes-Oh, is that so?-Very well. I'll be right down to see about it.-Thank you. Goodbye. [Hangs up the receiver and goes to Mrs. Simms-Vane.] Mrs. Simms-Vane, that was the Empire National Bank on the phone.

Mrs. Simms-Vane. Yes?

Miss Jones. The cashier has discovered what appears to be an alteration in a check you gave Andrews, the grocer. They asked me to go immediately to their down-town offices; and I told them I would.

Mrs. Simms-Vane. Very well.

Miss Jones [to Lucille]. You will remain here [101] 


\section{TWO CROOKS}

with Mrs. Simms-Vane. There will be nothing to do for her. [Goes to the door at right where she turns and says to Lucille] Even though it is raining, she will take her daily ride at four as usual. By that time, probably, I shall return.

Lucille [with a superior air]. Very good, Miss Jones.

[Exit Miss Jones. A moment's silence, then an outside door closes. Miller steps out from behind the curtain and beckons for Lucille to come to him. She does so and together they step out into the room and look threateningly at Mrs. Simms-Vane for a moment. They are now in her range of vision and she stares at them without the flicker of an eyelash.]

Mrs. Simms-Vane [calmly]. Lucille, who is this gentleman? [Lucille fidgets.] Why is he here? [Lucille becomes more nervous.]

Miller [brushing past Lucille]. I'll do the talking!

Mrs. Simms-Vane. I fear, Lucille, that I have been mistaken in you.

Miller [to Mrs. Simms-Vane]. Now, there'll be no nonsense!

Mrs. Simms-Vane. I think I understand.

Miller. Better for you, if you do!

Mrs. Simms-Vane. Sir, will you kindly step forward three or four steps?

Miller. What for?

Mrs. Simms-Vane. I am unable, because of my infirmity, to turn my head; and I prefer to talk looking into the eyes.

Miller [stepping in front of Mrs. Simms-Vane]. We'll not have much talk. [Quickly, to Lucille] 


\section{AND A LADY}

You mind that door. [Points to door, which Lucille closes as Miller goes to the telephone and cuts its green cord. Resuming his position in front of Mrs. Simms-Vane] Now, Mrs. Simms-Vane, I'll tell you why I'm here.

\section{Mrs. Simms-Vane. Yes?}

Miller. I come for the Thirty-three, and you're going to tell me where it is.

Mrs. Simms-Vane [slight surprise]. So you call it the Thirty-three?

Miller. Needn't pretend you don't understand what I'm talking about. I ain't got much time. Now, where is it? [Points a menacing finger at Mrs. Simms-Vane's face. She merely smiles and looks at him without making the slightest movement.]

Mrs. Simms-Vane [firmly, but softly]. Sir, you have made a mistake to come here.

Miller. Mistake? Ha! [Halfway laughs.]

Mrs. Simms-Vane. It is true that I am a helpless invalid and cannot call for assistance; but there is that which will cause you to fail. You shall have a disaster.

Lucille [as she comes to Miller, frightened]. Oh, Miller, what does she mean?

Miller [ignores Lucille. Speaks sneeringly to Mrs. Simms-Vane]. You mean you'll call on God? Well, my nerve's good for that stuff.

Mrs. Simms-Vane [referring to Lucille]. Hers is not. [Miller turns and looks at Lucille, who has become very nervous.]

Lucille. It's a lie! The old fossil!

[103] 


\section{TWO CROOKS}

Mrs. Simms-Vane [a little, slow smile passes over her face as she continues in her calm voice]. Nevertheless, I do not refer to divine assistance.

Miller. Then, what do you mean?

Mrs. Simms-Vane. I think you will fail, because you are not made of the material that succeeds. You are both of the base metals-unrestrained, passionate, and vulgar.

Lucille [her vanity is hurt]. The idea!

Mrs. Simms-Vane. Yes, and that is why you made a mistake to come into conflict with me.

Miller. Bah!

Mrs. Simms-Vane. At the very outset, sir, you made a mistake.

Miller. Mistake-what mistake?

Mrs. Simms-Vane. Almost your first words disclosed the fact that you did not know where the necklace is laid away.

Miller. You're not very clever yourself. You've just as well as admitted the Thirty-three's in this room.

[Jerks off his raincoat, throws it on the floor, and starts to search for the Thirty-three among the papers in the writing-desk drawers. Lucille still keeps guard at the door. Mrs. Simms-Vane, unable to turn her head, stares ahead at nothing.]

Mrs. Simms-Vane [after a pause, in her same calm voice]. Will you trust in one who has never broken her word to anyone?

Miller [stops suddenly and looks at Mrs. SimmsVane]. What are you trying to get at?

Mrs. Simms-Vane. Suppose I promise to re[104] 


\section{AND A LADY}

ward you [Lucille starts forward jealously] both to the full? [Lucille sinks back relieved.]

Miller. What are you giving us?

Mrs. Simms-Vane. The necklace is my most treasured possession, not because of its money value, but because my dear, dead husband gave it to me when we were young and very happy. [ $L u$ cille turns away, sickened by this expression of sentiment.]

Miller. What's that got to do with us?

Mrs. Simms-Vane. That is why I will not have it taken from me.

Lucille. Listen to her!

Miller [coarse laugh]. Ha!

Mrs. Simms-Vane. Then look out for yourselves. I warn you.

[Miller walks back until he stands in front of Mrs. Simms-Vane. Suddenly he takes a pistol from his pocket and thrusts the muzzle of it into her face.]

Miller [growling]. Where's the thing hid? [Mrs. Simms-Vane slowly closes her eyes and slowly opens them again. He pushes the revolver nearer her.] Where's it hid?

Mrs. Simms-Vane. Do you think I fear that you will pull that trigger?

Miiler. Why wouldn't I?

Mrs. Simms-Vane. Can you not see how beautiful that would be for me-a hopeless invalid?

Miller [not understanding]. Huh?

Mrs. Simms-Vane. But it is too much to hope. You would not shoot me. 


\section{TWO CROOKS}

Miller. I'll soon show you!

Mrs. Simms-Vane. Ah, no, that would make a noise.

Miller [impatiently]. What if it did?

Mrs. Simms-Vane. Then you could not continue your search. No, I cannot hope that you will pull that trigger.

Miller [realizing the truth of her words, drops the pistol to his side]. You're a tough old nut.

Mrs. Simms-Vane. Thank you, sir. That is very kind.

Miller. Bah! [Then to Lucille] Pull out the books, girlie. We've got to frisk the whole room.

Lucille [coming forward]. All right!

Miller. Go through it systematic and fast; and look in the vases!

Lucille. Yes, yes! [Begins to execute his commands.]

Miller. Remember, she said it was "laid away" -that's the cue.

Lucille. Uh-huh.

[Miller returns to the desk, tosses papers and boxes to the floor, opens the stamp box on the desk, finds a locked drawer, and feverishly splinters it open. Lucille is hastily pulling out the books from the shelves and searching the wall behind them for any secret hiding place of the necklace. The room is in a welter of disorder. Finally, Miller returns to his revolver which he left on the table as he made his rounds of the room, stares down at it, and bites his lip.]

Miller [growling]. Time wasted! [Looks at Mrs. Simms-Vane and takes a pair of steel pliers 


\section{AND A LADY}

from his side pocket, opens them, and looks down at them.] It's rough work; but it's got to be done. [Goes to Mrs. Simms-Vane and closes his hand over one of her white wrists. Her fingers move a little.] Huh! There's some feeling in this hand. I thought so. [He slips the toothed jaws of the pliers between the thumb and forefinger down upon the soft flesh in the crotch of her thumb and closes the pliers upon it.] Now, where's the necklace? [Mrs. SimmsVane silently stares at him.] Better tell. [She merely closes her eyes.] You better tell! [Lucille shudders as she sees that he is squeezing the pliers in his tightening grip.] Curse you! Out with it! Where's the necklace?

Mrs. Simms-Vane. That is painful; but I do not think pain will ever be my master. I shall not tell you.

Lucille. Stop! Stop, Miller! The blood's coming!

Miller. Let it come.

Lucille. But she won't tell! Oh, you're crushing the flesh! Stop! [Starts to pull him away.]

Mrs. Simms-Vane [opening her eyes]. Ah, she's weakened! I said you were both made of inferior stuff. This French doll of yours, sir, was willing to see you torture an old lady who cannot move and yet a few drops of red blood make her cry out. What a pair you are-all boastfulness; but your nerves are made of shoddy. [Miller drops the pliers in his pocket, looks at Lucille, and sneers.]

Lucille [to Miller]. Don't! Don't look at me like that! 


\section{TWO CROOKS}

Miller. Why not? The old dame's right about us. [Outside, a clock strikes three o'clock.]

Mrs. Simms-Vane [fretfully]. It's three. I ordered my hot milk for three.

Miller [wheeling toward Lucille]. The cook'll bring it in?

Lucille [sullenly]. Perhaps.

Miller. Quick, then! Go to the kitchen. Say she sent you for it. I'll take another look round the room. [Lucille shrugs her shoulders and exits. Miller starts to search in the desk drawers again.]

Mrs. Simms-Vane [sees him in the mirror]. Young man, I see you're searching in those drawers again. I would not waste my time doing that.

Miller [startled]. Why not?

Mrs. Simms-Vane. Perhaps I will tell you what you wish to know.

Miller. What?

Mrs. Simms-Vane. Come and stand in front of me.

Miller [he does so, staring at her]. Well?

Mrs. Simms-Vane. You may be surprised, sir, to hear that I cannot help admiring the boldness you have shown in coming here.

Miller. Aw, what are you giving me now?

Mrs. Simms-Vane. I have always been attracted by ability, wherever it showed itself and

Miller [with contempt]. Words, words.

Mrs. Simms-Vane. No-o, but you are a handsome young man, and it is a pity that your magnetism and power should be thrown away on such a worthless young woman as Lucille.

[108] 


\section{AND A LADY}

Miller. Aw, Lucille's all right.

Mrs. Simms-Vane. Pah! You saw her cringe! Miller. Well?

Mrs. Simms-Vane. A pretty face-that's all she is. And you are infatuated with her-you who could win women far above her class. She stands in your way. This very occasion is an example of it.

Miller. What are you driving at?

Mrs. Simms-Vane. In the next fifteen minutes she may cost you forty thousand dollars.

Miller [leaning nearer]. How's it figured?

Mrs. Simms-Vane. I don't trust her; but I could-trade with you.

Miller. Trade?

Mrs. Simms-Vane. Did it not occur to you, sir, that forty thousand dollars is very little to me? If I spent it, it would be charged to my heirs.

Miller. What's that got to do with the Thirtythree?

Mrs. Simms-Vane. I would willingly send you a check for the amount, if you would go away. Miller [scornfully]. Huh!

Mrs. Simms-Vane. But it is too much to ask you to take my word for that. However, I could take yours.

Miller [eagerly]. Yes?

Mrs. Simms-Vane. But not if Lucille were involved.

Miller. Why not?

Mrs. Simms-Vane. I love those stones the [109] 


\section{TWO CROOKS}

most of all material things-and I would not trust them to her.

Miller [glances toward door, then leans nearer to her, alert]. How's that again? Talk faster.

Mrs. Simms-Vane. I cannot. I meant that if I could trust you-you alone-with the necklace until I could arrange to buy it back from you, I would pay you more for it than its appraised value.

Miller. How much more?

Mrs. Simms-Vane. Twenty-five per cent more.

Miller. I'll do it! Where's the necklace?

Mrs. Simms-Vane. But I fear the girl.

Miller [discounting her]. Oh, that girl?

Mrs. Simms-Vane. Yes, you love her; and a man in love is not to be trusted.

Miller. Aw, she's not the only girl I got.

Mrs. Simms-Vane. O-oh-and still I've no doubt you have even agreed to share your gains with her.

Miller. Well?

Mrs. Simms-Vane. It is that which has invited my contempt.

Miller. I never promised her a split. Besides, I know you're right about Lucille.

Mrs. Simms-Vane. Then twenty thousand dollars is a high price to pay for this cheap little creature's favor.

Miller. Don't have to pay it-unless she knows I've got the sparklers.

Mrs. Simms-Vane. Would you then?

Miller. Yes, she's a little wildcat, and she'd squeal on me. 


\section{AND A LADY}

Mrs. Simms-Vane. Then you mean that you would not reveal to her that you have the necklace?

Miller. Sure.

Mrs. Simms-Vane. You mean that you would give me the chance to purchase back the diamonds from you?

Miller. Yes.

Mrs. Simms-Vane. You mean that you would promise to take nothing else from this house?

Miller. What else is there?

Mrs. Simms-Vane. There is a stamp box on the writing desk. You opened it. I heard its click.

Miller. What of it?

Mrs. Simms-Vane. It is made of solid gold.

Miller [surprised that he should have missed such a valuable article, picks it up and stares at it]. Gold? That made of gold?

Mrs. Simms-Vane. Yes.

[Thinking Mrs. Simms-Vane cannot see him, he starts to pocket the stamp box. She sees his movement reflected in the mirror and gives a low chuckle of satisfaction. He is startled, not quite sure whether she saw his action or not. Quickly, but reluctantly, he puts the stamp box on the desk.]

Miller [in an over-generous tone]. Well, what of it? I'd play straight; but how do I know that you-

Mrs. Simms-Vane. You would have the word of Justinia Simms-Vane. Her honor has never been questioned. It would last as long as your own. 


\section{TWO CROOKS}

Miller [stares at her a moment]. I'm no fool. Lucille's not worth the fuss. Where's the necklace?

Mrs. Simms-Vane. Come near me. [He does so.] Open the buttons of my dress.

Miller [accusingly]. But you said it was "laid away."

Mrs. Simms-Vane. I chose my words carefully. Open my dress.

Miller [opens her dress and sees the necklace round her throat]. Judas Garryowen! She wears them! What stones! What stones!

Mrs. Simms-Vane. Take it quickly. [He does so and at once begins to pick the stones from their settings.] What are you doing?

Miller. Aw- [He is too busy to explain.]

Mrs. Simms-Vane. I say, what are you doing?

Miller. Picking the stones from their settings.

Mrs. Simms-Vane. But I don't understand-

Miller [picks out remaining stones]. Just a way we have. [Drops chain into wastebasket.]

Mrs. Simms-Vane. What was that noise?

Miller. Chain going into the basket. I take no chances.

Mrs. Simms-Vane. But you will do me the favor to button my dress. Lucille-

Miller. Yes, yes; but look at them! [Gloats over diamonds.] Thirty-three perfect ones! A-ah, what a handful! Look! [Holds them before her.]

Mrs. Simms-Vane. They are pretty; but my dress-

Miller. All right. [Drops stones in his right [112] 


\section{AND A LADY}

pocket, fastens her dress, and starts to adjust her lace collar.]

Mrs. Simms-Vane. I hear Lucille bringing-

Miller. How you going to put her off the scent?

Mrs. Simms-Vane. Leave that to me. If you are the gentleman I think you are, you will have her give me the milk.

Miller. Well; but how will you fix her?

Mrs. Simms-Vane. Just continue your search.

Miller. But I've finished this room!

Mrs. Simms-Vane. Then try the next; but leave the girl to me.

Miller [takes out the diamonds, looks at them a moment]. All right. [Walks away.] But don't you play any tricks on me.

Mrs. Simms-Vane. Sir, that will depend upon you.

[ He misses her inference and starts going through the drawers again. Suddenly, Mrs. Simms-Vane hears him stop. Reflected in the mirror on the wall before her she sees him reach for the gold stamp box on the desk, slowly grasp it, and put it in his pocket. She sighs and closes her eyes. Lucille appears in the doorway, carrying a tray which holds a tall glass of hot milk.]

Miller [seeing Lucille]. You got the milk, huh?

Lucille. Yes, but the cook wanted to bring it in herself.

Miller. Well, I've frisked the room all over again.

Lucille. What'd you find?

Miller. No luck. The old lady's done us. 


\section{TWO CROOKS}

Lucille. Look some more. We got lots more time.

Mrs. Simms-Vane. I want my hot milk.

Lucille. Forget it! [Sets tray on the table.]

Miller [over-generous]. No, give her the milk.

Lucille [surprised]. What's come over you?

Miller. Come here. [Lucille does so. Half whisper] Listen, give her the milk and keep her busy. Do anything.

Lucille. What for?

Miller. I want to see if there's anything worth picking up in the other rooms.

Lucille. But-?

Miller. Go on; give her the milk.

[Astounded, Lucille stares at him; but she takes the milk to Mrs. Simms-Vane. Miller wanders Ihrough the door into the adjoining room. Again and again his shadow appears near the doorway, as though he were watching the women.]

Mrs. Simms-Vane. You forget, my dear, that I cannot move. Put the glass to my lips. [ $\mathrm{Lu}$ cille does so.] A little nearer. [Lucille puts the glass nearer Mrs. Simms-Vane's lips.] The other side. [Peeved, Lucille glances at her; but moves the glass to the other side of Mrs. Simms-Vane's mouth.] What's that? Dirt? Is that dirt in my milk? [Impatiently, Lucille looks at the milk. Whispering] Do not show any surprise, Lucille. Keep looking at the milk.

Lucille [whispering]. Yes.

Mrs. Simms-Vane [whispering]. He has the necklace! 


\section{AND A LADY}

Lucille [whispering]. Oh!

Mrs. Simms-Vane [whispering]. If you show him that you know, he will kill you. Don't move! [Loudly] Is it dirt in my milk? Look again.

Lucille. I'm trying to see. [Whispering] You're trying to make a fool of me!

Mrs. Simms-Vane [whispering]. No, but he has tricked you and means to leave you to your fate. He has the diamonds!

\section{Lucille [whispering]. Oh!}

Mrs. Simms-Vane [whispering]. The necklace without the stones is in the wastebasket. The revolver-is on the table.

Lucille [in hushed voice, as Miller enters]. Oh.

Miller [seeing Lucille's suspicious attitude, turns to Mrs. Simms-Vane]. What are you trying to docut Lucille off from me? [Lucille looks away.]

Mrs. Simms-Vane [significantly]. Did you find it-what you came for?

Miller [hesitates, then sullenly]. No. [Starts to look in the bookcases. Lucille sets glass on the table, runs to the wastebasket, looks in, and utters a cry of rage. Miller turns swiftly.]

Lucille. You've got it, you dog! [Both rush for the revolver. She gets it.] Stand back now!

Miller. But Lucille-

Lucille. You double-crossed me-after I loved you so!

Miller. Listen, girlie, the old lady's framed us. I love you, girlie. You know me. You get your share! This was the only way I could get the necklace! It was all for you! 


\section{TWO CROOKS}

Mrs. Simms-Vane. Oh, Lucille, you little fool! The other woman is the one!

Lucille. I thought so! I'm going to kill you!

Miller [desperately]. I love you!

Lucille. Oh! [Pained, she closes her eyes. Miller seizes a brass candlestick from the table and hurls it blindly at her, striking the wall behind her.] You dog! [She shoots. He falls to the floor.] Oh, what have I done? What have I done? [Covers her face. Outside a policeman's whistle is blown twice. Lucille is still too horrified by her crime to hear it; but Mrs, Simms-Vane smiles knowingly and closes her eyes.j

Mrs. Simms-Vane. I said it would be disaster for him to cross me. He broke his agreement with me. He did not know that I could see him in the mirror over the table when he took the little stamp box. [Outside the police whistle again.]

Lucille [hears whistle]. O-oh, the police!

Mrs. Simms-Vane. And now, you are a murderess.

Lucille [running to her]. No! No! Please save me!

Mrs. Simms-Vane. I wonder if you are really bad. I doubt it. You are too young to be put in jail.

Lucille. You will save me?

Mrs. Simms-Vane. I shall tell a little white lie for you, if you deserve it.

Lucille [piteous fright]. Oh, if you only would! [Off right the doorbell rings. Lucille becomes more frightened and glances apprehensively toward the door.] 


\section{AND A LADY}

Mrs. Simms-Vane. I shall say you shot him in defending me. But we must hurry! That may be the police ringing now.

\section{Lucille. Oh!}

Mrs. Simms-Vane. Put the revolver in my lap. [Lucille does so.]

Lucille. Oh, I don't deserve to be saved!

Mrs. Simms-Vane. Never mind. Go put your hand in the young man's coat pocket.

Lucille. Oh, no! I'm afraid to touch him!

Mrs. Simms-Vane. Do as I say.

[Reluctantly, Lucille goes to Miller. She starts to reach for his pocket, shudders, and recoils from him.]

Mrs. Simms-Vane. The right side. [Lucille is startled that Mrs. Simms-Vane should know the correct pocket; but she quickly thrusts her hand into it.] Do you feel the diamonds?

Lucille [gloating]. Yes; here they are. [As she lifts the stones from Miller's pocket, she pauses, swiftly putting back a stray wisp of hair over her right ear.]

Mrs. Simms-Vane. Are you sure you have all of them?

\section{Lucille. Yes!}

Mrs. Simms-Vane. You did not leave a single one?

Lucille [overconfident]. No, I'm sure!

Mrs. Simms-Vane. Then count each one and drop it into my hand.

[Lucille is startled, and fears that she has been trapped, but quickly recovers her composure.] 


\section{TWO CROOKS}

Lucille [counting the diamonds into Mrs. Simms$V$ ane's hand - the one that was not tortured by Miller]. One, two, three-how wonderful they are! [Insistent ringing of the doorbell causes her to hasten her counting.] Four, five, six- [She quickly continues to count toward thirty.]

[The doorbell has ceased ringing. An outside door opens and closes. A growing murmur of voices. A man exclaims, "But we heard a shot fired!" A woman replies, "But it couldn't have been here!" The man, "We'll have a look anyway."]

Lucille [still counting]. Thirty, thirty-one, thirty-two [a pause of surprise], thirty-three!

Mrs. Simms-Vane [suspiciously]. Thirty-three?

Lucille [bewildered, but relieved]. Yes, thirtythree.

Mrs. Simms-Vane. Then I have the stones my husband gave me,-all back again?

Lucille. All.

From right enter Miss Jones, in hat and raincoat, followed by Police Inspector.

Miss Jones [to Inspector]. I'll prove to you there was nothing- [Seeing Mrs. Simms-Vane, rushes to her.] Oh, Mrs. Simms-Vane, are you all right?

Mrs. Simms-Vane. Yes.

Miss Jones. Nothing has happened?

Mrs. Simms-Vane. No-everything.

Policeman Garrity appears in the doorway.

Garrity [to Miss Jones, as he appears]. Old lady safe? 


\section{AND A LADY}

[Miller stirs feebly. Miss Jones sees him.]

Miss Jones. Yes, but, Inspector [points to Miller], look!

Miller [feebly]. Hello, Inspector.

Inspector [to Garrity]. Miller, the Hawk! [To Mrs. Simms-Vane] Excuse me, ma'am, but who shot this man?

Mrs. Simms-Vane. The maid.

Lucille. I was defending her!

Miller. That's a lie! The little cat was the "inside" on this job. We messed it up, and she shot me. She thought I double-crossed her.

Lucille. Oh, how he talks! I never saw that man before in all my life! Did I, Mrs. Simms-Vane?

Mrs. Simms-Vane. My dear young woman, I tried to give you a chance. Now I advise the officers to arrest you. You were his accomplice.

Lucille. But you said-you promised-

Mrs. Simms-Vane. Certainly. But in my necklace there were not the number of stones you counted out to me. You kept one.

\section{Lucille. No! No!}

Mrs. Simms-Vane. Yes, you did. The necklace was given to me by my husband on my thirtyfourth, not my thirty-third, birthday. You thought I did not know the number of my own stones; so you kept one.

Miller. Ha! That serves the little devil proper. But it's just like her! I know her tricks! Look under the hair over her ears!

[Inspector and Garrity start to examine her; but she breaks away from them.] 


\section{TWO CROOKS}

Lucille. Keep away from me! I'll give her the stone! [She reaches under the hair over her right ear and throws the diamond into Mrs. SimmsVane's lap.] You old hag!

Mrs. Simms-Vane. Miss Jones [Miss Jones comes forward], have the officers take these persons away.

[Miss Jones nods to the officers to remove Lucille and Miller. Garrity takes Lucille into his custody and they exeunt right. The Inspector helps Miller up and starts toward the door with him, where Miller turns round.]

Miller [savagely to Mrs. Simms-Vane]. You'll not beat us again! [The Inspector pulls him out.]

Mrs. Simms-Vane [serenely ignoring his remark]. Miss Jones [Miss Jones goes nearer to her, waiting], you may order my carriage as usual.

[Miss Jones is surprised, but quickly nods assent and starts toward the door.]

\section{CURTAIN}




\section{WILL O' THE WISP}

BY

Doris F. Halman

Reprinted in the present volume through the courtesy of the Author. 


\title{
CHARACTERS
}

\author{
The White-Faced Girl \\ The Countrywoman \\ The Poet's Wife \\ The Serving-Maid
}

Copyright, 1916, by Doris F. Halman.

First produced at The 47 Workshop, Harvard University, December 8, 1916.

No amateur or professional performance of any kind may be given except with the author's permission and upon payment of royalty. For particulars, address Miss Doris F. Halman, 32 Webster Street, Brookline, Massachusetts. 


\section{WILL O' THE WISP}

Scene. Interior of a farmhouse at the end of things. A plain, gray room, with black furniture and a smoke-blackened fireplace. Door to outside, left back. Door to stairs, right. Fireplace in upper right-hand corner; armchair in lower right-hand corner. Below the door, left, a square table with a chair at either side. The whole center of the wall, back, is taken up by a huge window, through which one can glimpse the black spaces of a moor, rising in the distance to a sharp cliff-head silhouetted against the intense blue of an early evening sky. With the passage of the action, this blue fades into a starless night. There are two candles burning in the room, one on the table, the other on a shelf above the armchair.

When the curtain rises, the countrywoman, an old and withered dame, is lighting the candle on the table. Crouching by the fireplace at the other side of the room, is the ragged figure of a girl with a white face and big wistful eyes, a strange little figure wearing a tight-fitting gray cap which covers all her hair, a silent figure, never speaking. Until she lifts her head, she is little more than a dim gray heap in the shadows.

The Countrywoman. So I don't know what's to become of me any more, with my one boarder gone. A poet he was, to be sure, but a good one; and he 


\section{WILL O' THE WISP}

paid me enough every summer to keep my soul and body together through the rest of the long year. Seven summers he came that way, and now the time's gone by, and I hear never no word. How I'm to keep myself alive, I don't know; and since I've took you in, bless you, there's the two of us. It may be you'll have to go again, the way you came, out of the night, though you're a great comfort bein' here to talk to, and a help to me in my work. Not but what there'd be more comfort yet, if your poor tongue weren't cursed with dumbness! [She turns away, sighing, and a queer smile fickers over the stray's face.]

Dear sake, yes, I'm growin' used to you. But a stray who comes to the land's end is as welcome as any other. Nor are those likely to reach here at all, who aren't vagabonds-or poets. By which I think that my poet is gone for good, and you must follow after, and then I'll be left to dwell for the rest of my days alone with the spirits of the moor and of the sea beyond. Oh, alack! [She sits down, wiping her eyes.]

I'll not forget the night you came. A month ago it was; the second of June; and the day before was the time the poet always come, himself. When I see your white face peerin' through the window there, I thought 'twas him, late, and lookin' in for the joke of it, to see if I'd given him up. Then in another minute you was standing' in the door, poor white creature that you were. And behind you was the wind sweeping' over the moor, and the waves sighin' up the cliffhead from the sea. 


\section{WILL O' THE WISP}

God knows where you come from, and you couldn't tell. But you're not troublesome. [The creature smiles at her, as the old woman goes over to her, and pats her shoulder.]

No, you're not. Neither was he. Off all the time he was, with the will-o'-the-wisps of the field and the mermaids of the deep, learnin' their sweet songs. No trouble at all, either of you,-only, he paid. [A knock at the door. The old woman starts and cries out joyfully. As she hurries to open, she does not notice that the girl's face grows illumined as she stretches forth her thin arms in a gesture of infinite grace.]

He's come! After four weeks, at last! He'll pay again! [The door, opened by her, reveals a woman in her thirty-fifth year, dressed in the extreme of style. She enters, followed by a black-clad maid, who carries a traveling bag. Disappointed, but amazed, the old woman falls back before her. By this time, the figure near the fireplace is crouching expressionless as before.]

The Stylish Lady. Is this the farmhouse at the land's end?

The Countrywoman. Yes, so please you.

[She curtsies as well as her bent back will permit. The stray's eyes have gone from the lady to the maid, and are fixed on the servant when the lady speaks.]

The Lady. Ah!-You may set down the bag, Nora.

The Maid [with a soft brogue]. Yes, ma'am.

[She gazes nervously about the dusky room.]

The Lady [to the countrywoman]. My husband sent me to you. 


\section{WILL O' THE WISP}

[Quick as a flash, the stray's big eyes are fastened on the lady. They never waver till the end of the scene.]

The Countrywoman. Your husband? How? There are no husbands at the land's end. Nobody but me.

The Lady. My husband has been here. He used to board with you, in the summer time.

The Countrywoman. Oh! The poet?

The Lady. Yes. I am the poet's wife.

The Countrywoman. But-

The Lady. We've not been married very long. [She hastens to add, with a forced sigh] Of course, it pained me to leave him! But I was so wearied from social pleasures that he wanted me to rest; and what was I to do? I was even growing bored, not being as fresh as he to such fulness of life. But you can know nothing of that, here at the end of things. You've never seen the world?

The Countrywoman [glancing through the window]. I've seen how big it is, and how-queer.

[Her voice grows hushed with awe. Follows a slight pause. The serving-maid becomes aware of the crouching stray, and moves farther away, crossing herself. The lady's stare at the old woman ends in a burst of laughter.]

The Lady. Oh, how amusing! I think I shall enjoy my stay with you. Will you take me in for a while?

The Countrywoman [cackling with pleasure]. Now, by all the clouds in the sky to-night, I will!

The Lady. I shall require a room for myself and another for my maid. 


\section{WILL O' THE WISP}

The Countrywoman. And your husband, good ma'am? Doesn't he come?

The Lady. No. I thought better not. . . . There seemed to be some influence here that was not good for him.

The Countrywoman. Here, ma'am? At the land's end he loved so much?

The Lady [laughing unpleasantly]. Oh, I don't deny he found his inspiration in this neighborhood. Summer brought his best work, every one knows that. . . . Tell me, how did he use to spend his time?

The Countrywoman. Why, most of it, out there.

[She waves her hand toward the darkening scene beyond the windows.]

The Lady [sitting at the right of the table]. Ah? You see, he never told me about it in detail, for fear I-couldn't understand. But you think I can understand, don't you?

The Countrywoman. Good ma'am, are you acquainted with the spirits?

The Lady. Certainly not! What spirits?

The Countrywoman. Those he knew.

The Lady. Oh! So he did have other friendsbeside yourself?

The Countrywoman. They was all his friends, good ma'am. He's the only person I ever knew could walk on the moor by night, without the willo'-the-wisp should dance him over the cliff. Instead o' that, it taught him the tune it dances to, and he made a song out of it. My own man ven- 


\section{WILL O' THE WISP}

tured into the darkness years ago, and never came back more. But the poet and It was friends.

The Lady. A will-o'-the-wisp, what is that?

The Countrywoman [in a voice of awe]. It's what keeps you in the house o' nights. It's a wavin' light that beckons you to follow it. And when you've been for miles and miles, always behind, why, then it leaves you; and the morning finds you dead in a ravine, or floatin' under the cliff-head in the sea.

The Lady [laughing]. Oh, really! What a pleasant companion for my husband! [The crouching figure creeps forward $a$ bit from its place by the fireside. Again the maid, flattened against the wall, crosses herself.] But pray tell me, whom else did he know?

The Countrywoman. Poor Will, a goblin who cries through the land's end, under the curse of an old, old sin. And the mermaids with green hair, that sing when a ship goes down.

The Lady. Did my husband tell you all this?

The Countrywoman. Yes, good ma'am, and more; whenever for hunger he come home, he had a tale for me.

The Lady. And you believed it?

The Countrywoman. He was a dear young man, I'm not even blamin' the spirits, that they loved him.

The Lady [laughing]. But, I mean, do you believe in spirits?

The Countrywoman. How could I choose? I see them, I hear them. The night your husband 


\section{WILL O' THE WISP}

should have come-that was the first of JuneI saw the will-o'-the-wisp out yonder on the moor, as plain as I see my candles. Not dancin' it was, but goin' quite slow and steady-like, with its lantern lit, as if it was seekin' him. And I'm not wonderin' if, sooner or later, it didn't come peepin' and lookin' through this very window into my house, to find the friend it missed.

The Lady. Oh, what nonsense! What utter, silly bosh! [The serving-maid comes down to the left of the table, speaking in a worried whisper.]

The Maid. I'd not be sayin' the like, ma'am, if I was you. It's offering the goblins temptation.

The Lady [turning, astonished]. What! You, too, Nora? I thought you had more sense!

The Maid. In the old country, ma'am, it's the way with us all, to believe.

The Lady. Oh, dear me! Well, I can't grow superstitious, Nora, just to oblige you. That will do.

The Maid. Yes, ma'am. . . . But I think I'll be leaving you.

The Lady. What?

The Maid. Oh, it's afraid I am, what with the old woman's talk, and the look of the moor outside. We'd better be going, ma'am, the both of us. There's no good waits for us here.

The Lady. You may go when you please. For myself, I prefer to stay and meet-some of my husband's friends. I shall certainly not be frightened away by the tales my husband-left behind for me. 


\section{WILL O' THE WISP}

[She laughs again unpleasantly; and the creeping figure comes very near her chair. Across the table, the maid bursts into tears, and sinks down in the chair opposite.]

The Maid [sobbing]. How shall I take me way back, alone? Oh, the Lord pity me!

The Countrywoman. There, there, good soul, the spirits wish you no harm, they'll not hurt you.

The Lady [impatiently]. Oh, both of you, be still!

The Countrywoman. Now, you see, your husband should have come.

The Lady. My good woman, I told you, I preferred not; he is so contented where he is-among $m y$ friends.

The Countrywoman. Alack! Is he then never to come again?

The Lady. Don't expect him.

The Countrywoman. But the songs? The tunes he made, and paid for with his heart?

The Lady. Fortunately, it's no longer a question of that.

[The stray's white face peers round at her. Its eyes seem to burn the woman in the chair.]

The Countrywoman. Good ma'am, pretty ma'am, you don't mean he's give up-singin'?

The Lady. Oh, yes. Poets usually do, you know, when they marry rich women. Weak, the lot of them.

[The crouching figure half starts up; its teeth are bared; then it sinks back again. The countrywoman, covering her head with her apron, begins to sway in her chair.] 


\section{WILL O' THE WISP}

The Countrywoman. Alack! Alack the day! Alack the winter time!

The Lady. Indeed? I didn't know people like you cared for poetry.

The Countrywoman. He'll sing no more, he'll pay no more. The land's end will be poor and still.

The Lady. Ah, now I understand you. You have a point of view; well, so have the wives of poets. Just as he gave you comfort in return for his inspiration, we give them ease in which to love us. Why shouldn't we? Why should they play at their little toy battle with life, when we can put all existence into their very hands? That is our mission; and it makes them very comfortable, I assure you.

[The stray springs up with clawing hands behind the lady. The countrywoman sees her.]

The Countrywoman. Here, girl, here!

[At the cry, the stray sinks back on the floor. But her eyes never cease to burn the woman's face. The poet's wife, looking down, has now become aware of her. Her silly suspicion seems assured.]

The Lady [sharply]. Who is this?

The Countrywoman [moving the stray back]. A poor waif, ma'am. A harmless, dumb waif, who helps me in the house.

The Lady. Oho! Did you mention her among my husband's friends?

The Countrywoman. Why, no. He never saw her. Been here only a month, she has, the poor creature.

The Lady. Where did she come from? 


\section{WILL O' THE WISP}

The Countrywoman. The good Lord knows! Not I.

The Lady. Ah. Well, from the looks of her, I should say it didn't matter, how long she was with you. . . . Come here, girl.

The Countrywoman. Mind what the lady bids you.

[The figure on the floor lifts a face, now expressionless, to the poet's wife. For the third time, the maid crosses herself.]

The Lady. Hm! The total effect of you is notdangerous. [She takes the stray's face between her hands. A violent shudder shakes the latter from head to foot, as she shrinks back with a gliding motion; but this does not discourage the poet's wife.] Don't be afraid of me, silly thing! [She turns to the countrywoman.] Funny how fashion impresses them, isn't it? This girl turned clammy cold.

The Countrywoman [nodding]. It's the feel of her. [The poet's wife returns to her scrutiny of the girl's face.]

The Lady. Yet, you know, your features aren't so bad. If you only had a little color. . . . You should never wear gray with that white face of yours. [She addresses the room in general, and the maid in particular.] Country people invariably have no idea how to dress. Eh, Nora?

The Maid. Ma'am, for the love of God, be careful! I'm not liking the eyes of herself!

The Lady [laughing lightly]. Oh, her eyes are so much better than her clothes! But I forgot; you're not fit to talk to to-night, are you? Well, 


\section{WILL O' THE WISP}

that will do. [She turns back to the countrywoman.] Why do you let your servant wear that awful cap? Doesn't she ever take it off?

The Countrywoman. Many's the time I've spoke of it; but it's a stubborn habit with her. So I lets her have her way, for peace.

The Lady [to the stray]. But, my poor girl, that cap is awful! If only your hair showed, you'd be so much better looking. What makes you wear it?

[For answer, the stray, rising, shuffles past the poet's wife to the table. It is the first time during the scene that she has looked away from her. As she nears the table, the maid on the other side shrinks back. Once there, the stray turns on the woman, and, watching her instead of what she herself does, she reaches for the candle. She lifts the metal extinguisher from the candlestick, holds it out so that the poet's wife may see it, then with a quick motion places it over the flame. The candle goes out, leaving the room dim with one light. In her nervousness, the serving-maid sobs once aloud.]

The Countrywoman. What would this be?

The Lady. Do you know what she meant?

The Countrywoman. I don't see-I don't see. . .

The Lady. She's probably mad, poor soul.

The Maid. Oh, Mother of God! Mother of God! The magic!

The Lady. I fail to find any magic in a candle going out, when I've just watched the process. Really, I prefer bed to such gloomy companionship. [She rises, and speaks to the countrywoman.] Will you light us upstairs, please. I'm quite sorry I came. 


\section{WILL O' THE WISP}

The Countrywoman [re-lighting the second candle]. There, there, good ma'am. It'll all be more cheerful in the morning.

The Lady. I feel as if morning would never come, with this whole night dragging at me.

[The countrywoman gives the candle to Nora, who has picked up her mistress' bag. Then the old dame crosses toward the candle on the shelf.]

The Countrywoman. Now, if you and your woman will follow me. . . . The poet's room was ready for him. . . .

[This mention of the poet brings another convulsive motion from the stray. The lady's attention is thereby arrested.]

The Lady. Where does that creature sleep?

The Countrywoman. Oh, down here, on a mat by the fireside. She'll not trouble you more, good ma'am. She'll not trouble you more. [She opens the door to the stairs.]

The Lady [after a brief hesitation]. Come, Nora.

[She goes out. The countrywoman pauses to speak to the stray.]

The Countrywoman. Good night, girl. Go to sleep quietly. [She disappears, and we hear her voice] Now, good ma'am. Now, so please you. . .

[The room, lighted only by Nora's candle, is dim again. Outside, the night is very black. The servingmaid crosses the room silently. In its center, she passes close to the stray, who has crept there to look after the poet's wife. The maid, making a quick detour, gasps with terror. When she reaches the fireplace, she rushes for the stairs with a little scream [ 134] 


\section{WILL O' THE WISP}

that puts her candle out; we hear the door bang behind her. The room is completely black.

$A$ silence. Then the motion of some one springing upright; and the place is suffused with a dim glow of orange light. The light shines from the orangered hair of the white-faced girl, a burning mass of quivering, gleaming strands. And the girl herself stands revealed, a spirit-creature, red and white and clad in futtering gray, her body slim and swaying with infinite grace. Not even the poet's wife could question the beauty of her wild white face, lit into a fierce exaltation by the glow of that tumbling hair. In her fingers is the ugly cap, held mockingly toward the door; and then she drops it.

Now a faint music sounds from somewhere, a langorous melody; and the spirit begins to sway to it. Not quite a dance, yet nothing else, this moving through the room.

The door to the stairs opens, and the poet's wife appears, trailing a white room-robe about her. The white-faced girl smiles at her, smiles quite close to her, with a demon behind her smile.]

The Lady. Who are you?-Why do you smile at me,-unless-you're glad that I came down?You knew I would answer to that music-he used to sing me a song to it, when he courted me.Was it out of his love for you, he made that song? Oh, it might well have been, you with your long white arms and your strange white face!-But he sang it to me, do you hear? To me, to me, to me, it is my song!

You smile.-You are so sure it isn't mine.-But 


\section{WILL O' THE WISP}

you aren't singing it now, any more than I am!Where does that music come from?-What are you?

Oh, I knew there was something here that held him. - I had all the right to him. - I took his life, and made of it what I would,-but I couldn't reach his soul. It was bound up to something else, his soul.-I wanted to see.-I see now.-But I don't understand!

What are you? Can you talk? You can, you can, you devil! You called me down to tell your story, didn't you? Well, triumph over me,-triumph! -only speak! [The white-faced girl, in her dance, is moving toward the outer door, ever eluding the poet's wife, who takes a few steps after her.] No, you're not going away without it, you and your magic hair! [She reaches desperately for the waving hand, which glides from under her grasp.]

You burned him with that hair-you burned the soul out of him.-But now I've come in his place, and you can't burn me, and I will learn why you smile! [Again the reach, and the white hand slips away.]

Do you mean you can't talk?-Or do you want me alone? [The white-faced girl, near the door, has raised a beckoning hand. There is now a teasing invitation in her smile.] Oh, I'm not afraid to go with you, out there!-Wait! Wait!

[For the white-faced girl has opened the door. As the poet's wife crosses the room, the countrywoman comes, drawn by the talk, down the stairs. She gives a sudden shriek.]

The Countrywoman. Oh, God! 


\section{WILL O' THE WISP}

The Lady [briefly turning, annoyed]. What, you?

The Countrywoman. I heard. I came. [The poet's wife takes another step.]

Don't follow, don't follow, for the love of Heaven! It's the Will-O'-The-Wisp!

[In the doorway, the white-faced girl stoops, and smiles her smile, and beckons.]

The Lady [with authority]. Let be!-I am going after her!-I am going to learn the truth!

[She nears the door, just as the serving-maid appears at the foot of the stairs. With a scream, Nora rushes to the poet's wife, and clings to her.]

The Maid. Stay back! Stay back! It's to your death you go!

The Lady [pushing her to the floor]. Take your hands off me.-There are no such things as spirits! -It's a trick they made for me!-my husband and her! WAIT! -

[For the white-faced girl has passed outside. Only the glow of her hair, quite near, shines in through the open door.]

The Countrywoman. The Will-O'-The-Wisp!It's her!-It's her!

The Maid [crying out at the same time]. Stop, I tell ye! - Stop, stop, stop!

[The poet's wife is on the threshold. The orange light recedes, and the room darkens.]

The Lady [almost majestic]. Wait!-I'm not afraid!-WAIT FOR ME!-

[She, too, passes outside the door. The servingmaid breaks into a torrent of sobs. After a moment, in which the countrywoman reaches the window, 


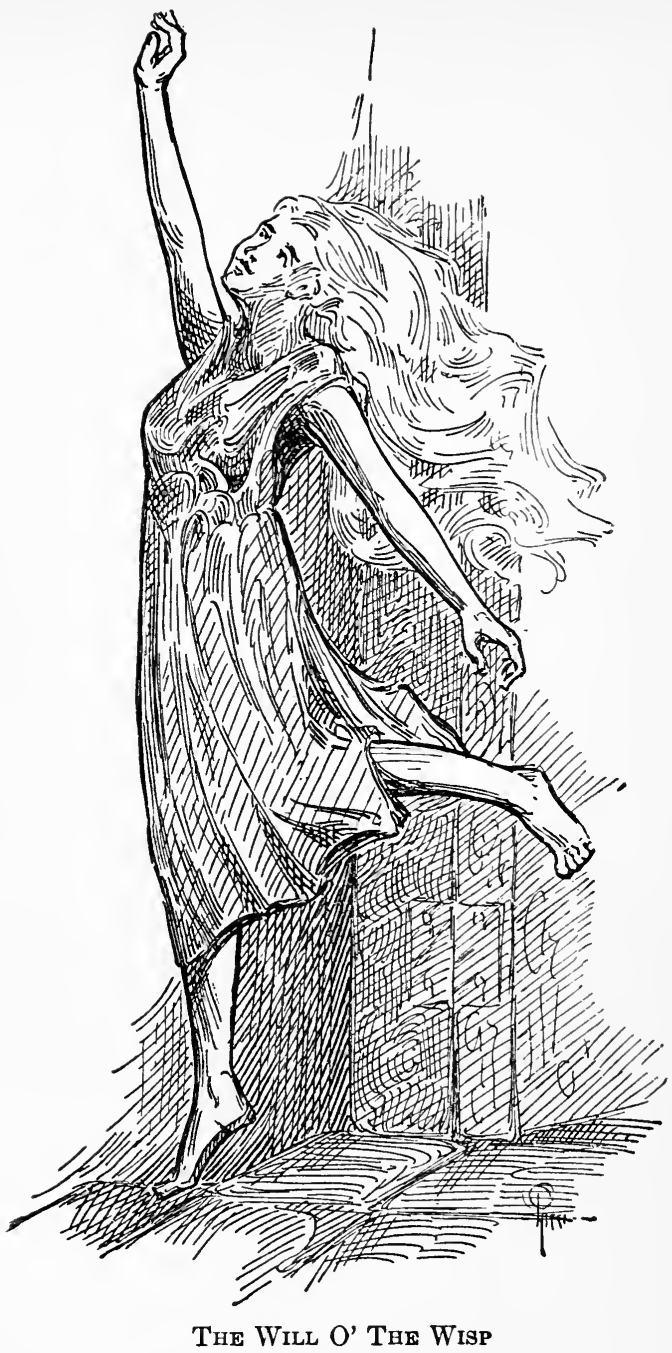




\section{WILL O' THE WISP}

the room is black again. And the music has died away.]

The Countrywoman. Hush!- [The sobs of the serving-maid die down to a low moan.] Come here by me at the window. Ah, see!

The Maid [whispering]. What is it?

[Now through door and window, there can be seen in the distance a moving light, growing smaller and smaller, making straight for where one saw the cliffhead over the sea.]

The Countrywoman. The light! The Will-O'The-Wisp! And something white behind it.

The Maid [whispering]. Is it-me mistress?

The Countrywoman [turning away]. Yes. God have mercy upon her.

[The maid has dragged herself over to the window, and kneels on the floor, looking out.]

The Maid. A shadow in the dark, lit up by that thing ahead! Oh, it is! It is!

The Countrywoman [nerving herself for the sight]. Ah, the spirit!-it's out beyond the cliff-head! And the cold sea lies beneath! Woe to one who follows the Will-O'-The-Wisp! Woe!

[Then a slight pause, in which the light no longer moves.]

The Maid [crying out]. Look, where the light is after standing still! And not a sign of her!Oh, she's gone over! Gone, she is! And she'll never come back!-

[She starts to keen-three long ochones-as the curtain falls.] 



\section{SPREADING THE NEWS}

BY

LADY GRegory

Reprinted from Seven Short Plays by Lady Gregory through the courtesy of Lady Gregory and Messrs. G. P. Putnam's Sons, Publishers, New York and London. 


\section{PERSONS}

Bartley Fallon

Mrs. FalloN

JACK SMITH

SHAWN EARLY

Tim CASEY

JAMES RYAN

Mrs. TARPEY

Mrs. Tully

A Policeman (Jo Muldoon)

A Removable Magistrate

Copyright by Ladr Gregory

Permission for amateur or professional performances of any kind must be obtained from Samuel French, 25 West 45 Street, New York.

\section{[142]}




\section{SPREADING THE NEWS}

Scene: The outskirts of a Fair. An Apple Stall. Mrs. Tarpey sitting at it. Magistrate and Policeman enter.

Magistrate. So that is the Fair Green. Cattle and sheep and mud. No system. What a repulsive sight!

Policeman. That is so, indeed.

Magistrate. I suppose there is a good deal of disorder in this place?

Policeman. There is.

Magistrate. Common assault?

Policeman. It's common enough.

Magistrate. Agrarian crime, no doubt?

Policeman. That is so.

Magistrate. Boycotting? Maiming of cattle? Firing into houses?

Policeman. There was one time, and there might be again.

Magistrate. That is bad. Does it go any farther than that?

Policeman. Far enough, indeed.

Magistrate. Homicide, then! This district has been shamefully neglected! I will change all that. When I was in the Andaman Islands, my system never failed. Yes, yes, I will change all that. What has that woman on her stall? 


\section{SPREADING THE NEWS}

Policeman. Apples mostly-and sweets.

Magistrate. Just see if there are any unlicensed goods underneath-spirits or the like. We had evasions of the salt tax in the Andaman Islands.

Policeman [Sniffing cautiously and upsetting a heap of apples]. I see no spirits here-or salt.

Magistrate [to Mrs. Tarpey]. Do you know this town well, my good woman?

Mrs. Tarpey [holding out some apples]. A penny the half-dozen, your honour.

Policeman [shouting]. The gentleman is asking do you know the town! He's the new magistrate!

Mrs. Tarpey [rising and ducking]. Do I know the town? I do, to be sure.

Magistrate [shouting]. What is its chief business?

Mrs. Tarpey. Business, is it? What business would the people here have but to be minding one another's business?

Magistrate. I mean what trade have they?

Mrs. Tarpey. Not a trade. No trade at all but to be talking.

Magistrate. I shall learn nothing here.

[James Ryan comes in, pipe in mouth. Seeing Magistrate he retreats quickly, taking pipe from mouth.]

Magistrate. The smoke from that man's pipe had a greenish look; he may be growing unlicensed tobacco at home. I wish I had brought my telescope to this district. Come to the post-office, I will telegraph for it. I found it very useful in the Andaman Islands. [Magistrate and Policeman go out left.] 


\section{SPREADING THE NEWS}

Mrs. Tarpey. Bad luck to Jo Muldoon, knocking my apples this way and that way. [Begins arranging them.] Showing off he was to the new magistrate. [Enter Bartley Fallon and Mrs. Fallon.]

Bartley. Indeed it's a poor country and a scarce country to be living in. But I'm thinking if I went to America it's long ago the day I'd be dead!

Mrs. Fallon. So you might, indeed.

[She puts her basket on a barrel and begins putting parcels in it, taking them from under her cloak.]

Bartley. And it's a great expense for a poor man to be buried in America.

Mrs. Fallon. Never fear, Bartley Fallon, but I'll give you a good burying the day you'll die.

Bartley. Maybe it's yourself will be buried in the graveyard of Cloonmara before me, Mary Fallon, and I myself that will be dying unbeknownst some night, and no one a-near me. And the cat itself may be gone straying through the country, and the mice squealing over the quilt.

Mrs. Fallon. Leave off talking of dying. It might be twenty years you'll be living yet.

Bartley [with a deep sigh]. I'm thinking if I'll be living at the end of twenty years, it's a very old man I'll be then!

Mrs. Tarpey [turns and sees them]. Good morrow, Bartley Fallon; good morrow, Mrs. Fallon. Well, Bartley, you'll find no cause for complaining today; they are all saying it was a good fair.

Bartley [raising his voice]. It was not a good fair, Mrs. Tarpey. It was a scattered sort of a fair. If we didn't expect more, we got less. 


\section{SPREADING THE NEWS}

That's the way with me always; whatever I have to sell goes down and whatever I have to buy goes up. If there's ever any misfortune coming to this world, it's on myself it pitches, like a flock of crows on seed potatoes.

Mrs. Fallon. Leave off talking of misfortunes, and listen to Jack Smith that is coming the way, and he singing.

[Voice of Jack Smith heard singing.]

I thought, my first love,

There'd be but one house between you and me, And I thought I would find

Yourself coaxing my child on your knee.

Over the tide

I would leap with the leap of a swan,

Till I came to the side

Of the wife of the Red-haired man!

[Jack Smith comes in; he is a red-haired man, and is carrying a hayfork.]

Mrs. Tarpey. That should be a good song if I had my hearing.

Mrs. Fallon [shouting]. It's "The Red-haired Man's Wife."

Mrs. Tarpey. I know it well. That's the song that has a skin on it!

[She turns her back to them and goes on arranging her apples.]

Mrs. Fallon. Where's herself, Jack Smith?

Jack Smith. She was delayed with her washing; bleaching the clothes on the hedge she is, and she daren't leave them, with all the tinkers that do be

[146] 


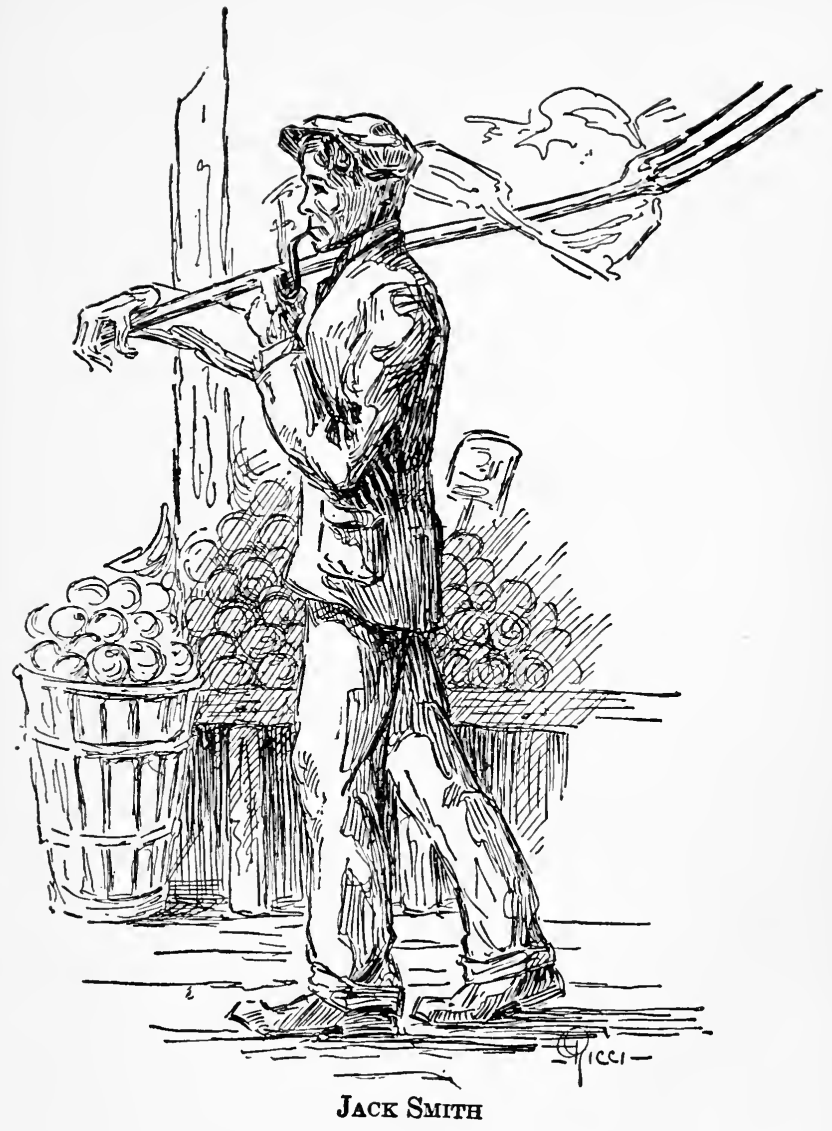




\section{SPREADING THE NEWS}

passing to the fair. It isn't to the fair I came myself, but to the Five Acre Meadow I'm going, where I have a contract for the hay. We'll get a share of it into tramps to-day. [ He lays down hayfork and lights his pipe.]

Bartley. You will not get it into tramps to-day. The rain will be down on it by evening, and on myself too. It's seldom I ever started on a journey but the rain would come down on me before I'd find any place of shelter.

Jack Smith. If it didn't itself, Bartley, it is my belief you would carry a leaky pail on your head in place of a hat, the way you'd not be without some cause of complaining.

[A voice heard, "Go on, now, go on out o' that. Go on I say."]

Jack Smith. Look at that young mare of Pat Ryan's that is backing into Shaughnessy's bullocks with the dint of the crowd! Don't be daunted, Pat, I'll give you a hand with her.

[He goes out, leaving his hayfork.]

Mrs. Fallon. It's time for ourselves to be going home. I have all I bought put in the basket. Look at there, Jack Smith's hayfork he left after him! He'll be wanting it. [Calls.] Jack Smith! Jack Smith!-He's gone through the crowd-hurry after him, Bartley, he'll be wanting it.

Bartley. I'll do that. This is no safe place to be leaving it. [He takes up fork awkwardly and upsets the basket.] Look at that now! If there is any basket in the fair upset, it must be our own basket! [He goes out to right.]

[ 148 ] 


\section{SPREADING THE NEWS}

Mrs. Fallon. Get out of that! It is your own fault, it is. Talk of misfortunes and misfortunes will come. Glory be! Look at my new egg-cups rolling in every part-and my two pound of sugar with the paper broke-

Mrs. Tarpey [turning from stall]. God help us, Mrs. Fallon, what happened your basket?

Mrs. Fallon. It's himself that knocked it down, bad manners to him. [Putting things up.] My grand sugar that's destroyed, and he'll not drink his tea without it. I had best go back to the shop for more, much good may it do him!

[Enter Tim Casey.]

Tim Casey. Where is Bartley Fallon, Mrs. Fallon? I want a word with him before he'll leave the fair. I was afraid he might have gone home by this, for he's a temperate man.

Mrs. Fallon. I wish he did go home! It'd be best for me if he went home straight from the fair green, or if he never came with me at all! Where is he, is it? He's gone up the road [jerks elbow] following Jack Smith with a hayfork.

[She goes out to left.]

Tim Casey. Following Jack Smith with a hayfork! Did ever any one hear the like of that. [Shouts.] Did you hear that news, Mrs. Tarpey?

Mrs. Tarpey. I heard no news at all.

Tim Casey. Some dispute I suppose it was that rose between Jack Smith and Bartley Fallon, and it seems Jack made off, and Bartley is following him with a hayfork!

Mrs. Tarpey. Is he now? Well, that was quick [149] 


\section{SPREADING THE NEWS}

work! It's not ten minutes since the two of them were here, Bartley going home and Jack going to the Five Acre Meadow; and I had my apples to settle up, that Jo Muldoon of the police had scattered, and when I looked round again Jack Smith was gone, and Bartley Fallon was gone, and Mrs. Fallon's basket upset, and all in it strewed upon the ground-the tea here-the two pound of sugar there-the egg-cups there-Look, now, what a great hardship the deafness puts upon me, that I didn't hear the commincement of the fight! Wait till I tell James Ryan that I see below; he is a neighbour of Bartley's, it would be a pity if he wouldn't hear the news!

[She goes out. Enter Shawn Early and Mrs. Tully.]

Tim Casey. Listen, Shawn Early! Listen, Mrs. Tully, to the news! Jack Smith and Bartley Fallon had a falling out, and Jack knocked Mrs. Fallon's basket into the road, and Bartley made an attack on him with a hayfork, and away with Jack, and Bartley after him. Look at the sugar here yet on the road!

Shawn Early. Do you tell me so? Well, that's a queer thing, and Bartley Fallon so quiet a man!

Mrs. Tully. I wouldn't wonder at all. I would never think well of a man that would have that sort of a mouldering look. It's likely he has overtaken Jack by this.

[Enter James Ryan and Mrs. Tarpey.]

James Ryan. That is great news Mrs. Tarpey was telling me! I suppose that's what brought 


\section{SPREADING THE NEWS}

the police and the magistrate up this way. I was wondering to see them in it a while ago.

Shawn Early. The police after them? Bartley Fallon must have injured Jack so. They wouldn't meddle in a fight that was only for show!

Mrs. Tully. "Why wouldn't he injure him? There was many a man killed with no more of a weapon than a hayfork.

James Ryan. Wait till I run north as far as Kelly's bar to spread the news! [ He goes out.]

Tim Casey. I'll go tell Jack Smith's first cousin that is standing there south of the church after selling his lambs. [Goes out.]

Mrs. Tully. I'll go telling a few of the neighbours I see beyond to the west. [Goes out.]

Shawn Early. I'll give word of it beyond at the east of the green.

[Is going out when Mrs. Tarpey seizes hold of him.]

Mrs. Tarpey. Stop a minute, Shawn Early, and tell me did you see red Jack Smith's wife, Kitty Keary, in any place?

Shawn Early. I did. At her own house she was, drying clothes on the hedge as I passed.

Mrs. Tarpey. What did you say she was doing?

Shawn Early [breaking away]. Laying out a sheet on the hedge. [He goes.]

Mrs. Tarpey. Laying out a sheet for the dead! The Lord have mercy on us! Jack Smith dead, and his wife laying out a sheet for his burying! [Calls out.] Why didn't you tell me that before, Shawn Early? Isn't the deafness the great hard- 


\section{SPREADING THE NEWS}

ship? Half the world might be dead without me knowing of it or getting word of it at all! [She sits down and rocks herself.] $\mathrm{O}$ my poor Jack Smith! To be going to his work so nice and so hearty, and to be left stretched on the ground in the full light of the day!

[Enter Tim Casey.]

Tim Casey. What is it, Mrs. Tarpey? What happened since?

Mrs. Tarpey. O my poor Jack Smith!

Tim Casey. Did Bartley overtake him?

Mrs. Tarpey. O the poor man!

Tim Casey. Is it killed he is?

Mrs. Tarpey. Stretched in the Five Acre Meadow!

Tim Casey. The Lord have mercy on us! Is that a fact?

Mrs. Tarpey. Without the rites of the Church or a ha'porth!

Tim Casey. Who was telling you?

Mrs. Tarpey. And the wife laying out a sheet for his corpse. [Sits up and wipes her eyes.] I suppose they'll wake him the same as another?

[Enter Mrs. Tully, Shawn Early, and James Ryan.]

Mrs. Tully. There is great talk about this work in every quarter of the fair.

Mrs. Tarpey. Ochone! cold and dead. And myself maybe the last he was speaking to!

James Ryan. The Lord save us! Is it dead he is?

Tim Casey. Dead surely, and the wife getting provision for the wake. 


\section{SPREADING THE NEWS}

Shawn Early. Well, now, hadn't Bartley Fallon great venom in him?

Mrs. Tully. You may be sure he had some cause. Why would he have made an end of him if he had not? [To Mrs. Tarpey, raising her voice.] What was it rose the dispute at all, Mrs. Tarpey?

Mrs. Tarpey. Not a one of me knows. The last I saw of them, Jack Smith was standing there, and Bartley Fallon was standing there, quiet and easy, and he listening to "The Red-haired Man's Wife."

Mrs. Tully. Do you hear that, Tim Casey? Do you hear that, Shawn Early and James Ryan? Bartley Fallon was here this morning listening to red Jack Smith's wife, Kitty Keary that was! Listening to her and whispering with her! It was she started the fight so!

Shawn Early. She must have followed him from her own house. It is likely some person roused him.

Tim Casey. I never knew, before, Bartley Fallon was great with Jack Smith's wife.

Mrs. Tully. How would you know it? Sure it's not in the streets they would be calling it. If Mrs. Fallon didn't know of it, and if I that have the next house to them didn't know of it, and if Jack Smith himself didn't know of it, it is not likely you would know of it, Tim Casey.

Shawn Early. Let Bartley Fallon take charge of her from this out so, and let him provide for her. It is little pity she will get from any person in this parish. 


\section{SPREADING THE NEWS}

Tim Casey. How can he take charge of her? Sure he has a wife of his own. Sure you don't think he'd turn souper and marry her in a Protestant church?

James Ryan. It would be easy for him to marry her if he brought her to America.

Shawn Early. With or without Kitty Keary, believe me it is for America he's making at this minute. I saw the new magistrate and Jo Muldoon of the police going into the post-office as I came up-there was hurry on them-you may be sure it was to telegraph they went, the way he'll be stopped in the docks at Queenstown!

Mrs. Tully. It's likely Kitty Keary is gone with him, and not minding a sheet or a wake at all. The poor man, to be deserted by his own wife, and the breath hardly gone out yet from his body that is lying bloody in the field!

[Enter Mrs. Fallon.]

Mrs. Fallon. What is it the whole of the town is talking about? And what is it you yourselves are talking about? Is it about my man Bartley Fallon you are talking? Is it lies about him you are telling, saying that he went killing Jack Smith? My grief that ever he came into this place at all!

James Ryan. Be easy now, Mrs. Fallon. Sure there is no one at all in the whole fair but is sorry for you!

Mrs. Fallon. Sorry for me, is it? Why would any one be sorry for me? Let you be sorry for yourselves, and that there may be shame on you for ever and at the day of judgment, for the words 


\section{SPREADING THE NEWS}

you are saying and the lies you are telling to take away the character of my poor man, and to take the good name off of him, and to drive him to destruction! That is what you are doing!

Shawn Early. Take comfort now, Mrs. Fallon. The police are not so smart as they think. Sure he might give them the slip yet, the same as Lynchehaun.

Mrs. Tully. If they do get him, and if they do put a rope around his neck, there is no one can say he does not deserve it!

Mrs. Fallon. Is that what you are saying, Bridget Tully, and is that what you think? I tell you it's too much talk you have, making yourself out to be such a great one, and to be running down every respectable person! A rope, is it? It isn't much of a rope was needed to tie up your own furniture the day you came into Martin Tully's house, and you never bringing as much as a blanket, or a penny, or a suit of clothes with you and I myself bringing seventy pounds and two feather beds. And now you are stiffer than a woman would have a hundred pounds! It is too much talk the whole of you have. A rope is it? I tell you the whole of this town is full of liars and schemers that would hang you up for half a glass of whiskey. [Turning to go.] People they are you wouldn't believe as much as daylight from without you'd get up to have a look at it yourself. Killing Jack Smith indeed! Where are you at all, Bartley, till I bring you out of this? My nice quiet little man! My decent comrade! He that 


\section{SPREADING THE NEWS}

is as kind and as harmless as an innocent beast of the field! He'll be doing no harm at all if he'll shed the blood of some of you after this day's work! That much would be no harm at all. [Calls out.] Bartley! Bartley Fallon! Where are you? [Going out.] Did any one see Bartley Fallon?

[All turn to look after her.]

James Ryan. It is hard for her to believe any such a thing, God help her! fork.]

[Enter Bartley Fallon from right, carrying hay-

Bartley. It is what I often said to myself, if there is ever any misfortune coming to this world it is on myself it is sure to come!

[All turn round and face him.]

Bartley. To be going about with this fork and to find no one to take it, and no place to leave it down, and I wanting to be gone out of this-Is that you, Shawn Early? [Holds out fork.] It's well I met you. You have no call to be leaving the fair for a while the way I have, and how can I go till I'm rid of this fork? Will you take it and keep it until such time as Jack Smith-

Shawn Early [backing]. I will not take it, Bartley Fallon, I'm very thankful to you!

Bartley [turning to apple stall]. Look at it now, Mrs. Tarpey, it was here I got it; let me thrust it in under the stall. It will lie there safe enough, and no one will take notice of it until such time as Jack Smith-

Mrs. Tarpey. Take your fork out of that! Is it to put trouble on me and to destroy me you want? 


\section{SPREADING THE NEWS}

putting it there for the police to be rooting it out maybe. [Thrusts him back.]

Bartley. That is a very unneighbourly thing for you to do, Mrs. Tarpey. Hadn't I enough care on me with that fork before this, running up and down with it like the swinging of a clock, and afeard to lay it down in any place! I wish I never touched it or meddled with it at all!

James Ryan. It is a pity, indeed, you ever did. Bartley. Will you yourself take it, James Ryan? You were always a neighbourly man.

James Ryan [backing]. There is many a thing I would do for you, Bartley Fallon, but I won't do that!

Shawn Early. I tell you there is no man will give you any help or any encouragement for this day's work. If it was something agrarian now-

Bartley. If no one at all will take it, maybe it's best to give it up to the police.

Tim Casey. There'd be a welcome for it with them surely! [Laughter.]

Mrs. Tully. And it is to the police Kitty Keary herself will be brought.

Mrs. Tarpey [rocking to and fro]. I wonder now who will take the expense of the wake for poor Jack Smith?

Bartley. The wake for Jack Smith!

Tim Casey. Why wouldn't he get a wake as well as another? Would you begrudge him that much?

Bartley. Red Jack Smith dead! Who was telling you?

Shawn Early. The whole town knows of it by this. 


\section{SPREADING THE NEWS}

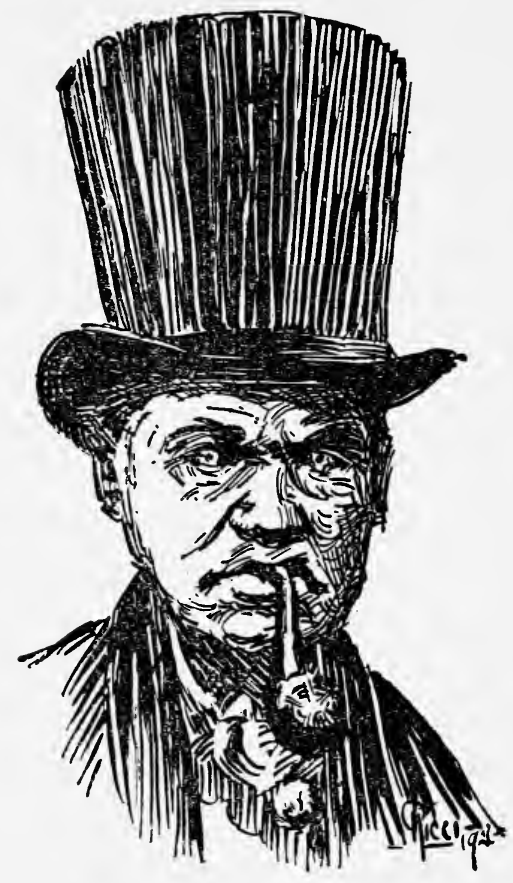

James Ryan at the FaIR

Bartley. Do they say what way did he die?

James Ryan. You don't know that yourself, I suppose, Bartley Fallon? You don't know he was followed and that he was laid dead with the stab of a hayfork? 


\section{SPREADING THE NEWS}

Bartley. The stab of a hayfork!

Shawn Early. You don't know, I suppose, that the body was found in the Five Acre Meadow?

Bartley. The Five Acre Meadow!

Tim Casey. It is likely you don't know that the police are after the man that did it?

Bartley. The man that did it!

Mrs. Tully. You don't know, maybe, that he was made away with for the sake of Kitty Keary, his wife?

Bartley. Kitty Keary, his wife!

[Sits down bewildered.]

Mrs. Tully. And what have you to say now, Bartley Fallon?

Bartley [crossing himself]. I to bring that fork. here, and to find that news before me! It is much if $I$ can ever stir from this place at all, or reach as far as the road!

Tim Casey. Look, boys, at the new magistrate, and Jo Muldoon along with him! It's best for us to quit this.

Shawn Early. That is so. It is best not to be mixed in this business at all.

James Ryan. Bad as he is, I wouldn't like to be an informer against any man.

[All hurry away except Mrs. Tarpey, who remains behind her stall. Enter magistrate and policeman.]

Magistrate. I knew the district was in a bad state, but I did not expect to be confronted with a murder at the first fair I came to.

Policeman. I am sure you did not, indeed.

Magistrate. It was well I had not gone home. 


\section{SPREADING THE NEWS}

I caught a few words here and there that roused my suspicions.

Policeman. So they would, too.

Magistrate. You heard the same story from everyone you asked?

Policeman. The same story-or if it was not altogether the same, anyway it was no less than the first story.

Magistrate. What is that man doing? $\mathrm{He}$ is sitting alone with a hayfork. He has a guilty look. The murder was done with a hayfork!

Policeman [in a whisper]. That's the very man they say did the act; Bartley Fallon himself!

Magistrate. He must have found escape difficult-he is trying to brazen it out. A convict in the Andaman Islands tried the same game, but he could not escape my system! Stand asideDon't go far-have the handcuffs ready. [ $\mathrm{He}$ walks up to Bartley, folds his arms, and stands before him.] Here, my man, do you know anything of John Smith?

Bartley. Of John Smith! Who is he, now?

Policeman. Jack Smith, sir-Red Jack Smith!

Magistrate [coming a step nearer and tapping him on the shoulder]. Where is Jack Smith?

Bartley [with a deep sigh, and shaking his head slowly]. Where is he, indeed?

Magistrate. What have you to tell?

Bartley. It is where he was this morning, standing in this spot, singing his share of songs-no, but lighting his pipe-scraping a match on the sole of his shoe- 


\section{SPREADING THE NEWS}

Magistrate. I ask you, for the third time, where is he?

Bartley. I wouldn't like to say that. It is a great mystery, and it is hard to say of any man, did he earn hatred or love.

Magistrate. Tell me all you know.

Bartley. All that I know - Well, there are the three estates; there is Limbo, and there is Purgatory, and there is -

Magistrate. Nonsense! This is trifling! Get to the point.

Bartley. Maybe you don't hold with the clergy so? That is the teaching of the clergy. Maybe you hold with the old people. It is what they do be saying, that the shadow goes wandering, and the soul is tired, and the body is taking a restThe shadow! [Starts up.] I was nearly sure I saw Jack Smith not ten minutes ago at the corner of the forge, and I lost him again-Was it his ghost I saw, do you think?

Magistrate [to policeman]. Conscience-struck! $\mathrm{He}$ will confess all now!

Bartley. His ghost to come before me! It is likely it was on account of the fork! I to have it and he to have no way to defend himself the time he met with his death!

Magistrate [to policeman]. I must note down his words. [Takes out notebook.] [To Bartley:] I warn you that your words are being noted.

Bartley. If I had ha' run faster in the beginning, this terror would not be on me at the latter end! Maybe he will cast it up against me at the 


\section{SPREADING THE NEWS}

day of judgment- I wouldn't wonder at all at that.

Magistrate [writing]. At the day of judgment-

Bartley. It was soon for his ghost to appear to me-is it coming after me always by day it will be, and stripping the clothes off in the night time?- I wouldn't wonder at all at that, being as I am an unfortunate man!

Magistrate [sternly]. Tell me this truly. What was the motive of this crime?

Bartley. The motive, is it?

Magistrate. Yes; the motive; the cause.

Bartley. I'd sooner not say that.

Magistrate. You had better tell me truly. Was it money?

Bartley. Not at all! What did poor Jack Smith ever have in his pockets unless it might be his hands that would be in them?

Magistrate. Any dispute about land?

Bartley [indignantly]. Not at all! He never was a grabber or grabbed from any one!

Magistrate. You will find it better for you if you tell me at once.

Bartley. I tell you I wouldn't for the whole world wish to say what it was-it is a thing I would not like to be talking about.

Magistrate. There is no use in hiding it. It will be discovered in the end.

Bartley. Well, I suppose it will, seeing that mostly everybody knows it before. Whisper here now. I will tell no lie; where would be the use? 


\section{SPREADING THE NEWS}

[Puts his hand to his mouth, and Magistrate stoops.] Don't be putting the blame on the parish, for such a thing was never done in the parish before-it was done for the sake of Kitty Keary, Jack Smith's wife.

Magistrate [to policeman]. Put on the handcuffs. We have been saved some trouble. I knew he would confess if taken in the right way.

[Policeman puts on handcuffs.]

Bartley. Handcuffs now! Glory be! I always said, if there was ever any misfortune coming to this place it was on myself it would fall. I to be in handcuffs! There's no wonder at all in that.

[Enter Mrs. Fallon, followed by the rest. She is looking back at them as she speaks.]

Mrs. Fallon. Telling lies the whole of the people of this town are; telling lies, telling lies as fast as a dog will trot! Speaking against my poor respectable man! Saying he made an end of Jack Smith! My decent comrade! There is no better man and no kinder man in the whole of the five parishes! It's little annoyance he ever gave to any one! [Turns and sees him.] What in the earthly world do I see before me? Bartley Fallon in charge of the police! Handcuffs on him! O Bartley, what did you do at all at all?

Bartley. O Mary, there has a great misfortune come upon me! It is what I always said, that if there is ever any misfortune-

Mrs. Fallon. What did he do at all, or is it bewitched I am?

Magistrate. This man has been arrested on a charge of murder. 


\section{SPREADING THE NEWS}

Mrs. Fallon. Whose charge is that? Don't believe them! They are all liars in this place! Give me back my man!

Magistrate. It is natural you should take his part, but you have no cause of complaint against your neighbours. He has been arrested for the murder of John Smith, on his own confession.

Mrs. Fallon. The saints of heaven protect us! And what did he want killing Jack Smith?

Magistrate. It is best you should know all. He did it on account of a love affair with the murdered man's wife.

Mrs. Fallon [sitting down]. With Jack Smith's wife! With Kitty Keary!-Ochone, the traitor!

The Crowd. A great shame, indeed. $\mathrm{He}$ is a traitor, indeed.

Mrs. Tully. To America he was bringing her, Mrs. Fallon.

Bartley. What are you saying, Mary? I tell you- -

Mrs. Fallon. Don't say a word! I won't listen to any word you'll say! [Stops her ears.] O, isn't he the treacherous villain? Ohone go deo!

Bartley. Be quiet till I speak! Listen to what I say!

Mrs. Fallon. Sitting beside me on the ass car coming to the town, so quiet and so respectable, and treachery like that in his heart!

Bartley. Is it your wits you have lost or is it I myself that have lost my wits?

Mrs. Fallon. And it's hard I earned you, slaving, slaving-and you grumbling, and sighing, 


\section{SPREADING THE NEWS}

and coughing, and discontented, and the priest wore out anointing you, with all the times you threatened to die!

Bartley. Let you be quiet till I tell you!

Mrs. Fallon. You to bring such a disgrace into the parish. A thing that was never heard of before!

Bartley. Will you shut your mouth and hear me speaking?

Mrs. Fallon. And if it was for any sort of a fine handsome woman, but for a little fistful of a woman like Kitty Keary, that's not four feet high hardly, and not three teeth in her head unless she got new ones! May God reward you, Bartley Fallon, for the black treachery in your heart and the wickedness in your mind, and the red blood of poor Jack Smith that is wet upon your hand!

[Voice of Jack Smith heard singing.]

The sea shall be dry,

The earth under mourning and ban!

Then loud shall he cry

For the wife of the red-haired man!

Bartley. It's Jack Smith's voice-I never knew a ghost to sing before-. It is after myself and the fork he is coming! [Goes back. Enter Jack Smith.] Let one of you give him the fork and I will be clear of him now and for eternity!

Mrs. Tarpey. The Lord have mercy on us! Red Jack Smith! The man that was going to be waked!

James Ryan. Is it back from the grave you are come? 


\section{SPREADING THE NEWS}

Shawn Early. Is it alive you are, or is it dead you are?

Tim Casey. Is it yourself at all that's in it?

Mrs. Tully. Is it letting on you were to be dead?

Mrs. Fallon. Dead or alive, let you stop Kitty Keary, your wife, from bringing my man away with her to America!

Jack Smith. It is what I think, the wits are gone astray on the whole of you. What would my wife want bringing Bartley Fallon to America?

Mrs. Fallon. To leave yourself, and to get quit of you she wants, Jack Smith, and to bring him away from myself. That's what the two of them had settled together.

Jack Smith. I'll break the head of any man that says that! Who is it says it? [To Tim Casey:] Was it you said it? [To Shawn Early:] Was it you?

All together [backing and shaking their heads]. It wasn't I said it!

Jack Smith. Tell me the name of any man that said it!

All together [pointing to Bartley]. It was him that said it!

Jack Smith. Let me at him till I break his head!

[Bartley backs in terror. Neighbours hold Jack Smith back.]

Jack Smith [trying to free himself]. Let me at him! Isn't he the pleasant sort of a scarecrow for any woman to be crossing the ocean with! It's back from the docks of New York he'd be turned [trying to rush at him again], with a lie in 


\section{SPREADING THE NEWS}

his mouth and treachery in his heart, and another man's wife by his side, and he passing her off as his own! Let me at him can't you.

[Makes another rush, but is held back.]

Magistrate [pointing to Jack Smith]. Policeman, put the handcuffs on this man. I see it all now. A case of false impersonation, a conspiracy to defeat the ends of justice. There was a case in the Andaman Islands, a murderer of the Mopsa tribe, a religious enthusiast-

Policeman. So he might be, too.

Magistrate. We must take both these men to the scene of the murder. We must confront them with the body of the real Jack Smith.

Jack Smith. I'll break the head of any man that will find my dead body!

Magistrate. I'll call more help from the barracks. [Blows Policeman's whistle.]

Bartley. It is what I am thinking, if myself and Jack Smith are put together in the one cell for the night, the handcuffs will be taken off him, and his hands will be free, and murder will be done that time surely!

Magistrate. Come on! [They turn to the right.] 



\title{
THE TURTLE DOVE
}

\author{
BY \\ Margaret Scott Oliver
}

Reprinted from Six One-Act Plays by Margaret Scott Oliver through the courtesy of the Author and Mr. Richard G. Badger, Publisher, Boston. 


\section{CHARACTERS}

Chorus

Chang-Sut-Yen, son of Chang-won-yin, the Great, ruler of the Province of Canton

The Mandarin

KWEN-LIN, His daughter

The God of Fate

The Property MaN

The Gong-Bearer

First produced April 6, 1915, at the Masque of Primitive Peoples, Horticultural Hall, Philadelphia.

Copyright, 1916, by Margaret Scott Oliver.

Permission for amateur or professional performances of any kind must be obtained from the author, who may be addressed at Oliver Oaks, Moylan-Rose Valley, Pennsylvania. 


\section{THE TURTLE DOVE}

The play is acted in the Chinese manner, without stage setting. The back drop is painted to represent a Willow plate. Chorus is present at the left side of the stage throughout the action, to explain the story, announce the characters as they appear, and thank the audience for its interest. The Property Man, in a black costume, remains at the back of the stage. At various specified times, he hands the necessary properties to the several characters, from a small box beside him. When not occupied with stage work, he spends the time reading a Chinese paper, and smoking a pipe or a cigarette.

All the persons in the play are in blue and white costumes, to make the plate picture. The Gongbearer may be in royal yellow, and Chorus in emerald green.

The Curtain is drawn slightly open, and the Gongbearer appears, strikes the gong three times very slowly and ten times rapidly, then walks to the right side of the stage, and stands there throughout the play. Chorus appears between the parted curtains, holds up his left hand while the Gong-bearer strikes once, then addresses the audience in a very suave manner.

Chorus. Most illustrious friends, I deliver the three bows to Heaven, Earth, and Man, [bows ceremoniously to right, left, and center] and obtrude 


\section{THE TURTLE DOVE}

myself on your exalted vision that you may know the meaning of our poor play. The story deals with the always new love of youth for maid, the abrupt tempering of a father's wrath to forgiveness, and the immutability of Fate.

Our hero, Chang-sut-yen, [Chang-sut-yen appears between the curtains, bows to right, left and center, then disappears behind the curtains] will come before you as a servant, but in reality he is none other than the son of Chang-won-yin, the Great, ruler of this province of Canton. [Gong-bearer strikes the gong.] The God of Fate decreed that he should be known as a turtle dove, and have his image forever emblazoned on the shining surface of a Willow plate. To avert this calamitous ending to his august life, Chang-sut-yen has fled the home of his father, and entered the service of a rich and powerful Mandarin, where he hopes, by virtue of his obscure position, to escape the notice of the God. But, as we have said, Fate is immutable, what the God plans must ever be, despite the efforts of puny man.

You will see the Mandarin, [Mandarin appears, bows, and disappears] rich, proud, majestic, with eyes for everything that may tend to make him more powerful, but superbly blind to virtue and worth in the humble.

Kwen-lin, his daughter [ Kwen-lin appears, bows, and retires] is swayed by love alone; a dangerous practice usually, but in this story, one begging your approval. Do not judge her harshly, in that her heart leads her. Remember she is a woman. Much may be forgiven women. 


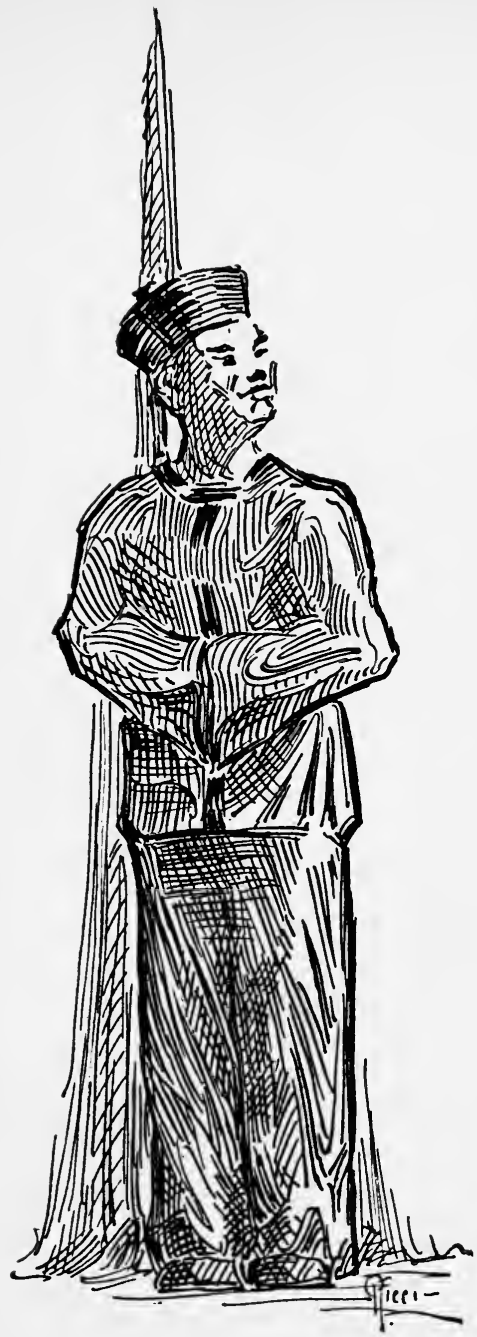

The Property Man Waiting to be Introduced 
[The Property Man appears, bows, and look inquiringly at Chorus, who hesitates an instant, and then, as if fulfilling a rather unpleasant duty, proceeds.] I would I might ignore the Property Man. He composed a version of this poetic tale, putting in all the ugly truths, and serenely forgetting all the possible flower-like episodes. As artists we could not consider it. [Property Man with a slight shrug leaves stage.] The Property Man is not sufficiently large minded to accept our ripe and impartial opinion. He is superby indifferent to the luminous fruit from his successful rival's quill, and will probably sulk through his duties. That you may not be disturbed by his presence, we have clothed him invisibly in black, and you will therefore be spared the pain of seeing him at all.

I fear I have kept you all too long from the feast prepared for your delectation. If my brothers behind the curtain show not that histrionic merit you so rightly demand, I pray you be lenient, and listen with ears, and see with eyes, not too critical. I conduct you at once to the moon-lit garden of the wealthy Mandarin, where Chang-sut-yen is loitering, hoping to meet there the Mandarin's beautiful daughter, Kwen-lin, who smiles on him. Is it not traditionally the fashion of women to adore most that youth who is forbidden?

I bow to you for your attentively honorable ears. I bow. I bow. [Gong-bearer strikes gong. Chorus walks to left of stage, and curtains are pulled apart, revealing Chang-sut-yen standing before the back drop.] 


\section{THE TURTLE DOVE}

Chang-sut-yen [singing]. Bor lo un doy, bor lo un doy, chin lo, chin lo, bor lo un doy. Kwen-lin will know that song. It is nothing, it says nothing, therefore it is pregnant with meaning, and my Bright Water-lily will understand. [Singing] Bor lo un doy, bor lo un doy, chin lo, chin lo, bor lo un doy. She will come, dancing like sun-rays on the flowers of my mind, and I will press my honorable lips to hers, and our solemn breaths will mingle. Though I seem but a servant, I am Changsut-yen, son of Chang-won-yin, the Great, ruler of this province. [Gong-bearer strikes gong.] I am also the most glorious lover the Gods have made. My soul was fashioned from the wind of Heaven, and the purple fire of the mountain peak. My illustrious body is the sturdy tree to which maidens will ever sigh their timid love.

Chorus. It is the Mandarin who walks this way.

Chang-sut-yen [singing]. Bor lo un doy, bor lo un doy, chin lo, chin lo, bor lo un doy,-who comes? Alas, not Kwen-lin the fragrant, but my master. He will spit anger that I linger in the garden. I must summon my snake tongue to puzzle his cow-brain, lest he suspect I wait for her. I will divest myself of my honorable senses, and speak with an empty head. I will be gloriously fool possessed. [Singing] Bor lo un doy, bor lo un doy, chin lo, chin lo, bor lo un doy.

[Enter Mandarin.]

Mandarin. The night is full of chill. If the God of Frost bites his sharp teeth into my fruit trees, they will perish. Br-r-r, cold! 


\section{THE TURTLE DOVE}

Chang-sut-yen [clasping Mandarin in his arms]. August one, the white moon lady slumbers in the chamber of Heaven, while I wait for you to light the path of my dreams.

Mandarin. Ancestors, save me!

Chang-sut-yen. We will make loud prayers to the tablets of our magnificently worthy ancestors after we embrace. Let me pluck you, and wear you across my heart, before your flower beauty fades.

Mandarin [recognizing him]. Miserable three footed dog, what maiden did you think to greet?

Chang-sut-yen. I press to my superb breast only your lily feet, honorable Cherry Blossom.

Mandarin. I am no Cherry Blossom.

Chang-sut-yen. You are all the Cherry Blossoms in the Garden of Earth, shedding perfume and petals with every sighing breeze.

Mandarin. I shed nothing but the light of Truth and Justice.

Chang-sut-yen. My heart cracks with love for you, and your tasks. At night when sleep seals the minds of other servants, I journey forth to count again your dazzling possessions. Your peach trees bend before me, and I am blinded. I beg to work for you until Death sews a black seam in my brain, and I go to my ancestors.

Mandarin. You have departed your unhappy wits. I give you to-morrow to offer gifts to the gods. Pursue sleep, and think not of my possessions, but rather of your venerable poverty. Your august brain is not large enough for Death to waste thread on. Thread is costly. Away with you, and rest.

$$
\text { [ } 176 \text { ] }
$$




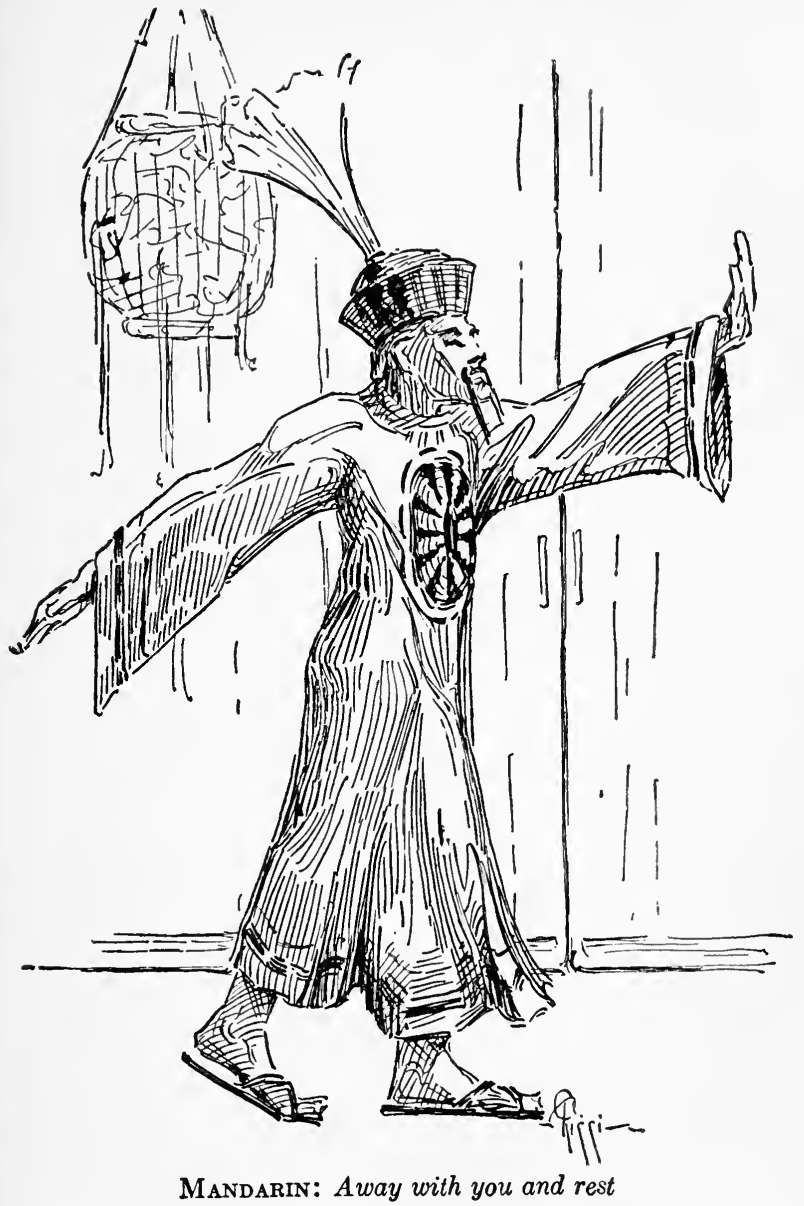




\section{THE TURTLE DOVE}

Chang-sut-yen. May your golden finger nails grow, and grow, and grow, until they grasp all wealth and honor. [Singing] Bor lo un doy, bor lo un doy, chin lo, chin lo, bor lo un doy.

[Exit Chang, singing.]

Mandarin. He is a faithful dog, who begs but a kick to make him lick my hand. I have given him too many tasks. He is bereft of his toad mind. I dislike a man who sings as he works. Life does not plan it so.

Chorus. Kwen-lin, Bright Water-lily, comes to meet her lover.

[Enter Kwen-lin, singing. Property Man hands her a branch of blossoms.]

Kwen-lin [singing]. Bor lo un doy, bor lo un doy, chin lo, chin lo, bor lo un doy.

Mandarin. The mad one croaked that. [Turns back and sings] Bor lo un doy, bor lo un doy, chin lo,-

Kwen-lin [clasping him]. Supreme lover! The happy breezes dance when your voice is the lute.

Mandarin. My important ears to be so assailed! The world box collapses, and tumbles round me.

Kwen-lin. Noble father! I thought it was my-

Mandarin. Your?

Kwen-lin. My Singing Bird.

Mandarin. A Cherry Blossom, and a Singing Bird! An illustrious choice for a man of high position.

Kwen-lin. You sound very like a singing bird.

Mandarin. Something has broken in their heads. Spring has tangled the brain threads. It must be Spring! 


\section{THE TURTLE DOVE}

Kwen-lin. It is Spring, and soon it will be superb Summer, then Fall, then Winter. The year gone pff! like that, and miserable life flower desolated.

Mandarin. Before the honorable year goes pff! like that, you will be an exalted wife.

Kwen-lin. A wife! I, a wife?

Mandarin. For seventeen years of moons, your nurses and teachers have polished you into a state of passable excellence. You are very wonderful as foolish little girls go. You are something of a somebody.

Kwen-lin. But to what impressive man are my charms to be presented?

Mandarin [looking at invisible garden]. This late frost will surely steal the jewels in my garden. The servant Chang must cover the iris. I can trust Chang.

Kwen-lin. You marry me to Chang-sut-yen?

Mandarin. Do I throw my child of five thousand and one delectable graces into the arms of a servant? I was speaking of my garden.

Kwen-lin. If I am to wed, let us speak of husbands.

Mandarin. Ah, many men have sought to wed you, but I have turned their eyes away, until the sublime one should ask.

\section{Kwen-lin. To whom do I go?}

Mandarin. To the greatest of all! To be dazzled, to be petted, to be surrounded by every superior luxury.

Kwen-lin [impatiently]. To whom do I go?

Mandarin. There is honor and eminence the [ 179] 


\section{THE TURTLE DOVE}

alliance will give me, and money it will add to my already considerable store. We will not, as a matter of policy, show we are flattered. We will be proud, we will be haughty, we will drive a shrewd bargain when the wealthy Ta-yin of Canton would make you his bride.

Kwen-lin. The Ta-yin of Canton! I will not marry the Ta-yin of Canton!

Mandarin. What strange words do your lips produce? Does my daughter oppose her insect mind to mine?

Kwen-lin. I will not marry the Ta-yin of Canton. He's ugly, he's bold, he's yellow as-

Mandarin. Gold!

Kwen-lin. He shakes when he walks-

Mandarin. He's a-

Kwen-lin. Hundred years old! My heart would crack with grief were I to marry him.

Mandarin. I never yet heard that any maiden died of grief at the prospect of being a bride.

Kwen-lin. Br-r-r-r!

Mandarin [jumping]. What was that?

Kwen-lin. My heart cracking. Death is clutching for me.

Mandarin [wearily]. Go away, Death. Take her, if you must, after she is wed. The wealthy Ta-yin can better bear the said expenses.

Kwen-lin. I'm dying now, dying, dying. It's quite delicious! [Lies down. Property Man puts a blue cushion under her head.] I'm almost dead!

Mandarin. You can't die like this. It's most absurd, besides being unbeautiful. 


\section{THE TURTLE DOVE}

Kwen-lin. Have no fear, my death will be magnificently beautiful. I have practiced many times, and know.

Mandarin. Get up, fox soul!

Kwen-lin [sitting $u p$ ]. Have respect for my solemnly departing life. My heart will not throb longer. [Lies down.] I am dead!

Mandarin [prodding her with foot]. Get up, get up, get up! I must carry her! [Stoops, and puts arms under Kwen-lin.] Oh, for the strong muscles of my lusty young arms. We have fed her too well. She weighs many pounds. [Stands up, and claps hands. Chang-sut-yen enters.]

Chang-sut-yen. My serene mind presents itself to you, great master.

Mandarin. Sleep should be gathering up the ends of your serene mind, but it is as well. My daughter's honorable body has persuaded itself to seek its illustrious ancestors-

Chang-sut-yen [kneeling beside Kwen-lin]. Kwenlin dead, dead! Then let the lady moon fall from the mighty loft of Heaven, and burn my life to ashes of wistaria!

Mandarin. Your overwhelming grief at my bereavement becomes a servant, but let not the pockets of your eyes fill with tears. Bear her to the house. She shall be whipped alive! [Kwen-lin shudders.] The sublime wasp shakes at that?

Chang-sut-yen [bending over Kwen-lin, and looking into her wide open eyes]. It was a death throe, exalted one. 


\section{THE TURTLE DOVE}

Mandarin. Can your arms support her?

Chang-sut-yen. I lift a Cherry Blossom with more effort.

Mandarin. Speak not of Cherry Blossoms. Pick her up. [Chang starts to lift Kwen-lin.] No, no, that is not wise. How shall we do it?

Chang-sut-yen [craftily]. I can guard the crystal vase of her departed soul, while you go for help.

Mandarin. It had not penetrated my disturbed brain. I go for help. [Exit Mandarin.]

Kwen-lin [sitting up]. Superb love mate!

Chang-sut-yen [hurriedly]. Augustly enter the world of the venerable dead again, luscious one, your honorable father looks this way.

Kwen-lin [lying down]. Do your eyes grow pearls that I am with my ancestors?

Chang-sut-yen. The love butterflies are winging in the happy recesses of my heart. My breath will smother me with joy.

Kwen-lin [sitting up]. Joy, when my father is going to marry me to the Ta-yin of Canton?

Chang-sut-yen. Exalted joy, because before that can happen my father will have the Ta-yin beheaded.

Kwen-lin. An orphan has no father.

Chang-sut-yen. I have a celestial now and then father, who does these necessary but disagreeable things. I think he will dispose of the wealthy Ta-yin if I ask him.

Kwen-lin. It must be a wonderful convenience. We will make a list of all those superbly annoying 


\section{THE TURTLE DOVE}

persons we do not like, and have your celestial now and then father behead them.

Chang-sut-yen. We will ponder it, Bright Water-lily, when we are not serenely happy.

Kwen-lin. I do not like being whipped alive! My teeth chatter when I think of it, and I can't be happy.

Chang-sut-yen. A base whip to touch you! Nay, my lips shall make you live. [Kisses her.] I am gloriously versed in lip magic. [Kisses her again.]

Kwen-lin. Let us fly on our illustrious legs, and be married with the six ceremonies, before my father returns. I like that lip magic. It makes singing here.

[Kwen-lin touches heart. She and Chang-sut-yen exeunt. The Property Man looks around the stage slowly, glances in the property box, then saunters casually off.]

\section{[CURTAIN]}

Chorus. I bow.

[Chorus leaves stage followed by Gong-bearer.] 


\section{THE TURTLE DOVE}

\section{Scene II}

[Chorus again appears before the closed curtains, and raises his left hand, while the Gong-bearer, who has walked to his original position at the right side of the stage strikes the gong once.]

Chorus. Many perfumed months have passed since Chang-sut-yen wedded Kwen-lin, and each has added a white hibiscus blossom to the garland of life. But now bitter winter comes, snow is on the paeony hill, the hosts of evil are abroad. The Mandarin, with never ending rage, has spent the months searching throughout the Empire to discover their dwelling place. Now he has learned where it is, and pursues Chang-sut-yen with a death dealing thong, which he will wield with dire results. It is the pleasure of the illustrious author that the villain act in a supremely unpleasant manner, in order to bring out the tenderness of the play. Our lovers, not knowing this is a comedy, (and therefore must conclude with smiles and feasting), are overwhelmed with fear. I beg you not to share this fear, except inasmuch as it may make the after enjoyment of the happy ending more piquant and superbly satisfying.

I bow to you, and conduct you to the home of Chang-sut-yen, and Kwen-lin, his wife.

[Gong-bearer strikes gong. Chorus walks to his place at the left of stage. The Curtains are drawn apart, and reveal Chang-sut-yen, and Kwen-lin. The Property Man is at the back of the stage, as before.] 


\section{THE TURTLE DOVE}

Kwen-lin. Is my august father yet stamping on the road? Peep out of the door, heroic one, and show but part of one eye, lest the radiance from both light the world like stars, and he swoop upon us.

Chang-sut-yen [looking out of imaginary doorway]. I see not his angry body.

Kwen-lin. I would not face him here. Let us go outside, and sit neath the eaves of the pagoda. He may miss our presence, and leave without shattering this temple of our love dreams.

[Property Man opens invisible door, they descend two steps and sit down, and Property Man closes the door.]

Chang-sut-yen. Little humming bird, your heart wings beat wildly against my solemn breast.

Kwen-lin. His fiery breath will wither our blood. Feel how it scorches the gray veil of night. $\mathrm{He}$ is coming to consume us, he is coming to consume us! I fear his terrible rage.

Chang-sut-yen. Nay, tremble not, for I, your lover, shelter you in my heart.

Chorus. The Mandarin comes.

Kwen-lin [sadly]. The wine cup is drained, the love songs all are silenced.

[Enter Mandarin.]

Mandarin. Base thief and destroyer, at last I have found the hole in which you hide!

Chang-sut-yen. A lover seeks only food for his love. If he destroys or thieves what matter? Love is first. 


\section{THE TURTLE DOVE}

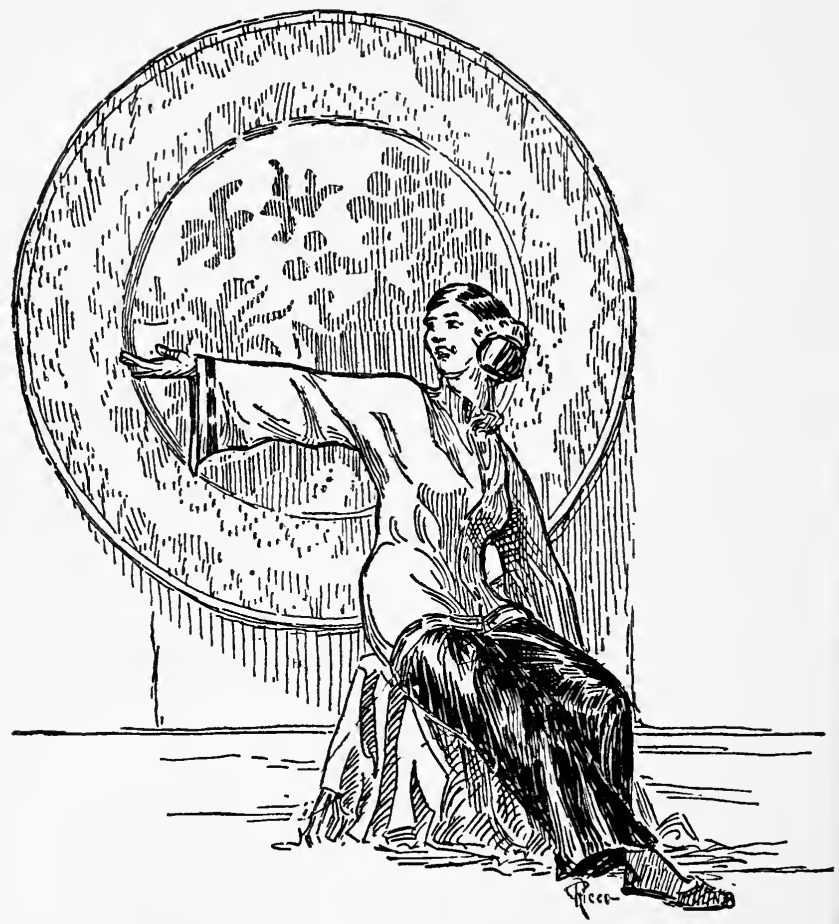

KWEN-LIN: Peep out of the door, heroic one

Mandarin. My tongue sends flame into your viper soul. Go to your ancestors, they beckon you.

Kwen-lin. Let us escape across the bridge!

[Property Man holds bamboo stick horizontally for bridge.] 


\section{THE TURTLE DOVE}

Chang-sut-yen. Why should we flee?

Kwen-lin. Why should we perish? To the bridge! We will outrun him.

[They run onto bridge.]

Chang-sut-yen [grasping bamboo]. The bridge shakes. Its ribs are rotten. We will fall into the water.

Kwen-lin [off stage]. I fall, I drown!

Chang-sut-yen. Bright Water-lily, float upon the water's face.

Mandarin. I pull down your star from Heaven's dome.

Chang-sut-yen. My star dropped to Earth, when the light of hers failed.

[Property Man hands whip to Mandarin.]

Mandarin. I strike with my exalted whip. By the God of Fate, you die!

[Strikes Chang with whip. Chang falls. Gongbearer strikes gong. The God of Fate, wearing grotesque mask, enters.]

Fate. Who calls me to the world of men?

Mandarin. What unknown fear are you?

Fate. I am the God of Fate.

Mandarin. I have sent a dog to death. [Stoops and takes a small red bag from Chang's breast.]

Fate. Chang-sut-yen is mine! He must not die.

Mandarin. My exulting mind does not record your meaning.

Fate [stooping over Chang, and putting the red bag back]. Chang-sut-yen, son of Chang-won-yin, the Great, I give you back your heart! [Gong. bearer strikes gong.] 


\section{THE TURTLE DOVE}

Mandarin. Chang-sut-yen, son of Heaven! I bow in the dust three times. [Prostrates himself.]

Fate [to Chang]. Arise, and continue your exalted life.

Chang-sut-yen [rising]. My path is lost in crookedness until I join her. Let me go.

Fate. The gods have not yet dried the ink on the pages of your book of life. You must live, to live upon a Willow plate.

Chang-sut-yen. And be broken by the heavy hand of august Time, and unkind Chance. [Property Man hands knife to Chang.] With this frosty blade, I cut the circle of life, and press my lips to the jade cup of nothingness. I am a lover bereft of my mate.

Fate. You must live! [Touches Chang's arm with staff. The knife falls to the ground. Property Man picks it up, and puts it back in the property box.]

Chang-sut-yen. Kwen-lin, I leap across the river of Heaven to your arms!

Fate. She is not dead. She dreams, and smiles upon the bosom of the water.

[To Kwen-lin] Awake! Awake!

[Kwen-lin enters, and goes to Chang.]

Fate. Your sublime father, Chang-won-yin, has gone to his ancestors. You are Chang-sut-yen, the Great, ruler of this province.

[Gong-bearer strikes gong.]

Chang-sut-yen. I renounce my rule. I am a lover, not a ruler.

Fate. You are a turtle dove. [To Mandarin]. [188] 


\section{THE TURTLE DOVE}

To your home, and set forth majestic feasting. Chang-sut-yen will honor your house. He rules. Chang-sut-yen. I rule not. I am a lover.

Kwen-lin. Exalted one, a lover is a turtle dove.

Fate. It is sometimes given to women to know the truth. Thus Fate is fulfilled, and Chang-sutyen, the turtle dove, will live upon a Willow plate.

[Gong-bearer strikes the gong twice.]

\section{[CURTAIN]}

Chorus. For your eager ears, for your shining eyes, for your smiling faces, I bow, I bow, I bow.

[Chorus followed by the Gong-bearer goes behind the curtains.] 



\title{
ALLISON'S LAD
}

\author{
BY \\ Beulah Marie Dix
}

Reprinted, from Allison's Lad and Other Martial Interludes, by Beulah Marie Dix, through the courtesy of the Author and Messrs. Henry Holt and Company, New York. 


\section{THE PEOPLE}

Colonel Sir William Strickland Captain George Bowyer Lieutenant Robert Goring Francis Hopton /gentlemen Tom Winwood $\}$ volunteers Colonel John Drummond, of the Roundhead party

\section{THE PLACE}

The village of Faringford, in the western midlands of England

\section{THE PERIOD}

The close of the Second Civil War, autumn, 1648

Copyright, 1910, by Henry Holt and Company.

No amateur or professional performance of any kind may be given except with the author's permission and upon the payment of royalty. For particulars address the author in the care of the publishers, or at 2026 Argyle Avenue, Hollye wood, California. 


\section{ALLISON'S LAD}

It is midnight of a cheerless autumn day, with a drizzle of slow rain. In an upper chamber of the village inn of Faringford, lit by guttering candles and a low fire that smolders on the hearth, are gathered five gentlemen of the Cavalier party, made prisoners that morning in a disastrous skirmish.

In a great arm-chair by the hearth [at stage left] sits their leader, Sir William Strickland. He is a tall, keen man of middle age, of the finest type of his party, a gallant officer and a high-souled gentleman. He has received a dangerous wound in the side, which has been but hastily dressed, and he now leans heavily in his chair, with eyes closed, almost oblivious of what goes on about him.

His captain, and friend of long standing, George Bowyer, a sanguine, stalwart gentleman of Strickland's own years, has planted himself in the center of the room, where he is philosophically smoking at a long pipe, while he watches the play at the rude table, which stands at the [stage] right.

Round the table, on rough stools, Goring, Hopton, and Winwood sit dicing and smoking, with a jug of ale between them for the cheering of their captivity. Goring is a swaggering young soldier of fortune; Hopton, a gentleman of the Temple, turned soldier, with something of the city fop still to be traced in his bearing. He has been wounded, and bears about his 


\section{ALLISON'S LAD}

forehead a blood-flecked bandage. Winwood, the third gamester, is a mere lad of seventeen, smoothfaced, comely, with a gallant carriage.

It is to be noted that the men play but half-heartedly. Indeed, the cheerlessness of the midnight hour, in the dim chamber, with the rain tapping on the mullioned windows, may well bring home to them the dubiousness of their captive state and set them to anxious question of what the dawn may have in store. Goring, of the three the most hardened and professionally a soldier, is the first to speak, as he throws the dice.

Goring. Cinq and tray!

Winwood. The main is yours, Rob Goring.

Goring. That's a brace of angels you owe me, Frank Hopton.

Hopton. Go ask them of the scurvy Roundhead had the stripping of my pockets.

Bowyer [with the good-humored contempt of the professional for the amateur]. The more fool you to bear gold about you when you ride into a fight!

Winwood. A devil fly off with the money! The rebels have taken my horse-a plague rot them!

Goring. Faith, I'd care not, if the prick-eared brethren had not got me, and got me fast. 'Tis your throw, Tom Winwood.

[Winwood takes the dice-box, but pauses, anxiously awaiting an answer to Hopton's next question.]

Hopton. What think you, Captain Bowyer? Are they like to admit us speedily to ransom?

[Bowyer shakes his head, smiling, half indifferent.] Goring. You're swift to grumble, Frank. 


\section{ALLISON'S LAD}

You've not been yet ten hours a prisoner. Throw, Tom, a wildfire burn you!

Winwood. There, then! And vengeance profitable gaming! We can't muster four farthings amongst us.

Goring. Curse it, man, we play for love and sport! I've never yet had enough of casting the dice. Look you, [casts the dice] I better you by three.

Winwood. On my life, no! I threw a tray and quatre.

Goring. Go to with your jesting! You mean a tray and deuce.

Winwood. Tray and quatre I threw.

Goring [starts to his feet, with his hand leaping to draw the sword which, as a prisoner, he no longer wears]. Will you give me the lie in my teeth?

Winwood [pluckily springs to his feet, with the same impulse]. Aye, if you say I threw-

[At the sound of the angry voices and of the stools thrust back, Strickland opens his eyes and glances toward the brawlers.]

Bowyer [laying a heavy hand upon a shoulder of each]. Hold your tongues, you shuttle-headed fools! [Thrusts Goring down into his seat.]

Hopton. You'll rouse the Colonel, and he ill and wounded. Sit you down again!

Winwood [dropping sullenly into his place]. Yet 'twas a tray and quatre.

Goring. Frank, you saw the cast. A tray and deuce, and I will so maintain it.

[The three at table talk heatedly in dumb-show, [ 195] 


\section{ALLISON'S LAD}

Hopton playing the peace-maker, until at last he wins the disputants to shake hands. Meantime Bowyer has gone anxiously to Strickland's side.]

Bowyer. How is it with you, Will, old lad? Your wound is easier?

Strickland. My wound? 'Tis nothing, I tell you.

Bowyer. Why, then, take heart! Matters might well be worse.

[He takes a candle from the chimneypiece, and relights his pipe.]

Strickland. Cold comfort, George!

Bowyer. We are defeated, prisoners, yes, I grant you. Yet we have fought our best. And for the future-by this light, our enemies have used us handsomely so far! No doubt they'll speedily accept of ransom.

Strickland [with eyes fixed on Winwood]. From my heart I hope so!

Bowyer. Aye, to be taken thus in his first fight, 'tis pity for little Tom Winwood.

Strickland. You say-

Bowyer. 'Tis of the lad yonder that you are thinking.

Strickland. Yes, I was thinking of Allison's lad.

[As the result of Hopton's persuasion, Winwood at that moment is most heartily drinking a health to Goring.]

Bowyer. My cousin Allison's boy. Look but upon him now! A half minute agone he and Rob Goring were ready to fly at each other's throats, and now they drink good-fellowship together.

[196] 


\section{ALLISON'S LAD}

Faith, by times young Tom is monstrous like unto his father.

Strickland. Your pardon! Tom is his mother's son, Allison's lad, every inch of him-every thought of him. There's no taint of the father in the boy.

Bowyer. Yes. I wonder not that you speak thus of Jack Winwood. 'Twas a damnable trick he served you, when he won Allison from you with his false tales.

Strickland. Aye, and well-nigh broke her heart thereafter with his baseness. You stood beside me, George, there at Edgehill, when we looked upon the death-wound-in his back!

Bowyer. Poor wretch! Gallant enough at the charge, but at two o'clock in the morning he'd no more courage than-

Strickland. He was a coward, and false from first to last. For God's sake, George, never say that boy is like his father! For his mother's sake-

Bowyer. Aye, 'twould go near to killing Allison, should Tom prove craven.

Strickland. He'll never prove craven. He's his mother's son. Let be, George! I'm in no mood for speech.

[Bowyer goes back to the table, where Winwood, in the last minutes, has played with notable listlessness and indifference.]

Hopton. 'Tis your cast, Tom.

Winwood. Nay, but I'm done!

Goring. Will you give over?

Winwood. But for a moment. My pipe is out.

[Rises, and goes to Strickland.] 


\section{ALLISON'S LAD}

Hopton. Come, Captain! In good time! Bear a hand with us.

[Bowyer sits in Winwood's place at table, and dices.]

Winwood. You called me, sir?

Strickland. I did not call, but I was thinking of you. Sit you down!

[Winwood sits on a stool at the opposite side of the hearth, and cleans and fills his pipe.]

I watched you to-day, Tom. You bore yourself fairly in the fight. I was blithe to see it.

Winwood. God willing, you'll see better in the next fight, sir.

Strickland. Go to! You did all that might be asked of a youth for the first time under fire.

Winwood. Ah, but 'twas my second time under fire, sir.

Strickland. Second time? How's that, my boy?

Winwood. Last June, faith, I was at Bletchingley when we held the house four hours against the rebels, my school-fellow, Lord Bletchingley, and I, and the servants. I came by a nick in the arm there. I still have the scar to show.

[Rises eagerly, and puts back his sleeve to show the scar.]

Strickland [lightly]. 'Twas right unfriendly of you, Tom, to keep me so in the dark, touching your exploits.

Winwood [half embarrassed with the sense of having said too much, turns from Strickland and lights his pipe with the candle that he takes from the chimney-piece]. Truth, sir, I was shamed to speak to you of Bletchingley. 


\section{ALLISON'S LAD}

Strickland. Shamed? What do you talk of?

Winwood. Why, our fight at Bletchingley, it must seem mere child's play unto you, a tried soldier, my father's old comrade.

[He speaks the word "father" with all the proper pride that a son should show.]

Strickland. But your mother. She would have been proud to know that you had borne you well in the fight. You should have told her, Tom.

Winwood [in swift alarm]. Told my mother? Why, sir, she-she would have been troubled. Perchance she would not have heard to my going out for the King with you, because of Bletchingley.

Strickland. Why because of Bletchingley?

Winwood. Why? Well, you see, sir-sure, 'twas there I had this wound.

[Reseats himself on the stool opposite Strickland.]

Strickland. And for that you think she would have kept you from the field? Lad, you do not altogether know your mother. [Bowyer, at the end of a talk in dumb-show with Goring and Hopton, has risen, and now goes out at the single door, wide and heavy, that leads from the chamber (center, back) to the outer corridor. At the sound of the closing of the door, Strickland starts.] What was that?

Goring [rises and salutes]. 'Twas Captain Bowyer, sir, went into the outer room to speak with the sentries. [Reseats himself.]

Hopton. Heaven send he get them to talk! I'd fain know what's to become of us.

Goring [stretching himself]. Go sleep, like a wise man, and cease your fretting! 


\section{ALLISON'S LAD}

[ He presently rests his head on his folded arms, which he places on the table, and goes to sleep.]

Strickland. Sound advice, Tom! You were best take it.

Winwood [smoking throughout]. Sleep? How can I, sir? I would it were day. I hate this odd and even time o' night. What think you will come of us?

Strickland. What matters it, boy? We have fought our fight, and you bore yourself gallantly, Tom.

Winwood. Easy to do, sir, in the daylight, with your comrades about you, but this-this waiting in the dark! God! I would it were day. At two in the morning I've no more courage than-

Strickland [in sharp terror]. Tom! Hold your peace.

[Bowyer comes again into the room. Hopton springs eagerly to his feet.]

Hopton. What news, Captain?

Bowyer. Bad. They're quitting the village this same hour.

Goring. A retreat by night?

[Rises and confers in dumb-show with Hopton.]

Bowyer. Your wound cannot endure this hasty moving, Will. In mere humanity they must let you rest here at the inn. You'll give them your parole.

Strickland. You'll talk to our captors of paroles, after so many paroles have been broken by men that are a shame unto our party?

Bowyer. But you are known for a man of honor. 


\section{ALLISON'S LAD}

And by happy chance the colonel in command of these rebels has come hither within the hour. He will listen to me. I knew him of old-one John Drummond.

\section{Winwood. Drummond!}

[ His hand clenches convulsively upon his pipe, which snaps sharply under the pressure. Colonel Drummond enters the room. He is a grave, stern gentleman of middle age, in military dress, with cuirass, and sword at side. Winwood, at his entrance, shifts his position so that his back is toward him, and sits thus, with head bent and hands tight clenched.]

Bowyer. In good time, Colonel Drummond!

Drummond [throughout with the fine dignity of a soldier and a gentleman]. I fear not, Captain. There are three of you here in presence with whom I must have a word. [Seats himself at table.] Lieutenant Goring!

Goring [with some swagger]. Well, sir?

Drummond. At Raglan Castle you gave your promise never again to bear arms against the Parliament. Now that you are taken with arms in your hands, have you aught to say in your defense?

Goring. Before I gave that promise to your damned usurping Parliament, I swore to serve the King. I keep the earlier oath.

Drummond. And for that you will answer in this hour. Now you, Mr. Hopton!

Bowyer. Frank Hopton, too?

Drummond. What defense is yours for your breach of parole? 


\section{ALLISON'S LAD}

Hopton. It was forced from me. A forced promise, faith, 'tis void in the courts of law.

Drummond. It well may be, but not in a court of war.

Strickland. George! Did he say there werethree had broken faith?

Drummond. And now for you, Thomas Winwood!

[Winwood starts to his feet, but does not face Drummond.]

Bowyer. Tom! Not you!

Drummond. Last June at Bletchingley, you, sir, gave to me personally your word of honor never again to take up arms-

Strickland [rising, for the moment unwounded, with all his strength]. Face that scoundrel! Face him and tell him that he lies!

Winwood [unwillingly turns and faces Drummond, but stammers when he tries to speak]. I-I-

Strickland. Speak out!

Drummond. Well, Mr. Winwood?

Strickland. Answer! The truth! The truth! Have you broken your parole?

Winwood [desperately at bay, with his back to the wall, his comely young face for the moment the face of his coward and trickster father]. God's death! I've done no more than a hundred others have done. They've not kept faith with us, the cursed rebels. Why the fiend's name should we keep faith with them? It was a forced promise. And the King, I was fain to serve him, as my father served him, like my father

[202] 


\section{ALLISON'S LAD}

Strickland. Like your father!

[He staggers where he stands, a wounded man, a sick man-mortally sick at heart.] Allison's lad!

Bowyer [catching Strickland as he staggers]. Will!

Strickland [masters himself and stands erect]. Let be! Colonel Drummond, I ask your pardon for my words, a moment since. I could not believe-I could not believe- [ He sinks upon his chair.] He is his father's son, George! His father's son!

Drummond. Come here, Winwood! [Heavily Winwood goes across the room and halts by the table, but throughout he keeps his dazed and miserable eyes on Strickland.] You realize well, the three of you, that by the breaking of your paroles you have forfeited your lives unto the Parliament.

Hopton. Our lives! You've no warrant-

Drummond [laying his hand upon the hilt of his sword]. I have good warrant-here. I was minded first to stand the three of you against the wall in the court below and have you shot, in the presence of your misguided followers.

Bowyer. Colonel Drummond, I do protest!

Drummond. You waste your words, sir. This hour I purpose to give a lesson to all the promisebreakers of your party.

Goring. You purpose, then, to butcher us, all three?

Drummond. Your pardon! Two of you I shall admit to mercy. The third-

Hopton. Well! Which of us is to be the third?

Drummond. You may choose by lot which one [ 203] 


\section{ALLISON'S LAD}

of you shall suffer. You have dice here. Throw, and he who throws lowest-

Hopton [with a burst of half hysterical laughter]. Heaven's light, Rob, for once ye'll have enough of casting the dice!

Drummond. Winwood, you are the youngest. You shall throw first. Winwood!

[Winwood stands as if dazed, his eyes still on Strickland.]

Goring. Are you gone deaf, Tom Winwood?

Winwood [thrusts out a groping hand]. I-IGive me the dice!

Hopton [putting the dice-box into Winwood's hand]. Here! Be quick!

[A moment's pause, while Winwood, with twitching face, shakes the box and shakes again.]

Goring. For God's love, throw!

Winwood [throws, uncovers dice, and averts his eyes]. What is it?

Drummond. Seven is your cast. You, Hopton! [Feverishly Hopton snatches the box, shakes, and casts quickly.] Eleven!

Hopton [almost hysterically]. God be thanked for good luck! God be thanked!

Goring. Damn you! Hold your tongue! [Hopton snatches a cup from the table and drinks thirstily. Goring throws and holds dice for a moment covered.] It's between us now, Tom!

Winwood [wiping his forehead with his sleeve]. Yes. [Goring uncovers the dice.]

Drummond. Eight!

Goring [with a long breath of relief]. Ah! [204] 


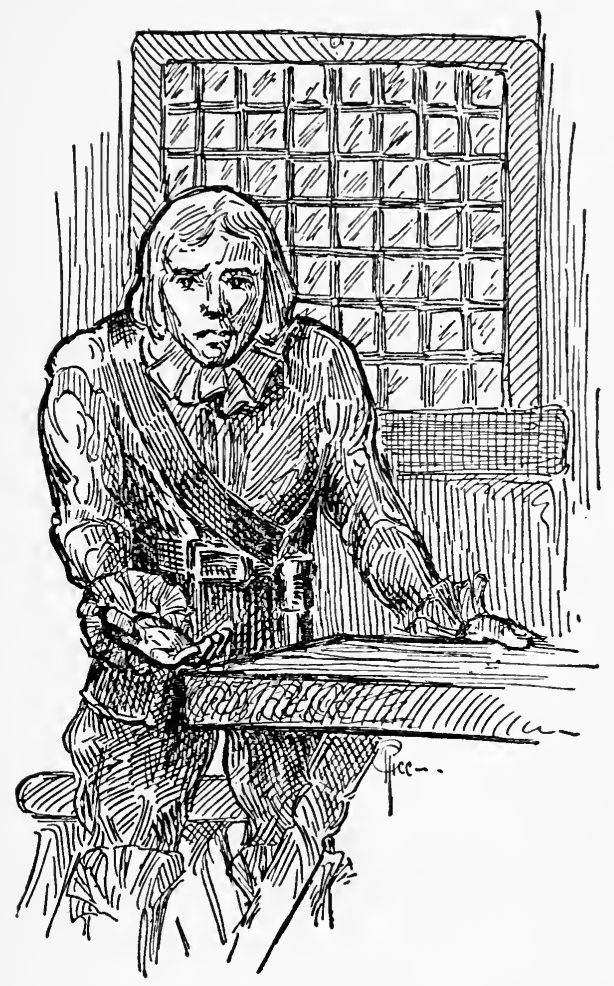

Winwood: $I-I-$ Give me the dus 


\section{ALLISON'S LAD}

Drummond [rising]. The lot has fallen upon you, Mr. Winwood.

Winwood. I am-at your disposal, sir.

Drummond. You have ten minutes in which to make you ready.

Goring. Ten minutes!

[Winwood sinks heavily into his old seat at table. Presently he draws to him the dice and box, and mechanically throws again and again.]

Bowyer [intercepting Drummond, as he turns to leave the room]. You shall listen to me, Drummond. The boy's my kinsman. He-

Drummond. Stand aside, George Bowyer!

[He goes out of the room.]

Bowyer [following Drummond out]. Yet you shall listen! Drummond! Listen to me!

Hopton. But 'tis mere murder. 'Tis against all law.

Goring. Will you prattle of law to Cromwell's men? [Comes to table and lays a hand on Winwood's shoulder.] Tom, lad, I would we could help you.

Winwood. I've thrown the double six-twice. 'Tis monstrous droll, eh, Rob? Before-I could throw no higher than seven-no higher than seven!

[ $H$ is voice rises higher and higher, and breaks into shrill laughter.]

Goring. Steady! Steady, lad!

[Strickland looks up, as if rousing from a trance.]

Hopton [hastily fills a cup and offers it to Winwood]. Here, Tom, drink this down.

Winwood [snatches the cup and starts to drink, [206] 


\section{ALLISON'S LAD}

but in the act looks up and reads in his comrades' faces the fear that is on them, that he is about to disgrace the colors that he wears. He sets down the cup]. You-you think- Will you-leave mefor these minutes? A' God's name, let me be!

[Hopton and Goring draw away to the window and stand watching Winwood anxiously. He has taken up the dice-box, and again is mechanically casting the dice.]

Hopton. How will he bear himself yonder?

Goring. You mean- -

Hopton. There in the courtyard, when they-

Goring. Speak lower!

Strickland [rises with effort, crosses, and lays his hand on Winwood's shoulder]. Tom!

Winwood [starting up, furiously]. You're ashamed of me! You're ashamed! Don't pity me! Let me be! Curse you, let me be!

Strickland [sternly]. Tom! Look at me!

Winwood [turns defiantly, meets Strickland's eyes, and desperately clings to him]. I can't! I can't! If they'll wait till it's light-but nowin the dark - Make them wait till morning! I can't bear it! I can't bear it!

Strickland. Be still! You must face it, and faco it gallantly.

Winwood [stands erect, fighting hard for self. control]. Gallantly. Yes. My father-he died for the King. I musn't disgrace him. I must bear myself as he would have done.

Strickland. Don't speak of him! Think on your mother. 


\section{ALLISON'S LAD}

Winwood. Must you tell her-why they shot me? She would think of it-of that broken promise-as a woman might. God's life! Why will you judge me so? My father would have understood.

Strickland. Yes. He would have understood you well.

Winwood. What do you mean? I'm a coward -a promise-breaker. You think that. But my father-he died for the King. He- [In Strickland's face he reads that of which in all these years he has been kept in ignorance.] How did my father die?

Strickland. Not now, Tom! [Bowyer comes again into the room.]

Winwood [almost beside himself]. Answer me! Answer me! Bowyer! You're my cousin. Tell me the truth! As God sees us! How did my father die? How did my father live? You won't answer? You've lied! You've lied! All of you you-all these years! He was a coward. You don't deny it! A coward-a false coward-and I'm his son! I'm his son!

[Sinks upon a stool, by the table, with face hidden, and breaks into rending sobs.]

Bowyer. Will! Will! You can bear no more.

Strickland [shakes off Bowyer's arm and goes to Winwood]. Stand up! Stand up! You are your mother's son as well as his!

Winwood [rising blindly, as if Strickland's voice alone had power to lift him]. A coward! You see. Like him. And there in the courtyard- Ah, God! I'll break! I'll break! 


\section{ALLISON'S LAD}

Strickland. You will not. For her sake-for her blood that is in you-Allison's lad!

Winwood [with slow comprehension]. Youloved her!

Strickland. Yes. And love that part of her that is in you. And know that you will bear you well unto the end.

Winwood. I'll-I'll- It's not the death. It's not that. It's the moment-before the bulletGod! If I fail-if I fail-

Strickland. You will not fail.

Winwood. You believe that? You can believe that of me?

Strickland. I believe that, Tom.

Bowyer. Will! The ten minutes are ended.

Strickland. So soon! So soon!

Bowyer. Drummond will suffer me be with him to the last. Come, Tom, my lad!

[Goes up, and from a chair beside the door takes a heavy military cloak-which shall thereafter serve as Winwood's shroud. He holds it throughout so that Winwood may not mark it.]

Winwood [takes his hat, and turns to Goring and Hopton, with a pitiful effort at jauntiness]. God be wi' you, boys! [Crosses, and holds out his hand to Strickland.] Sir William! I'll-try. Butcan't you help me? Can't you help me when- [Clings to Strickland's hand.]

Strickland. I can help you. You shall bear you as becomes her son.

Winwood. Aye, sir.

Strickland. And I shall know it. God keep you! [209] 


\section{ALLISON'S LAD}

Winwood [faces about, to Bowyer]. I am ready, sir. [Goes to door, and on the threshold wheels and stands at salute.] You shall have news of me, Sir William! [Winwood goes out, and Bowyer, with the cloak, follows after him.]

Hopton. What did he mean?

Goring. He'll die bravely, poor lad, I'll swear to that! [Strickland sways slightly where he stands.] Sir William! You're near to swooning. Sit you down, sir.

Strickland. I pray you, gentlemen, for these moments do not disturb me.

[Stands upon the hearth, erect, steady, and very still.]

Hopton. Truth, the man's made of stone. I thought he had loved poor Winwood as his own son.

Goring. Quiet, will you? [Removes his hat.]

Hopton. What-

Goring. Think on what's happening in the courtyard, man!

[A moment's pause, and then from below, in the rainy courtyard, is heard the report of a muffled volley.]

Hopton. Hark!

Strickland [in an altered, remote voice]. Well done!

Goring. Grant that he made a clean ending!

Strickland [turns slowly, with eyes fixed before him, and the sudden smile of one who greets a friend]. Tom! Well done, Allison's lad!

[Pitches forward.] 


\section{ALLISON'S LAD}

Goring [catching Strickland in his arms]. Sir William! Help here, Frank!

[They place Strickland in his chair. Goring starts to loosen his neck gear. Hopton kneels and lays his hand on Strickland's heart. On the moment Bowyer comes swiftly into the room.]

Bowyer. Will! Will! The lad died gallantly. He went as if a strong arm were round him.

Hopton [lets fall the hand that he has laid on Strickland's heart. Speaks in an awe-struck voice]. Perhaps there was!

Goring [rises erect from bending over Strickland]. Captain! Sir William-

[Bowyer catches the note in Goring's voice, and removes his hat, as he stands looking upon what he now knows to be the dead body of his friend and leader.]

\section{CURTAIN}




\title{
ULYSSES
}

\section{Scene 2, Act III, of "Ulysses"}

\author{
BY
}

\author{
Stephen Phillips
}

Reprinted from Ulysses by Stephen Phillips through the courtesy of Mrs. Stephen Phillips and The Macmillan Company, Publishers, New York and London. 


\section{CHARACTERS}

\section{in the selection}

\section{Athene \\ ULYSSES}

Penelope, his wife

Telemachus, his son

Eurycleia, his old nurse

Antinous (young, insolent, splendid) I Chief

Eurymachus (mature, politic, specious) Suitors to

Ctesippus (elderly, rich, ridiculous) J Penelope

Phemius, a minstrel

Eumeus, a swineherd

$\left.\begin{array}{l}\text { Melantho } \\ \text { Clytie } \\ \text { Chloris }\end{array}\right\}$ handmaidens

Suitors, Handmaidens, Attendants

Copyright, 1902, by The Macmillan Company.

Permission for amateur or professional performance of any kind must be secured from Mrs. Stephen Phillips, who may be addressed in care of The Macmillan Company. 


\section{ULYSSES}

\section{ACT III}

\section{SCENE 2}

Interior of the banqueting-hall in Ulysses' palace. The walls richly decorated and encrusted with colored patterns, bosses and friezes of animals, etc. Two columns plated with bronze sustain the roof, the central part of which is raised so as to admit the light. On a wall hang the three spears and three shields as ordered by Ulysses, ${ }^{1}$ and in another place his bow in a richly-decorated case. The hall is lighted by lamps held by Attendants. The main entrance from without is through a doorway with a raised threshold in the center of the stage at the back: this door stands open to the vestibule and the moonlight: a staircase on the left leads up to another door opening into the women's apartments. A dais extends along the back of the hall: on this and on the floor to right and left are disposed the tables and couches where the Suitors are discovered revelling, with the faithless Handmaidens interspersed among them and drinking from their cups, and Attendants standing by and serving. Telemachus sits at the head of one of the tables. In the center of the hall is an open space, with a fire burning on the hearth in the midst, and beside it the chairs of Penelope and the Minstrel,

${ }^{1}$ See the notes on page 241.

[215] 


\section{ULYSSES}

the former unoccupied. Phemius the Minstrel is seated in his chair by the hearth, singing-

Great is he who fused the might Of the earth and sun and rain

Into draughts of purple light,

Draughts that fire the heart and brain:

Let us praise him when the goblets flash in light And the rapture of the revel fills the brain.

What were revel without wine?

What were wine without a song?

Let us hymn the gift divine

With a music wild and strong,

With a shouting for the god who gave the wine, And a guerdon to the minstrel for his song.

Blest is he who strikes the lyre At the feast where princes quaff:

Higher mounts the mirth and higher,

Loud and louder peals the laugh-

[Phemius breaks off suddenly, gazing on the Suitors in horror while a dim mist comes down on the hall and the moonlight is obscured.]

Antin. What ails thee, man?

Eurym. Why dost thou stare on us?

Phem. O wretched men! What doom is coming on ye?

What mist is this that overspreads the world? Shrouded are all your faces in black night!

[They laugh together softly and sweetly.]

[ 216 ] 


\section{ULYSSES}

See how the feast is dabbled o'er with blood, And all your eyes rain tears, and though ye laugh Sweetly on me, ye laugh with alien lips!

[Again they laugh sweetly upon him.]

And a voice of wailing arises and all the walls

Drip fast with blood, yea, and with blood the roof!

[They laugh again.]

And the porch is full and full is the court of ghosts And spirits hurrying hell-ward in the gloom, Yea, and the light hath perished out of heaven!

Laugh not so idly on me with your lips,

But arise and flee! your doom is at the doors.

[Phemius hurries out of the hall. The mist clears and Ulysses is seen standing on the threshold in the central doorway unobserved by any.]

Antin. Madness is come upon him!

\section{Eurym.}

O, a poet!

Ctes. He hath taken from me all desire for food. And there! is that blood there? Eurymachus! Am I not rosy and round as ever I was?

Eurym. You are, Ctesippus.

Ctes. And I see no ghosts. Antin. He hath drunk o'ermuch: hence all this mist and blood.

Eum. [to Telemachus]. O master, see you that old beggar man?

Say, shall I put him from the door? Out, out!

[With exaggerated roughness.]

Ulys. [coming down into the hall]. I crave a word, sir, with Ulysses' son.

Which is he?

Eum.

There! 


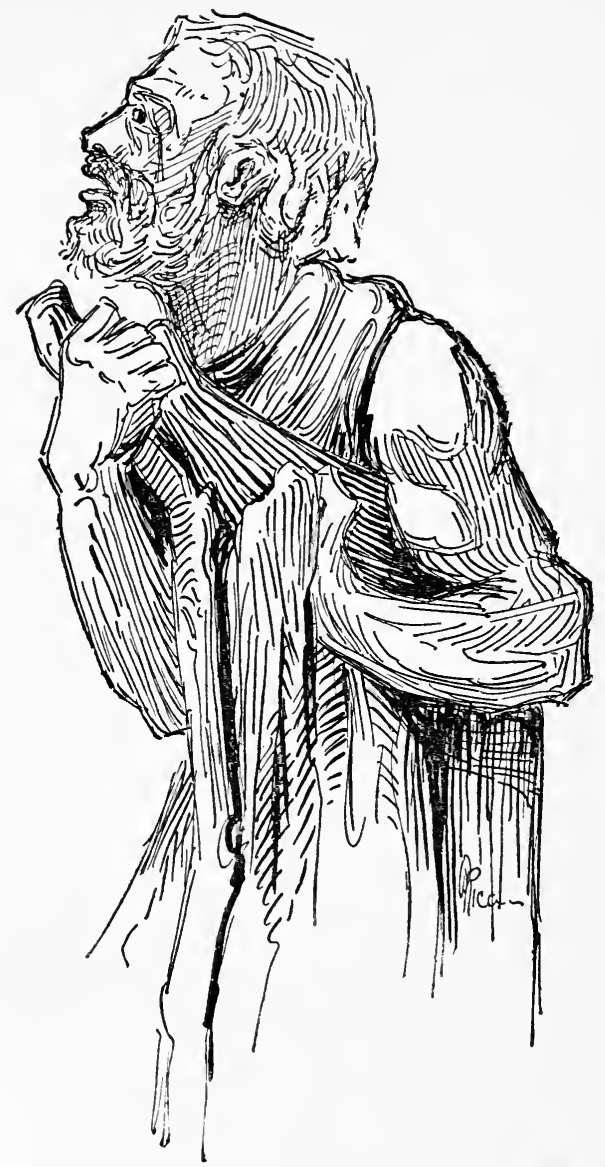

ULYsses: I crave a word with Ulysses' son 


\section{ULYSSES}

Ulys. [approaching Telemachus humbly].

Suffer me, sir, a word!

I bring you tidings of your father.

Telem. [with simulated harshness]. O!

The old tale!

Ulys. [cringingly]. Sir!

Telem.

Eum.

Telem.
Out with thee!

Out!

Or stay!

Thou shalt have leave to limp from guest to guest And eat what thou canst beg. As for your tale, My father is long dead.

\section{Ulys. \\ Then first from you}

I beg a crust of bread, or sip of wine.

Telem. Here's for thee.

[Tosses him bread.]

Ulys. Humbly, sir, I thank you. [He passes from guest to guest.]

A Suitor. Here.

[Pushes wine-cup to him.]

Ctes. My appetite is fled: take what you will. Eurym. Here is a gristly morsel for old gums.

Mel. [to Antinous, as Ulysses approaches].

Antinous, keep the old man far from me!

He'll soil this robe; and hath a smell of swine.

Ulys. I would not soil you, lady; but you, sirAntin. You louting beggar, I have nought for you!

From me!

[He strikes him on the mouth.]

Eurym. He stood thy buffet like a rock!

Ulys. O my deep soul, endure!

[219] 


\section{ULYSSES}

Telem. [starting up]. Antinous,

I'll have no beggar struck within my halls!

Antin. Oho! And did I strike one of thy blood Or of thy guests? Thou filthy beggar, off!

[Strikes him again.]

Ulys. Athene, patience!

Eum. All my blood boils up.

[Throws log savagely on fire.]

Ulys. [coming near to Antinous]. O noble sir, of all who feast around,

Tall men and fair, thou art the fairest far,

And splendid in thy youth and in thy strength.

But I am old and many have I seen

So fair, so strong, fallen into misery.

Princes whom in their pride the gods laid low.

Remember in thy strength the evil days.

Antin. [starting $u p$ ]. This dismal beggar I'll endure no more,

Who gibbers at the feast of evil days.

Away with him or I will hurl him forth.

Ctes. A sad feast this-the minstrel first sees blood:

And now this beggar croaks to us of age.

Clyt. Since he came in we are all grown miserable. Mel. Sirs, drive him forth, that we may laugh again.

Suitors [rising from the tables]. Out with the old crow! cast him out: away!

[They come round Ulysses and hustle him to the door.] Telem. I say the old man shall not be thrust forth.

[Aside to Ulysses] Is it now, father, is it now?

[220] 


\section{ULYSSES}

Eum.

When, when?

Suitors [hustling Ulysses]. Out with him!

Handmaids.

Spit on him!

Suitors.

Unloose the dogs!

Ctes. [interposing]. A word, a word! thy mother still delays:

Let us beguile the time; leave him to me,

And we'll wring laughter from this kill-joy yet.

[To Ulysses with mock deference]

Give me your hand, old man!

[To Suitors]

These beggars all

Were princes once. Now hearken! Sir, I see

Behind these rags and filth what man thou art.

Tell us-and now I look on thee I mark

A something noble in thy air-thou hadst

A palace once, and riches, hadst thou not?

Ulys. A palace and great riches had I once. [General laughter.]

Ctes. [to Suitors]. What said I? Yet in rags the great are known.

Wast thou not in old days thyself a king?

Ulys. In the old days I was myself a king.

[All laugh heartily.]

Ctes. [to Suitors]. Hush!

[To Ulysses] Look around; even such a hall hadst thou.

Ulys. [gazing slowly around]. Once did I feast in some such hall as this.

Ctes. Not by thine own fault (ah! I know it well)

But by some anger of the gods thou art fallen.

Olys. The gods, the gods have brought me to this pass. 


\section{ULYSSES}

Antin. Impudent liar!

Ctes.

And thou didst leave behind

A wife most beautiful, a queen of women!

Telem. How long will he endure?

Eum.

O for a blow!

Mel. He is grown cautious, he'll not speak to that.

Clyt. His wife! Some addled hag that tendeth swine!

Mel. Was woman found to mate her with such mud?

Telem. His spirit is dead in him.

Eum.

Thou art broken at last!

Clyt. He speaks not! See, the old fool's eyes are dim.

Mel. [with mock caress]. O shall I kiss thy tears away, my love?

Chlor. Thy wife is old: wilt thou have me, fair youth?

Clyt. O wouldst thou take me, bridegroom, to thy halls!

Eurym. Cease, cease! Ye all mistake. He hath come here

A suitor for Penelope.

Antin. [throwing cup at him]. Then take this gift to aid thy suit.

A Suitor [throwing $a$ bowl]. And this.

Ctes. [throwing a scrap from the feast]. And this.

Others [casting things upon him]. And here: and here.

Ctes.

Now up and urge thy suit!

โ222! 


\section{ULYSSES}

Telem. [to Eumœus]. Why wait a word that never comes? The swords!

Eum. Stay, stay: he looks on us, and his eye burns.

[Enter Penelope down staircase from the upper chambers; she walks slowly and sadly to her chair beside the hearth in the center of the room.]

Suitors [making way for her and then gathering to right and left of her in the central space]. The Queen, the Queen!

Antin. Now be the bridegroom chosen! Eurym. Lady, this is the night when thou shalt choose.

Grave is thy mien: here's that shall make thee smile. Bring forth this wooer lordliest and last.

Ctes. These rags are but a guise: a noble man!

Pen. [to Telemachus]. Child, knowest thou this old man whom they mock?

Telem. Mother, it is an old poor beggar man Who says that he brings tidings of my father. Wilt thou not hear him, mother, ere thou choose?

Eurym. Art thou still eager, lady, for new lies? Antin. Art thou not weary of these beggars' tales?

Pen. I have been too oft deceived: now my still heart

I bare no more to every beggar's eye: Sacred shall be this hunger of my soul And silent till the end-

[To Telemachus, who makes signs to her]

What wouldst thou say?

[223] 


\section{ULYSSES}

Telem. [taking her apart]. Mother, a word; but a word.

Antin. [interposing]. Stand back, young sir! There shall be no more plots between you two. [Murmurs of assent.]

Nor beggars weave another web-of lies.

The moon is full! Now shalt thou choose at once.

Telem. Mother!

Antin. An end of tricks!

Some Suitors.

Thy word, thy word!

Others. Now answer!

Others. Now no more delay!

All.

Choose, choose?

[They all crowd about Penelope to hear her decision, Ulysses in the meantime crouching in the ashes by the hearth.]

Ulys. Goddess, hast thou forsaken me at last?

Telem. [to Ulysses]. A moment, and too late! Ulys. I wait the sign!

Pen. Speak any then who will: I'll answer him. Ctes. I claim to speak the first.

Eurym. By right of age.

Ctes. Lady, I cannot speak as a raw boy,

But as a man of comfortable years;

Though in my youth more terrible was none To foemen; and I like not to remember

The blood that I have spilt. Behold me now

A man not old, but mellow, like good wine,

Not over-jealous, yet an eager husband.

This figure something of Apollo lacks,

But though I might not catch the eye of a girl, Still a wise woman would consider well,

[224] 


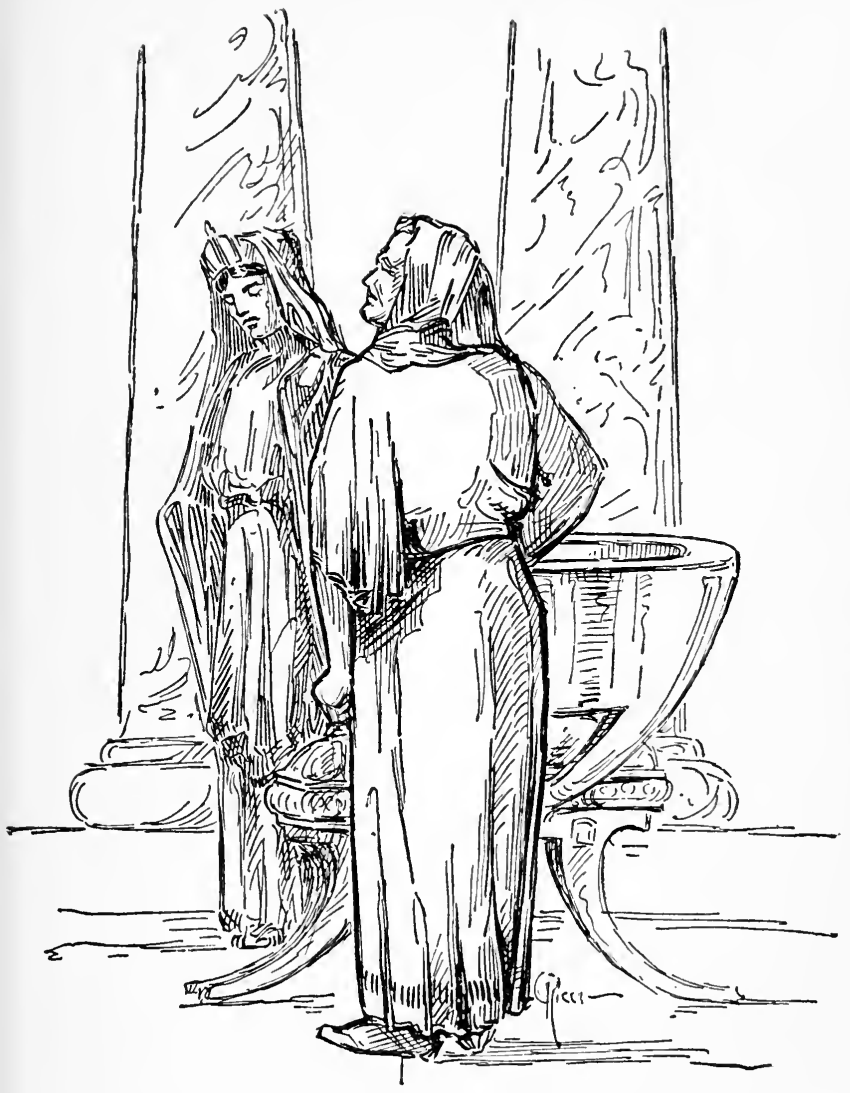

Penelope and Eurycleia 


\section{ULYSSES}

Ponder by nights ere she would let me go.

Yet I would urge less what Ctesippus is

Than what Ctesippus has the power to give.

[To Attendants] Now hold up to the moon that glimmering robe;

Turn it this way and that; this coffer now, With armlets of wrought gold, brooches of price, And golden bowls embossed with beasts and men; These draught-boards, ivory inlaid with silver, That glistering tire and these enamelled chains. Lo, whatsoever woman can desire

I'll give thee without pause and without stint, Wilt thou but suffer me to lead thee home.

Pen. Ctesippus, not the glory of gems or gold Can move me: hath the sea a pearl so rich As dead Ulysses which it treasureth

Far down, far from these eyes? Rather would I Possess some rag of him drawn up perchance By nets of seamen hauling 'neath the moon Than all these jewels glistering at my feet. How couldst thou think to please me with these toys, When in that chamber I have garnered up Garments more rich to me, faded and dim, Old robes and tarnished armour lovelier far? Those hadst thou seen, thou couldst not offer these.

Eum. [to Ctesippus]. Now thou hast leave to go[Murmurs.]

Your pardon, princes.

Eurym. Lady, I bring no gauds of pearl and gold,

I know thou art not this way to be lured.

[ 226] 


\section{ULYSSES}

I share thy grief for him who now is dead:

Noble was he, a wise man and a strong.

$O$ were he here, I first would clasp his hand.

A moment till my voice return to me.

[ He bows his head on his hands.]

But she who sits enthroned may not prolong

The luxury of tears; nor may she waste

In lasting widowhood a people's hopes,

So hard is height, so cruel is a crown.

Thou art a queen: a moment then for grief;

Then for the people what remains of life.

I offer thee the comfort of high cares,

And consolation from imperial tasks:

To share with me the governance of a land

And bring thy woman's insight to the state,

The touch that's gracious, deft, and feminine.

Sea-gazing consort of a hero dead

Reign thou with me; and find in rule relief!

That thou no longer art a girl, and green,

Troubles me not; rather I prize thee more

For that long suffering and sleeplessness

And the sweet wisdom of thy widowhood.

Thou hast caught splendour from the sailless sea,

And mystery from many stars outwatched;

Rarer art thou from yearning and more rich.

Humbly I would entreat you for my answer.

Pen. Sir, could I list to any, 'twere to thee:

Fair were thy words, and such as women love, And thou has found my brain, but not my heart,

Feigning a ruth I felt thou didst not feel.

Ask me not to forget in public good

This solitary, dear, and piercing loss.

[227 ] 


\section{ULYSSES}

Rather would I remember one dead man, Wasting the years away, and yet remember, Than rule a living kingdom by thy side.

Alas! I am a woman utterly!

Antin. Enough of jewels, and enough of thrones! Would these men lure thee? I by thee am lured. For thee, O woman, thee alone, I thirst. Time, that doth mar us all, and dims, and damps, Ashens the hair and scribbles round the eye,

Weareth not thee, thou miracle, away,

Ever in beauty waxing without wane.

No more I'll toss upon a burning bed,

Leap out at midnight on a smouldering floor,

Pacing, pacing away the aching night.

Thou, thou didst light this fire, and thou shalt quench it.

Telem. [aside to Ulysses]. Dost thou hear, father?

Ulys.

Goddess, now the sign!

Antin. Or, if thou wilt not, I'll compel thee. [Murmurs.]

$\mathrm{O}$ !

I care not for your murmurs: I risk all!

Come now away! or on the instant I

Will catch thee in these arms up from the ground And fling thee o'er my shoulder, and run with thee As from a house aflame.

Telem.

I'll spill thy blood.

Ulys. Unleash me, goddess, let me go.

Eum.

Up, up!

Antin. For what dost thou still wait? For whom, for whom? 


\section{ULYSSES}

Thy husband? he is dead, drowned in the ooze: The fish are at him now in the deep slime.

\section{Pen. O!}

Telem. [to Ulysses]. Art thou tame?

\section{Ulys.}

I bite these

bloody lips.

Antin. Or if he be not dead, what is he now? A shambling shadow, a wrecked, mumbling ghost, A man no more: no better than yon beggar That huddles to the fire: so bowed, so worn, So ragged and ruined, and so filthy and fallen! Look on that beggar! There thy husband see!

Pen. Splendid Antinous, I tell thee this; That if my husband on this moment came In by that door even as yon beggar man, So bowed, so worn, so ragged and so fallen, Him would I rather catch unto this heart And hold his holy ruins in my arms, Than touch thee in thy glory and thy strength. Ulys. [starting up]. O nobly spoken! [Uproar.]

Antin. Now answer.

Eurym.

Ctes.

Pen. [bewildered]. Sirs, but one moment, will you give me leave?

Then do I swear by all the gods to choose.

A womanish last request-a silly favour!

Antin. O!

Eurym. [fawning on her]. Lady, I will not refuse thee. 


\section{ULYSSES}

Pen.

'Tis

That I may satisfy me if this beggar

Perhaps doth bring me tidings of Ulysses.

Antin. This but to put us by!

Eurym. [still fawns].

Suffer her, sirs!

[The Suitors retire sullenly up. Penelope comes back to her seat at the fire beside which Ulysses crouches. As she approaches him he trembles.]

Pen. Old man, wilt thou deceive me yet again? Be not afraid: there's nought in me to fear.

Ulys. I'll not deceive thee, lady: nearer draw And motion all away!

[Penelope signs to all to move away.]

Canst thou endure

The shaft of sudden joy, yet make no cry?

Pen. Though I shall fall I'll not cry out: say, say.

Ulys. Ulysses lives-thou art gone whitebe still!

Grip fast thy chair and look upon the ground!And he is very near to thee even now.

Pen. Where, where?

Ulys.

This night is he in Ithaca;

Perchance even now is rushing to his halls;

Might at this moment come in by that door.

Pen. How shall I trust thy tale? If thou sayest true

Thou ne'er shalt beg again.

Ulys.

I come from him.

Pen. What is thy name?

Ulys. Idomeneus from Crete.

He charged me with these tidings-and this ring.

[230] 


\section{ULYSSES}

Pen. This would he not have given: $O$ this was pulled

From his dead finger!

Ulys.

Lady, if I lie,-

If on this night Ulysses comes not home,-

Then give me to thy thralls to slay me here.

Pen. Ah! they will kill him.

Ulys. Fear not; he is wise.

Only do thou each moment still delay

Thy answer.

Pen. Yet what plea?

Ulys.

Propose to them

Some simple trial whereby thou mayst choose.

Pen. What, what?

Ulys. The bow: is that Ulysses' bow?

Pen. Cherished and daily suppled by these hands.

Ulys. Say thou wilt choose whoe'er shall bend his bow.

But still to interpose some brief delay,

Call you some woman forth to bathe my feet.

Pen. Melantho, bring clear water hither and bathe this old man's feet.

Mel.

I? I'll not touch his feet,

For I can touch the lips of better men.

Ulys. Lady, some woman that hath seen much sorrow

As I have.

Pen. Eurycleia, bathe his feet.

[Eurycleia brings water in a brazen vessel to Ulysses; as he lifts his robe she sees the scar and drops the basin.] 


\section{ULYSSES}

Eur. The scar there.

Ulys.

Wouldst thou slay me?

hold thy peace.

Pen. What ails thee, Eurycleia?

Eur.

O my mistress!

These old hands tremble even at such a task.

Antin. [advancing]. Now, lady, now! This is delay enough!

Hast thou at last heard tidings of thy lord?

Doth he come home to-night?

Pen.

Alas, alas!

$\mathrm{He}$ is drowned, and from his finger, lo! this ring. Antin. Thou'rt satisfied at last?

Suitors.

Now answer:

choose.

Pen. No one of you I like above the rest, Yet have I sworn to choose: so I will put This matter to a simple trial.

Suitors.

Pen. See where behind you hangs Ulysses' bow.

He that can bend his bow and loose a shaft, Him will I take as husband from you all.

[They rush to take it.]

Suitors. The bow!

Pen. [staying them]. My son alone shall reach it down,

After such time shall be the first to touch it.

[Penelope retires down to watch the trial. Telemachus brings down the bow and a sheaf of arrows. Ctesippus advances, and after much groaning and panting fails to string it.] 


\section{ULYSSES}

Ctes. Easily in the morning could I bend it, But I have supped!

[Eurymachus essays to string it and fails.]

Eurym. Lady, wilt choose a husband

For brutish force? what play hath the mind here?

[Antinous fails to string the bow.]

Antin. If I can bend it not, no man can bend it.

Pen. [to Others]. And will you not essay? or you?

Others.

Not we.

Another. Where craft and strength have failed, what use for us?

Pen. I will wed no man till he bend that bow.

[Angry murmurs among the Suitors.]

[Lightning flashes; Ulysses recognizes by the sign that the moment for action has come.]

Ulys. [rising]. Lady, and princes, but to make you sport,

I will essay to bend Ulysses' bow:

[Loud laughter.]

To make you sport-for I have supped full well. Antin. Impudent rags! Thou shalt not vie with us.

Telem. The beggar shall make trial: come, old man!

Ctes. The old man! excellent! All [laughing loudly]. The beggar man!

Eurym. Come forth, thou wooer lordliest and last. Antin. Here is a broad mark for thy shaft, old man.

Pen. Ah, mock him not!

Ulys. Sirs, but to make you sport. [He totters towards the bow.]

[233] 


\section{ULYSSES}

Athene, strength! $\mathrm{O}$ if my might should fail me!

[ He takes the bow, and after simulated faltering, strings it amid the amazed silence of the Suitors. He springs to his height, and appears in his own likeness, his rags falling from him, and disclosing him armed and in the full glory of manhood.]

Dogs, do ye know me now?

Pen. [rushing towards him]. Ulysses!

Ulys.

Back!

Suitors [amazedly amid themselves]. Ulysses! is it he? Is it he-Ulysses?

[ Ulysses shoots, killing Antinous, who falls.]

Ulys. Who is for me? The swords there and the shields!

[Telemachus and Eumceus snatch down the weapons, and arming Ulysses and themselves, stand by him.]

Eurym. [coming over fawningly from among the Suitors towards Ulysses]. Hero restored, I'll stand by thee for one!

Ulys. [striding out and spearing him]. Would'st fawn on me? go fawn among the dead.

[Eurymachus falls. The Suitors, finding no weapons on the walls, crowd waveringly together.]

Ctes. [encouraging them]. We are ten to one: crush, crush them by sheer weight.

[The Suitors make a headlong rush upon Ulysses and his companions, but are stayed in mid rush by thunder, lightning, and supernatural darkness, followed by the apparition of Athene standing by Ulysses.]

Suitors. The gods fight for him. Fly! we are undone.

[Athene and Ulysses with Eumous and Tele. 


\section{ULYSSES}

machus fall on them, and they are driven in fierce brief medley, visible by flashes of lightning, and with noise of groans and falls, out headlong through the door. Sounds of slaughter continue to be heard from the court without. The darkness lifts, discovering Ulysses standing on the threshold at the upper end of the hall, Athene still at his side. He turns, laying by sword and shield, while Penelope gazes in passionate uncertainty toward him from the corner of the hall.]

Ulys. [solemnly]. First unto Zeus and to Athene praise!

Go all of you apart! even thou, my son, And leave me with Penelope alone.

Ath. Thou art come home, Ulysses! Now farewell!

For violated laws are here avenged, And I, who brought thee through those bitter years, Those bitter years which make this moment sweet, I, even, in this moment have no share.

[Athene disappears.]

[Ulysses and Penelope slowly approach each other across the hall, with rapt gaze, hesitatingly. Then she is folded to his breast in silence, while the voice of the Minstrel is heard without, repeating the words of the song from the first Act,

\section{And she shall fall upon his breast}

With never a spoken word,

and the fire on the hearth, which has burnt low through out this scene, leaps up into sudden brightness.]

\section{CURTAIN}

[235]

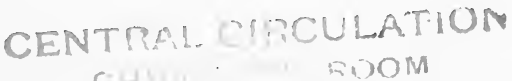




\section{NOTES ON THE PLAYS}

Much of the satisfaction in dealing with a problem, once one knows how to go about it, comes from working it out for one's self. These notes have been written solely to call to the attention of the students certain concrete and practical matters that they may be glad to have brought to their notice before they start their study with the plays concerned. The writer has, to be sure, included cautions in the matter of the tone or spirit of two of the plays; but with this exception, he has not interfered with the students in their pleasant task of developing a full appreciation of the seven plays.

It must be remembered that inadequacies of costuming, setting, and properties are of slight importance in class-room work, because the players are free to work wholly for the sake of their interpretation and its expression. Their audience is part of their own "stock company" and, being perfectly familiar with the play, it does not have to see the physical equipment in order to understand the work.

\section{The Golden Doom}

The serious tone of the play must be carefully sustained, and a real effort made to reproduce the charm that lies in the simplicity of language, thought, and incident. 


\section{NOTES ON THE PLAYS}

In mixed classes, any of the rôles may be played by girls, but the rôles of the Sentries are least suited to them.

The question of what characters-if any-may properly be considered "type " characters, should provoke profitable discussion.

In the text, exits and entrances are not always indicated as left or right. The class should decide this matter in such cases.

\section{Will O' The WisP}

A strong effort must be made to sustain the proper atmosphere, for the students will not have the help of the lighting effects that the dramatist conceived. Perhaps the room can be darkened at the end of the play. A violin could be played off stage to provide the melody that the text calls for. Music is not essential in the classroom work with any of the plays in this book, but in the case of "Will O' The Wisp" it will greatly help the students to give the latter part of the play in the proper tone.

\section{Spreading the News}

In classroom work with this play there is no real need for the players to speak in dialect. The dramatist has used the diction and idiom of rural Irish communities, and these supply sufficient " color" to the dialogue. If the students can use a light brogue, so much the better; but no dialect is preferable to dialect overdone or badly done.

In cases where the dramatist has not indicated [ 238] 


\section{NOTES ON THE PLAYS}

the side of the stage, the class should determine whether the exits and entrances are right or left. The music for Jack Smith's song of "The RedHaired Man's Wife," as provided by Lady Gregory, is given below:

\section{THE RED-HAIRED MAN'S WIFE}
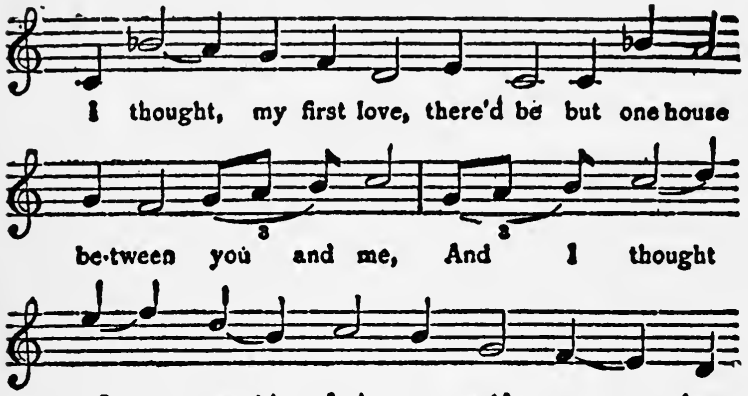

1 would find your - self coax - ing

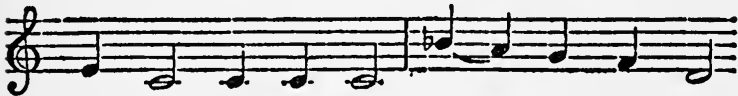

my child on your knee. 0 - ver the kde

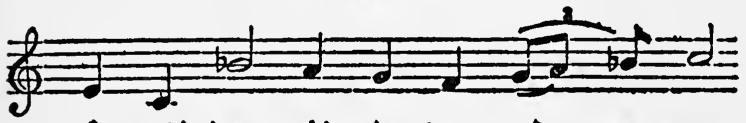

I would leap with the leap of a swan,
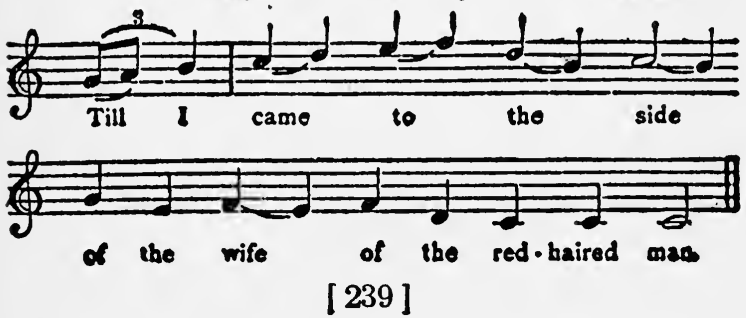


\section{NOTES ON THE PLAYS}

\section{The Turtue Dove}

The students must understand the playful seriousness in which "The Turtle Dove" is to be given. Played in another spirit, the piece loses much of its quaintness and delicacy.

In mixed classes any of the rôles may be taken by girls. Indeed, the Chang-sut-yen should be a girl, for then the lovers can play their parts without any constraint or embarrassment.

The class will have to determine the sides of the stage by which the various characters enter and leave.

The following is the dramatist's music for the song in the play.

CHINESE MELODY

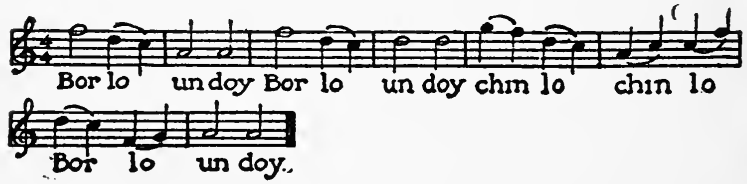

\section{Allison's LAD}

In this play some of the dialogue is not supposed to be heard by certain of the characters. The dramatist is justified in presenting such a condition: in real life people in a room may talk in groups, and here the dramatist has merely let the audience overhear one particular group. In order that the other characters shall seem not to hear or watch the speakers, however, these other characters must appear busy with their own affairs. 


\section{NOTES ON THE PLAYS}

\section{ULYSSES}

The Ulysses story is familiar to most high school boys and girls. In Stephen Phillips's three-act play, the second scene of the third act is the final scene in the play. The entire third acts deals with the home-coming of the hero. In the first scene of the act, Ulysses has reached Ithaca; he meets Athene, who assures him of her aid but cautions him not to attack the suitors until she sends the sign - a lightning flash. She disguises him as a beggar. Ulysses reveals his identity to Eumaus and Telemachus, whom he meets at the former's hut, and tells them of his plan to go to the palace as a beggar and attack the suitors there when Athene shall send the sign. They promise to help him, and, preceding him to the palace, remove from the walls of the hall all the weapons and armor save the three spears and shields that Ulysses and they will need. Penelope has been forced by the suitors to agree to choose one of them for a husband as soon as the moon shall appear at the full. The time of the second scene is the evening of the full moon.

In the classroom work it may be well to omit the slaughter of the suitors, and to end the scene with Ulysses' disclosure of his identity. If the killing of the suitors is to be represented, it is well to have them rush off the stage, with Ulysses following them. The slaughter cannot adequately be represented in the classroom, and affords little opportunity for careful individual work. Aside from 


\section{NOTES ON THE PLAYS}

this section of the scene, however, the selection is entirely actable in the classroom.

The men and women characters are even in number. The important women characters are somewhat fewer than the important men characters, however, so that in a mixed class it may be well to have girls take the rôles of Eurymachus and the minstrel, Phemius. Of course, it is not necessary to have many suitors and handmaidens. The large cast-it is the largest in the seven playssalls for a careful distribution of the players on the stage. Many effective groupings are possible, and the determination of the best arrangement of the players is an interesting problem.

At times Ulysses, Telemachus, and Eumcus speak so that the rest of the characters do not hear them; the remarks they make at such times are short and may be called "asides." These asides must be "covered," which means that while they are being spoken the characters not concerned must appear busy with their own speech and action. To manage this skillfully requires care, but it is entirely possible to cover effectively the asides in this play.

If possible, the song of the minstrel should be set to music; if this is not possible, the minstrel may recite the words of the song, preferably to a string accompaniment off the "stage." No music is printed in the Macmillan edition of the play.

The beautiful blank verse deserves careful delivery. The student should realize that blank verse must not be read like prose, but with a re-

[242] 


\section{NOTES ON THE PLAYS}

gard both to its metrical quality and to the sound of the words and phrases. Take the line

Thou hast caught splendour from the sailless sea.

Here there is a wavelike rhythm, where the two strong accents, one on splen and one on sail, are almost like the crests of two waves that, having gathered momentum through the preceding syllables and reached their climax, break on the next syllable. Reading the line like prose spoils this effect. Then there is the sound of the long vowels, and of the s's and l's; these sounds must be given their proper chance to add to the emotional tone of the passage.

The words of the song that is referred to at the close of the selection, form an exquisite lyric. They are

O set the sails, for Troy, for Troy is fallen, And Helen cometh home;

$O$ set the sails, and all the Phrygian winds Breathe us across the foam!

$\mathbf{O}$ set the sails unto the golden West!

It is o'er, the bitter strife.

At last the father cometh to the son,

And the husband to the wife!

And she shall fall upon his heart

With never a spoken word. 



\section{PART III}

Notes to the INstructor 


$$
\text { . }
$$




\section{NOTES TO THE INSTRUCTOR}

\section{NOTES ON CHAPTER I}

In Chapter I the nature of the several problems involved in the preliminary study of a play has been indicated. The instructor will find it well to assign as home-work for the students the consideration of these problems, and to have the students discuss them fully and frankly in the classroom.

To be valuable, the work should be done with considerable intensiveness. The instructor may wish to make some other division of the work of the preliminary study than the one suggested, and certainly the six problems are not of equal scope or difficulty. With several of the plays a consideration of music will not be called for at all, and circumstances may make that problem an unimportant one in any case. The instructor will very likely wish to divide the problem of the setting into three, treating the physical background, the costumes, and the properties, as separate matters; he may wish to split the character study, similarly, into several parts. One method of procedure is to divide the class into as many groups as there are problems for consideration, and to assign to each group the special work of making an intensive study of one of the problems. When any particular problem is taken up in the classroom, the particular group 


\section{NOTES TO THE INSTRUCTOR}

that has been assigned to its consideration leads in the discussion, the other students being free to criticize the opinions presented and to advocate their own. One or more single problems may be considered in the course of a single recitation, the number depending upon the importance of the questions to be discussed and the degree of intensiveness that the instructor considers proper for their treatment. If the group or committee plan is not desired, the entire class can be assigned to study the problem or problems assigned as the subject for a given recitation.

In any case the discussion should be largely informal. The interpretation of a play is a project, and the entire class should be actively concerned in every phase of it; but the more informal the discussion is, the more will the students be disposed to take part in it. Many thoughtful and ingenious suggestions will be made in the course of an informal class discussion that would otherwise not be volunteered at all, and each member of the class will find his own ideas enriched, clarified, and corrected by the ideas of his fellows.

In the general study of the play there is ample occasion for written work as well as for oral reports and impromptu discussions. The instructor may require the students to put in writing the opinions and suggestions that they formulate in the course of their home study of the various problems. In this case, the reports, - some of them, at least-can be read in class, and made to form the basis of the discussions. Summaries of the 


\section{NOTES TO THE INSTRUCTOR}

discussions, too, may be written, or written arguments may be prepared, supporting or opposing suggestions made in the course of the classroom work. In length, such written exercises may be single paragraphs or full themes, and in type they may be either exposition, argument, description, or narration, or any combination of these fundamental types. There is ample opportunity, too, for the writing of letters requesting information, advice, or the loan of materials. For needed books or articles, advertisements may be written to be posted on school bulletins or printed in the school newspaper; news items, too, may be composed for the school paper. Indeed, there is hardly a limit to the possibilities for written and oral composition in relation to the preliminary study of a play in the classroom.

Members of the dramatic class may be doing such work in other departments as would bear directly upon the dramatic work. For example, some dramatic student may be enrolled in an art class engaged in costume designing. Or a history class, of which some of the dramatic class are members, may be considering the period in which the play that is being studied is set, and so learning facts valuable for the dramatic class in matters of scene, costuming and manners. Again, it is possible that other departments would modify the work which certain of the members of the dramatic class are taking in order that that work could bear more directly than otherwise on the dramatic work. Thus the Art Department might accept sketches of stage settings, posters or signs of the play, or 


\section{NOTES TO THE INSTRUCTOR}

the like, in lieu of other poster or sign work. Or students might be permitted to adjust their work in the music classes so that it would relate practically to their dramatic study. Shop work by the boys and sewing by the girls might be likewise correlated: miniature stage sets, and costume models, either small or full-size, would be helpful to the dramatic class and provide attractive work for the individuals concerned.

Before the acting is begun, the arrangement of the classroom must be considered. Some dramatic classes may be so fortunate as to have the use of the school auditorium. Where the auditorium is unavailable, a large room, preferably without stationary desks, and with free space at one end, will prove very satisfactory. But the work can be done even in an ordinary classroom, although the movement of the players will be cramped, and they will be too close to the rest of the class for full effectiveness. Where there is anything approaching a free space for the actors, there will be a possibility of suggesting the setting in some way. Screens and movable blackboards will serve to suggest the walls of a room, and stools, desks, and tables will serve many purposes. The idea is not to furnish any imitation of the real setting, but merely to mark the limits of the imagined scene and definitely to locate the most important objects in the setting. The players will be at a loss if they must remember-unaided by any object to mark it-where this chair is, or that table, or the door, or the fireplace, or the garden

[250] 


\section{NOTES TO THE INSTRUCTOR}

gate, or the entrance to the palace. Then, too, if a player is to sit down at any time, he should have something to sit on; and where a number of characters are to be grouped about a table, they cannot well make believe to be there unless they have a table or something that will take its place.

Similarly, something may be done to suggest costumes and properties. Many of the students will be glad to lend some simple things, and the various departments of the school can be laid under requisition for other articles. It is surprising how a shawl, an apron, an old hat, a cane, an umbrella, an overcoat, a candle, or a few dishes will serve to help the class in their make-believe. Indeed, it is well to have something to represent each important property, unless the makeshift would have to be ridiculously unlike the original. Where a telephone is called for, an old instrument with a short dummy wire is generally procurable, and one of the class can easily attach a small battery to an electric bell-both borrowed from the Science Department, - and the bell can be rung off stage by someone not acting at the time it is to be used. Students often show a wealth of ingenuity in suggesting equipment for the classroom "stage," and they enjoy meeting the challenge to their inventive powers.

\section{NOTES ON CHAPTER II}

In preparing the material for Chapter II the writer has sought to provide the students with the [251] 


\section{NOTES TO THE INSTRUCTOR}

information they need if they are to do their work thoroughly and intelligently. Without such information the young player is likely to lack the necessary grounding for his work: he will not know at what to aim or how to proceed, and he may not only commit serious errors, but may fundamentally misconceive the lines along which he should proceed in his interpretation.

Before they begin the detailed interpretation of their first play, the students should read the whole of Chapter II in order to obtain a general perspective of the field in which their work of interpretation lies. An exhaustive study of the chapter is not recommended, since that would be a working with theory rather than practice. The reading of the chapter for perspective need not be repeated when the other plays are studied.

When they have a general conception of the principles set forth in Chapter II, the members of the class should take the first step in the detailed interpretation of their play. This consists of the work indicated in the sections on The Situations, Realizing the Setting, and Getting Inside the Character. Discussions in the classroom, following individual work at home, will be very valuable here. But a thorough study of all the characters in a play entails a good deal of work, and for this reason the characters may be divided among groups of students, the groups being required to report to the class upon their work.

The work with The Situations, Realizing the Setting, and Getting Inside the Character con- 


\section{NOTES TO THE INSTRUCTOR}

stitutes the first step in the detailed interpretation of the play. When this step has been taken, the class is ready to begin the presentation of the play, and the acting (together with the class discussions of the work) will now constitute the matter of the recitations. In the preparation of their rôles the students should make constant reference to the principles presented in the sections on Acting as Team Work, the Auditory Appeal, and the Visual Appeal.

\section{The Plan of the Recitation}

The writer submits the following plan as one that has proved entirely satisfactory with his own dramatic classes.

\section{Assignment and Preparation of the Lesson.}

When the class is ready to act the play, the instructor (or a committee of the class) assigns a definite section of the play for the next recitation. In the assignment, the various rôles are distributed among the several groups-usually six-into which the class has been divided. If the cast is large, a group may be asked to prepare more than one rôle, and if the cast is small, more than one group may be given the same character. The students prepare their rôle or rôles to the end of the section covered by the assignment.

In this preparation of the assignment the student considers four matters:

a. The value of his rôle in the part of the play assigned for study. The student must realize what

[253] 


\section{NOTES TO THE INSTRUCTOR}

contribution his rôle makes to the situation or situations included in the day's assignment. The value of this study lies in the fact that it provides the student with an objective toward which to work in his preparation of the lesson.

b. The action and grouping of the characters on the stage. The student must visualize the stage picture or the series of stage pictures in order both to see his own work against a proper background, and to conceive his " business" properly.

c. The ideas and states of feeling expressed or implied in the lines of his rôle. The detailed thoughts and feelings entertained by the character vary in different passages, though they are all expressions of a unified, underlying state of thought and feeling. With this background of thought and emotion firmly in mind, the student must analyze each passage in his rôle to find the exact idea and the exact feeling it expresses or implies. The student's work of expression is to be definite, and to make it definite he must have definite ideas and feelings to express.

d. How to read his lines, and what to do (tho auditory and visual appeals) in order fully to express the ideas and feelings that his character entertains, at the same time expressing them so as to show the individuality of the character. This reading and action constitute the acting itself. While allimportant as the concrete expression of the student's interpretation of his rôle, it is based, of course, upon the study of the three other phases of the lesson preparation. In this study of the ex- 


\section{NOTES TO THE INSTRUCTOR}

pression, the student does not merely decide what to do and how to read his lines; he actually reads the lines aloud and makes the facial expression, gestures, and bodily movements that he thinks appropriate. No preparation can be adequate that is not carefully practised at least once, and preferably several times.

\section{The Recitation: Setting the Stage.}

Standing committees on Costume, Setting, and Properties serve throughout the work with any given play. In the matters with which they are especially concerned, they carry out the suggestions that the class made during the general discussion of the play; but since the physical equipment of the stage is meager, the members of these committees can perform their special duties in addition to sharing in the acting. They may be able to prepare the stage and lay out the properties and costumes before the recitation. If not, they prepare the material beforehand, and as soon as they reach the classroom they set the stage and put in convenient piaces the costumes and what properties are not to be on the stage at the start of the recitation. Any special committee, such as a Music Committee, also makes itself ready to render its contribution when the time comes for it to do so.

3. The Recitation: Planning the Action in General. In the matters of the action and grouping of the players on the stage, it is not well to leave more than [255] 


\section{NOTES TO THE INSTRUCTOR}

the details to be developed in the course of the acting of the day's assignment. Each student, in his preparation, has conceived in his own way the general action and the grouping, and these diverse conceptions must be unified. A short discussion suffices to plan, in general, both the positions of the players at the start of the day's work and the more important changes that will be called for during it. At the same time, the general nature of the larger bodily movements is determined so far as these materially affect the work of players other than those making the movements. It is well at this point to ask members of the class to "walk through" the action of the day's assignment, as was suggested on page 26 . The advantage of planning the general action and grouping is that the players will all have the same conception of about where they are to stand and about what they are to do in relation to one another; as a result, they will be free to concentrate on the details of their expression, and there will be little need to interrupt their work to correct their grouping and larger action.

\section{The Recitation: The Acting.}

After the action and grouping have been planned in general, the acting begins. The instructor (or a Directing Committee) calls upon members of the class to begin the work, each character being assigned to a student that has prepared the particular rôle now given him. In their grouping and more important bodily motions, the players will 


\section{NOTES TO THE INSTRUCTOR}

follow the plan that the class has just worked out. At a good stopping place the work is halted and the class discusses the interpretation, it being understood that all criticism is to be constructive. At George Washington these discussions are quite informal, any student being permitted to speak provided he first gets to his feet. Remarks are addressed to the class or to a player and not to the instructor unless he is asked particularly for his opinion or advice. When the discussion is over the work proceeds, other students taking the place of the first set, and so on. The acting of a particular section of the play may be so badly done that it is acted over again in the light of the suggestions developed in the course of the discussion.

In the criticisms, the principles set forth in Chapter II are used as the basis of judgment, and the decisions reached by the class in the course of the general study of the play are referred to, in order to keep the interpretation unified. Other recitations of a similar type follow this first one, until the whole play has been acted.

The play is now acted a second time, in order to give the class the satisfaction of making a smoother performance than was possible the first time the work was done. In some cases a third, or Final Performance, without class discussion except at the close, is given, to which a few members of the Faculty may be invited. For this performance, the class chooses the cast, those who have done the best work being given the rôles. 


\section{NOTES TO THE INSTRUCTOR}

\section{The Students and the Rôles}

\section{(. Male and Female Characters.}

A reading of the lists of the characters in the seven plays in the book will show that there is a total of more male than female characters. For classes that are not "mixed" this condition will occasion no difficulty. Boys do not object to playing women's rôles except before girls, and few girls dislike to play men's parts. In a boys' class "Will-o'-the-Wisp " may be omitted, and in a girls' class "Allison's Lad" need not be used. Even in mixed classes, the preponderance of male characters in the seven plays will not be a source of difficulty, for if there are more girls than boys in the class, girls can easily take many of the male rôles and will not dislike doing so. In "The Golden Doom " all the parts may be played by girls, and all the rôles in "The Turtle Dove" may be assigned to girls-even that of the Mandarin. It is even preferable in the last-named play to have a girl take the part of Chang-sut-yen. In the last two plays named, the dress of the characters is so unlike that of the present day in America, that the playing of the men's rôles by girls does not seem strange to player or audience. Except "Allison's Lad" the writer has used all of the seven plays in this volume at Evander Childs High School, where girl students are decidedly in the majority. As a matter of fact, it is almost invariably the case that male characters predominate in really valuable plays that are suitable for classroom use and that have more than two or three rôles. 


\section{NOTES TO THE INSTRUCTOR}

\section{Varying the Rôles.}

Is it better for a student to keep one rôle ihroughout any one play or for each student in his turn to play several parts? Circumstances will vary in different classes. The advantage in keeping the same rôle is that a more careful study can be made of a character than would be possible where a student plays in turn more than one rôle. On the other hand, it makes for development of his powers of insight and understanding to have to identify himself with more than one character during the study of a play. A boy of forceful nature and much innate dignity may, for example, be well suited for the part of Ulysses; but if he must also play Eurymachus and Antinous he tends to widen his sympathy-certainly to develop his powers of expression-in the portrayal of qualities which are not markedly his own. Then, too, the more important rôles should not be confined to the small number of students that could play them if the practice of keeping one rôle were followed throughout the work with any one play.

\section{Slang and Bad Grammar in the Plays}

Some may feel that in a school only texts free from slang or other errors in speech should be provided for the use of the students. But in the great novels that we study, the ignorant characters use anything but standard English; to have made the rustics in "Silas Marner" speak irreproachably, or to have had the Crunchers, in "A Tale of Two 


\section{NOTES TO THE INSTRUCTOR}

Cities," choose their words as carefully as do $M r$. Lorry and Sidney Carton, would have been bad art, because it would not have been true to life. In "Ivanhoe," wonderful story that it is, Scott has made Wamba and Gurth and other of the ruder characters talk too well, and this mars the effectiveness of the book. In the work with plays, the presence of slang and bad grammar in the mouths of uneducated men and women is effective in its realism, and there is no danger that the students will be led to first endure, then pity, then embrace such errors. The writer's experience has been just the contrary. Where a character is recognized by the class to be untrained in his speech, his errors are very vividly associated with that lack of training, and whenever the students hear the same errors spoken by people in real life, they associate the errors with the uneducated characters that committed them in the plays. As a result, they definitely stamp instances of bad English as errors of ignorance.

\section{Composition}

In the Notes on Chapter I, it was pointed out that in the general study of a play there is practically an unlimited opportunity for oral and written composition on various subjects directly or indirectly concerned with the work. The same condition obtains in the matter of the detailed interpretation. The discussions in the classroom provide occasion for much oral composition, and written criticisms or reports of the day's work may 


\section{NOTES TO THE INSTRUCTOR}

very properly be called for. The " final" performances provide opportunity for the writing of announcements, programs, advertisements (composed as though for the school paper), and letters inviting a few of the most interested members of the Faculty to attend and judge the work. Criticisms of any of the class performances may be written as reportorial work. Comparisons of plays studied, or estimates of characters in the plays, afford interesting subjects for written themes or for oral discussion. These are, of course, only some of the many subjects that may be assigned for composition work in connection with the plays. The class will doubtless wish to have a bulletin board. On this, press clippings of criticisms of good plays that are current on the professional stage may profitably be posted-particularly criticisms published by Dramatic Leagues or Societies-and such clippings may well lead to worth-while discussions. When any of the members of the class see good dramatic performances, either professional or amateur, they should make a report to the class and bulletin a summary of their judgment. At George Washington, in the course of the term, the members of the dramatic classes write original one-act plays.

\section{In General}

The purpose of the dramatic work is not to train students to become actors and actresses,far from it. In their classroom acting boys and girls are not taught stage tricks, but are led to 


\section{NOTES TO THE INSTRUCTOR}

translate the printed word into sense appeal. Work in the Visual Appeal gives ease and poise in the bearing of the students, and teaches the value of proper facial expression and gesture in the expression of thought and feeling. Aside from some slight attention that may be paid to it in the Elocution classroom, our schools have neglected the use of the body as an element in the effective expression of thought and feeling. But surely both facial expression and gesturing-the latter including general bearing and physical poise-are recognized outside the schools as important factors in the communication of ideas and feelings and in the expression of personality. What Pope said of writing may be applied to these physical factors in expression:

"True ease in writing comes from art, not chance, As those move easiest who have learn'd to dance. 'Tis not enough no harshness gives offence,The sound must seem an echo of the sense."

The section on the Auditory Appeal has been made very full because the average high school student is ignorant of how to use his voice effectively. One of the greatest values of dramatic work in the classroom is the training it affords in oral expression. The motivated and socialized work with plays is sufficiently interesting to cause the student to make a genuine effort at proper oral expression if he realizes fully the nature of the problem that he faces. The training that the dramatic work affords will develop an ability that will be 


\section{NOTES TO THE INSTRUCTOR}

evident in any oral reading. One of the chief reasons that our boys and girls read aloud no better than they do is that they are not in the habit of seeking to understand just what the thought and feeling are in any passage they read; and if they do realize these, they have not developed the art of making the thought and feeling evident in the way they read. In the dramatic work, these matters are emphasized.

Well-written plays serve admirably as models of the effective expression of thought in language, and the instructor may profitably lead his charges to a fuller realization than they would otherwise secure of the clear, appropriate language in which the plays in this book are written. Of all writers, the author of a good play can be guilty of no slovenly or hazy expression, or foggy thinking back of it. He must keep the attention of the audience alert, and he must be wholly clear in everything he writes, since everything must give definite information, or afford definite insight into matters of the play. Often fine shades of thought or emotional attitudes must be disclosed in single sentences or even single words, and this makes imperative the choice of exactly the right terms. The style of speech assigned to each person in the play must have an individual flavor, which means that the sentence structure, as well as the diction, must have significant characteristics.

Nor should the value of the content of worthwhile plays be lost sight of. In their work with such plays, the students have to do with human 


\section{NOTES TO THE INSTRUCTOR}

nature in transcripts from life. After all, the biggest thing in the lives of our boys and girls is going to be the task of being men and women among men and women, and any school study that deals with the workings of the human mind and heart is of the utmost value to them. To a certain extent we are all properly players in our daily lives. A proper dramatic training is an important preparation for life itself: the nurse, the physician, the salesman, the welfare expert,-every man or woman with a definite work calling for powers of mind and heart-has to play a part. The rôle of friend is an absorbing and exacting one. Selfcontrol, power of quick analysis of character and passing mood and mental state, effective expression of just the thought and feeling that one should show at any given time,-all these are important factors in the great art of being men and women among men and women on the great stage of life.

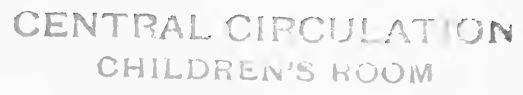

[264] 




\section{-}

. 



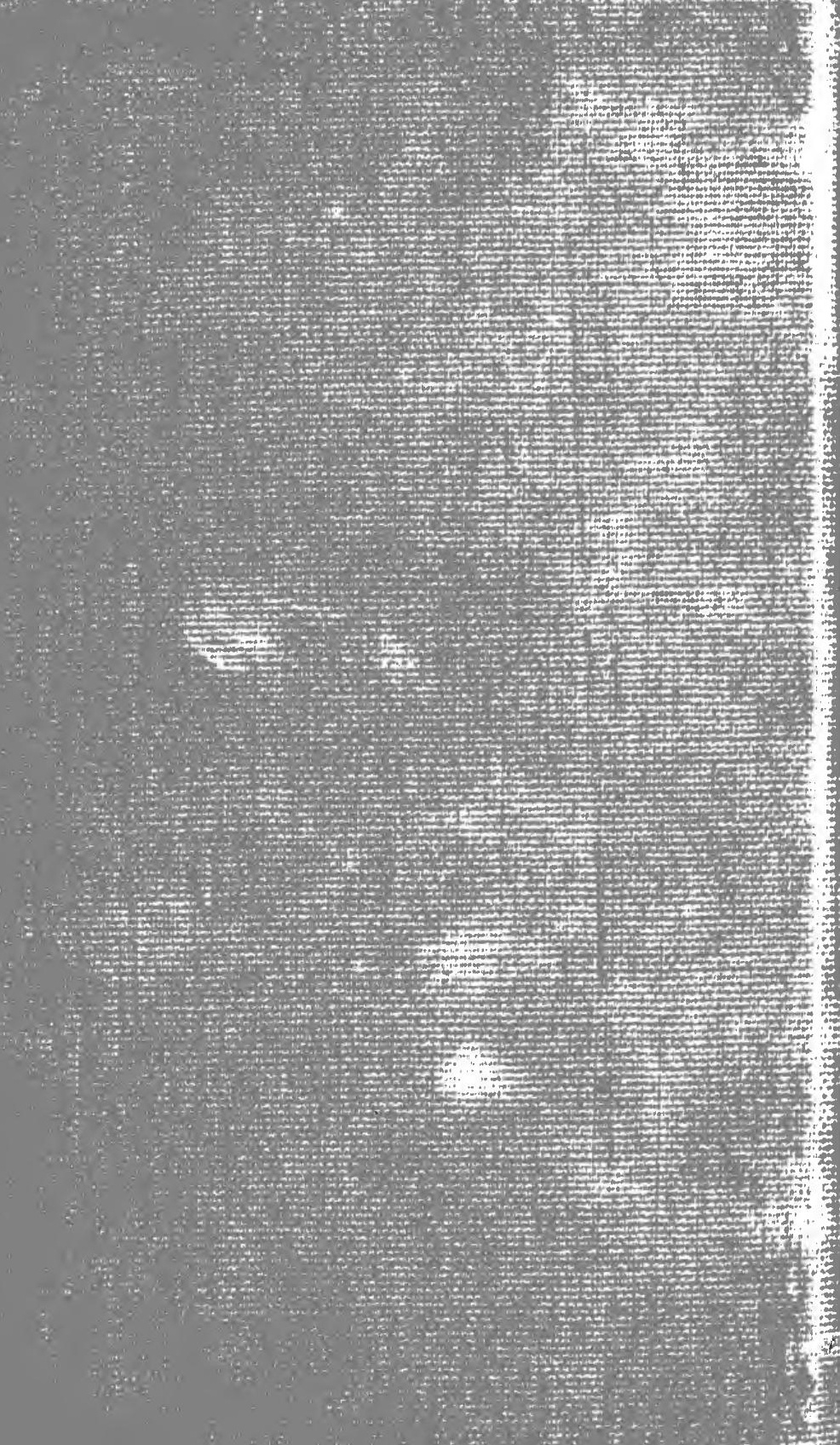

